\title{
ERICK PFEIFER
}

\section{Projeto e Controle de um UAV Quadrirotor}

Dissertação apresentada à Escola Politécnica da Universidade de São Paulo para obtenção do título de Mestre em Engenharia.

SÃO PAULO 


\section{ERICK PFEIFER}

\section{Projeto e Controle de um UAV Quadrirotor}

Dissertação apresentada à Escola Politécnica da Universidade de São Paulo para obtenção do título de Mestre em Engenharia

Área de Concentração:

Engenharia de Sistemas

Orientador:

Prof. Dr. Fuad Kassab Junior

SÃO PAULO 
Este exemplar foi revisado e corrigido em relação à versão original, sob responsabilidade única do autor e com a anuência de seu orientador.

São Paulo, de de 2013.

Assinatura do autor

Assinatura do orientador

FICHA CATALOGRÁFICA

Pfeifer Erick

Projeto e controle de um UAV quadrirotor / E. Pfeifer. -Versão corr. --0 São Paulo, 2013.

$115 \mathrm{p}$.

Dissertação (Mestrado) - Escola Politécnica da Universidade de São Paulo. Departamento de Engenharia de Telecomunicaçöes e Controle.

1. Aeronaves não tripuladas 2 . Aeronaves quadrimotoras 3. Rotor 4. Controle linear 5. Filtros de Kalman I. Universidade de São Paulo. Escola Politécnica. Departamento de Engenharia de Telecomunicações e Controle II. t. 


\section{DEDICATÓRIA}

Dedico este trabalho aos meus pais e irmão, os pilares da minha vida. 


\section{RESUMO}

Este trabalho dedica-se ao projeto e desenvolvimento de um veículo aéreo não tripulado. Tais veículos podem ser utilizados em diversas aplicações como monitoramento, vigilância, transporte, resgate, entre outros. Dentre os diversos tipos de veículos aéreos, este trabalho irá focar no modelo do quadrirotor, composto por quatro hélices contra-rotoras que estabilizam e movimentam o veículo. Para alcançar o objetivo de controlar este tipo de veículo, várias propostas e metodologias podem ser aplicadas, todas buscando contemplar o controle de todas ou parte das variáveis de estado presentes nesta planta. Neste texto serão descritas: as equações cinemáticas e dinâmicas que regem este sistema; o projeto e composição mecânica da aeronave; definição de sensores e atuadores juntamente com seus métodos de utilização; implementação de controlador linear por alocação direta de polos e Regulador Linear Quadrático juntamente com observador de estados de ordem plena e filtro de Kalman, para recuperação de estados não mensurados e filtragem de ruídos. Serão apresentados resultados em simulações para cada método de controle selecionado visando optar pelo melhor controlador para a aplicação da aeronave. O método selecionado será implementado para controlar a aeronave com os sensores e atuadores selecionados. Esta implementação será realizada a partir da técnica HIL - Hardware in The Loop juntamente com o software MATLAB/Simulink visando validar o controlador em conjunto com a planta real, bem como o modelo dinâmico construído.

Palavras-chave: Veículos aéreos não tripulados. Quadrirotor. Controle linear. Filtragem de Kalman. 


\section{ABSTRACT}

This work is dedicated to the project and development of an unmanned aerial vehicle. Such vehicles can be employed in various applications such as monitoring, surveillance, transportation, rescue and others. Among the types of aerial vehicles, this work is focused on the quadrotor, composed by four counter-rotating propellers which stabilize and displace the vehicle. In order to fulfill the objective of controlling this vehicle, many methodologies and propositions can be applied, seeking the control of all or a snippet of the state variables present in the system. There will be described in this work: the cinematic and dynamic equations that govern this system; the mechanical project and construction of the aircraft; sensors and actuators definition, along with its usage methods; linear control implementation of the pole placement and Linear Quadratic Regulator techniques along full order state observer and Kalman filtering in order to recover and filter non-measured states. Performance results in simulations will be presented on each control implementation to validate the best controller for the application and this implementation will be applied on the projected aircraft using the sensors and actuators selected. This implementation will be given through the HIL - Hardware in the Loop method using MATLAB/Simulink software to validate the control technique applied and the constructed dynamic model.

Keywords: Unmanned Aerial Vehicles. Quadrirotor. Linear control. Kalman filtering. 


\section{LISTA DE ILUSTRAÇÕES}

Figura 1. Quadrirotor Bréguet-Richet Gyroplane No. 1................ 1

Figura 2. VTOL Harrier Jump Jet......................................... 2

Figura 3. Fotografia da aeronave VTOL Oemichen No. 2. .............. 5

Figura 4. Esboço da aeronave VTOL Oemichen No. 2. ................. 5

Figura 5. Fotografia da aeronave VTOL produzida para as forças aéreas dos EUA em 1921 .......................................................................... 6

Figura 6. Fotografia da aeronave VTOL Skycar. ........................ 6

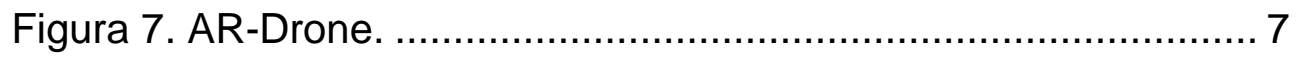

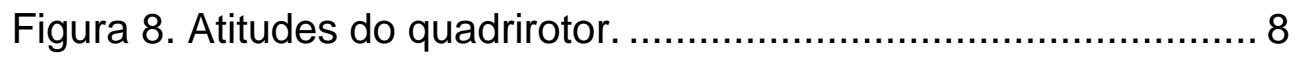

Figura 9. Variações nas velocidades angulares e respectivos resultados em movimentações lineares e angulares................................. 9

Figura 10. Quadrirotor OS4 ........................................... 11

Figura 11. Quadrirotor STARMAC II...................................... 12

Figura 12. Quadrirotor X-4............................................... 13

Figura 13. Modelo quadrirotor X-3D...................................... 13

Figura 14. Sistemas de coordenadas inerciais e do quadrirotor...... 16

Figura 15. Sentido de rotação para cada propulsor....................... 20

Figura 16. Haste de dimensão "L" no quadrirotor.......................... 22

Figura 17. Tipos de motores comumente utilizados. .................... 34

Figura 18. Motor AXI 2212-34 ............................................... 35 
Figura 19. Dimensões (em milímetros) do motor AXI 2212-34........ 35

Figura 20. Hélice Draganfly com duas pás.................................... 36

Figura 21. Hélice GWS com três pás. ........................................... 36

Figura 22. Projeto do amplificador de força para ensaio. ................ 37

Figura 23. Resultado final da montagem do amplificador de força.. 38

Figura 24. Dinamômetro Instrutherm DD-300. .............................. 38

Figura 25. Vista da configuração do dinamômetro em detalhe. ....... 39

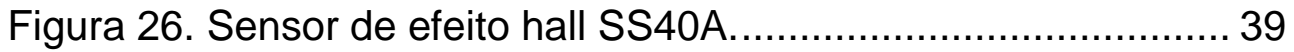

Figura 27. Configuração total do ensaio de empuxo do rotor........... 40

Figura 28. Controlador Hobby King ESC 30A. ............................ 40

Figura 29. Gráfico de empuxo e corrente dos ensaios................... 42

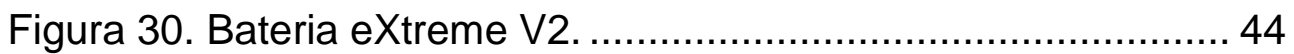

Figura 31. Bateria auxiliar Turnigy 1.0 3S.................................. 45

Figura 32. Desenho técnico em software CAD do Quadrirotor........ 46

Figura 33. Imagem do UAV concluído......................................... 47

Figura 34. Diagrama de blocos do sensor ADIS16354AMLZ. ......... 49

Figura 35. Fotografia do sensor ADIS16354AMLZ ........................ 50

Figura 36. Magnetômetro HMC5883L.......................................... 51

Figura 37. Gráfico para verificação de interferências por hard ou soft iron. 53 
Figura 38. Gráfico compensado para verificação de interferências por hard ou soft iron.

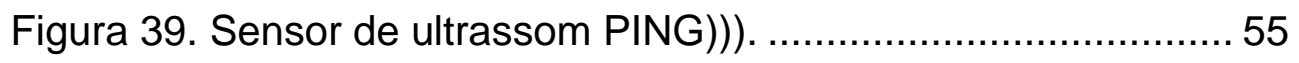

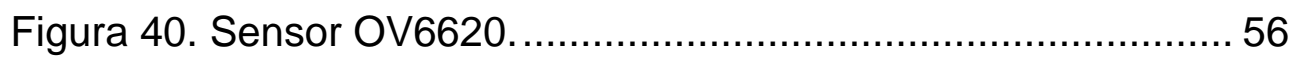

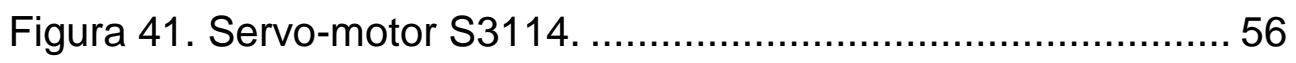

Figura 42. Projeto do mecanismo de pan e tilt da câmera. .............. 57

Figura 43. Mecanismo de orientação da câmera............................. 57

Figura 44. Diagrama de blocos da eletrônica embarcada a partir do MCU central 59

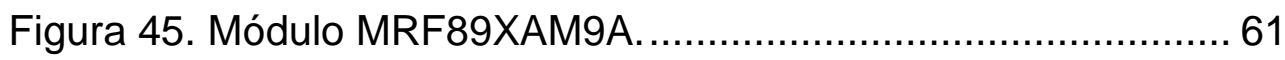

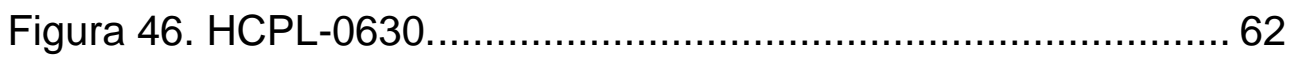

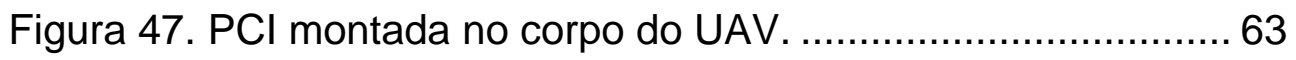

Figura 48. Diagrama principal no MATLAB/Simulink $\circledast$ para o modelo e controle 76

Figura 49. Bloco da dinâmica do UAV........................................... 77

Figura 50. Diagrama do bloco de controle do UAV. ...................... 77

Figura 51. Diagrama para o bloco de observação de estados. ........ 78

Figura 52. Referências e respostas para as posições lineares do UAV, utilizando controle por alocação de polos. 79

Figura 53. Referências e respostas para as posições angulares do UAV, utilizando controle por alocação de polos. 80

Figura 54. Esforços de controle nos rotores, utilizando alocação de polos. 80 
Figura 55. Consumo de corrente utilizando controle por alocação de polos. 81

Figura 56. Referências e respostas para as posições lineares do UAV, utilizando controle LQR. 82

Figura 57. Referências e respostas para as posições angulares do UAV, utilizando controle LQR. 83

Figura 58. Esforços de controle nos rotores, utilizando LQR. 83

Figura 59. Consumo de corrente utilizando controle LQR. 84

Figura 60. Configuração do quadrirotor para os ensaios de checagem de ruídos de medição. 85

Figura 61. Variâncias instantânea dos sinais mensurados pelo acelerômetro. 86

Figura 62. Variâncias instantânea dos sinais mensurados pelo giroscópio. 87

Figura 63. Variâncias instantânea dos sinais de posição linear. ..... 87

Figura 64. Variância instantânea do sinal do sensor magnetômetro. 88

Figura 65. Diagrama do bloco de introdução de ruídos de medição no sistema. 89

Figura 66. Amortecedor de vibração Shore 38. 90

Figura 67. Referências e respostas para as posições lineares do UAV, com presença de ruídos de medição e processo. 91

Figura 68. Referências e respostas para as posições angulares do UAV, com presença de ruídos de medição e processo. 92 
Figura 69. Esforços de controle nos rotores, com a presença de ruídos de medição e processo. 92

Figura 70. Consumo de corrente do UAV, com a presença de ruídos de medição e processo. 93

Figura 71. Diagrama de blocos para o ensaio prático utilizando HIL. 94

Figura 72. Diagrama principal para interface e controle com o UAV, no software MATLAB/Simulink. 95

Figura 73. Posições lineares do UAV, limitando a movimentação do corpo para alcançar a referência de altitude. 98

Figura 74. Posições angulares do UAV, limitando a movimentação do corpo para alcançar a referência de altitude. 99

Figura 75. Diagrama de estados para o UAV com controlador embarcado. 101

Figura 76. Atitudes estimadas do UAV, com controle embarcado e período de amostragem de $20 \mathrm{~ms}$ 104

Figura 77. Rastreamento da referência de orientação do UAV. .... 105 


\section{LISTA DE TABELAS}

Tabela 1. Especificações do motor AXI 2212-34 35

Tabela 2. Ensaios de empuxo, velocidade angular e consumo de corrente. 41

Tabela 3. Principais parâmetros da bateria eXtreme V2. 44

Tabela 4. Principais parâmetros da bateria Turnigy $1.03 \mathrm{~S}$. 45

Tabela 5. Principais parâmetros mecânicos do chassi do UAV. 47

Tabela 6. Parâmetros característicos do sensor ADIS16354AMLZ. 49

Tabela 7. Principais características do sensor OV6620. 55

Tabela 8. Principais parâmetros do transceiver MRF89XAM9A..... 60

Tabela 9. Especificação da Alocação de Polos. 69

Tabela 10. Máximos valores de cada estado do sistema. 71

Tabela 11. Máximos valores de cada entrada do sistema. 71 


\section{LISTA DE SÍMBOLOS}

\begin{tabular}{|c|c|c|}
\hline Símbolo & Unidade & Descrição \\
\hline$\Phi$ & $\mathrm{rad}$ & $\begin{array}{l}\text { Ângulo de arfagem (Pitch) em relação ao } \\
\text { sistema Terra. }\end{array}$ \\
\hline$\Theta$ & rad & $\begin{array}{l}\text { Ângulo de rolagem (Rol) em relação ao } \\
\text { sistema Terra. }\end{array}$ \\
\hline$\psi$ & $\mathrm{rad}$ & $\begin{array}{l}\text { Ângulo de guinada (Yaw) em relação ao } \\
\text { sistema Terra. }\end{array}$ \\
\hline $\mathrm{P}$ & $\mathrm{rad} / \mathrm{s}$ & $\begin{array}{l}\text { Velocidade angular de pitch em relação ao } \\
\text { sistema Corpo. }\end{array}$ \\
\hline Q & $\mathrm{rad} / \mathrm{s}$ & $\begin{array}{l}\text { Velocidade angular de roll em relação ao } \\
\text { sistema Corpo. }\end{array}$ \\
\hline $\mathrm{R}$ & $\mathrm{rad} / \mathrm{s}$ & $\begin{array}{l}\text { Velocidade angular de yaw em relação ao } \\
\text { sistema Corpo. }\end{array}$ \\
\hline$x$ & $m$ & $\begin{array}{l}\text { Posição linear em X, do corpo em relação } \\
\text { ao sistema Terra. }\end{array}$ \\
\hline $\mathrm{Y}$ & $m$ & $\begin{array}{l}\text { Posição linear em Y, do corpo em relação } \\
\text { ao sistema Terra. }\end{array}$ \\
\hline Z & $m$ & $\begin{array}{l}\text { Posição linear em Z, do corpo em relação } \\
\text { ao sistema Terra. }\end{array}$ \\
\hline$X_{\mathrm{c}}$ & - & $\begin{array}{l}\text { Eixo } \mathrm{X} \text {, do sistema de coordenadas } \\
\text { Corpo. }\end{array}$ \\
\hline$Y_{\mathrm{c}}$ & - & $\begin{array}{l}\text { Eixo Y, do sistema de coordenadas } \\
\text { Corpo. }\end{array}$ \\
\hline$Z_{\mathrm{c}}$ & - & Eixo Z, do sistema de coordenadas Corpo. \\
\hline$U$ & $m / s$ & $\begin{array}{l}\text { Velocidade linear em X em relação ao } \\
\text { sistema Corpo. }\end{array}$ \\
\hline $\mathrm{V}$ & $m / s$ & $\begin{array}{l}\text { Velocidade linear em Y em relação ao } \\
\text { sistema Corpo. }\end{array}$ \\
\hline w & $m / s$ & $\begin{array}{l}\text { Velocidade linear em Z em relação ao } \\
\text { sistema Corpo. }\end{array}$ \\
\hline$R_{\phi}$ & - & $\begin{array}{l}\text { Matriz de rotação em torno do eixo X do } \\
\text { sistema Corpo. }\end{array}$ \\
\hline$R_{\theta}$ & - & $\begin{array}{l}\text { Matriz de rotação em torno do eixo Y do } \\
\text { sistema Corpo. }\end{array}$ \\
\hline$R_{\Psi}$ & - & $\begin{array}{l}\text { Matriz de rotação em torno do eixo } Z \text { do } \\
\text { sistema Corpo. }\end{array}$ \\
\hline S & - & $\begin{array}{l}\text { Matriz de rotação dos ângulos de Euler } \phi \text {, } \\
\theta \text { e } \psi \text {. }\end{array}$ \\
\hline$\vec{\omega}$ & $\mathrm{rad} / \mathrm{s}$ & $\begin{array}{l}\text { Vetor velocidade angular do corpo em } \\
\text { relação ao sistema Terra. }\end{array}$ \\
\hline
\end{tabular}




\begin{tabular}{|c|c|c|}
\hline $\mathrm{T}$ & - & $\begin{array}{l}\text { Matriz de transformação de velocidades } \\
\text { angulares entre os sistemas Corpo-Terra. }\end{array}$ \\
\hline$\tau_{\text {prop } 1}, \tau_{\text {prop } 2}, \tau_{\text {prop } 3}, \tau_{\text {prop } 4}$ & $N$ & Empuxo gerado por cada propulsor. \\
\hline$K_{v \text { prop } 1}, K_{v \text { prop } 2}, K_{v \text { prop } 3}, K_{v \text { prop } 4}$ & N. $\mathrm{s}^{2} / \mathrm{rad}^{2}$ & $\begin{array}{l}\text { Constantes velocidade-empuxo de cada } \\
\text { propulsor. }\end{array}$ \\
\hline$\omega_{\text {prop } 1}, \omega_{\text {prop } 2}, \omega_{\text {prop } 3}, \omega_{\text {prop } 4}$ & $\mathrm{rad} / \mathrm{s}$ & Velocidade angular gerada por propulsor. \\
\hline$U_{1}$ & $N$ & $\begin{array}{l}\text { Empuxo total do corpo, na direção do eixo } \\
Z_{c} \text {. }\end{array}$ \\
\hline$L$ & $m$ & $\begin{array}{l}\text { Haste entre o centro de massa do corpo e } \\
\text { o ponto de geração de empuxo de cada } \\
\text { propulsor. }\end{array}$ \\
\hline$m$ & $K g$ & Massa total do quadrirotor. \\
\hline$g$ & $m / s^{2}$ & Aceleração da gravidade. \\
\hline$U_{2}$ & $N . m$ & $\begin{array}{l}\text { Momento resultante gerado pelos } \\
\text { empuxos dos propulsores } 4 \text { e } 2 \text {, em torno } \\
\text { de } X_{\text {c. }}\end{array}$ \\
\hline$U_{3}$ & $N . m$ & $\begin{array}{l}\text { Momento resultante gerado pelos } \\
\text { empuxos dos propulsores } 3 \text { e } 1 \text {, em torno } \\
\text { de } Y_{c} \text {. }\end{array}$ \\
\hline$M_{\text {prop } 1}, M_{\text {prop } 2}, M_{\text {prop } 3}, M_{\text {prop } 4}$ & $N . m$ & $\begin{array}{l}\text { Momento exercido pela rotação individual } \\
\text { de cada propulsor. }\end{array}$ \\
\hline$K_{m \text { prop } 1}, K_{m \text { prop } 2}, K_{m \text { prop } 3}, K_{m \text { prop } 4}$ & N.m. $s^{2} / \mathrm{rad}^{2}$ & $\begin{array}{l}\text { Constante velocidade-momento de cada } \\
\text { propulsor. }\end{array}$ \\
\hline$U_{4}$ & $N . m$ & $\begin{array}{l}\text { Momento realizado por todos os } \\
\text { propulsores, em torno de } Z_{c} \text {. }\end{array}$ \\
\hline$F^{\text {Corpo }}$ & $N$ & $\begin{array}{l}\text { Conjunto de forças exercidas, } \\
\text { referenciadas ao corpo do quadrirotor, } \\
F^{\text {Corpo }}=\left[\begin{array}{lll}0 & 0 & U_{1}\end{array}\right]^{T}\end{array}$ \\
\hline$\tau^{\text {Corpo }}$ & $N . m$ & $\begin{array}{l}\text { Conjunto de momentos exercidos, } \\
\text { referenciados ao corpo do quadrirotor, } \\
\tau^{\text {Corpo }}=\left[\begin{array}{lll}U_{2} & U_{3} & U_{4}\end{array}\right]^{T} \text {. }\end{array}$ \\
\hline$V^{\text {Corpo }}$ & $\mathrm{m} / \mathrm{s}$ & $\begin{array}{l}\text { Conjunto de velocidades lineares, } \\
\text { referenciadas ao corpo do quadrirotor, } \\
V^{\text {Corpo }}=\left[\begin{array}{lll}U & V & W\end{array}\right]^{T} \text {. }\end{array}$ \\
\hline$\omega^{\text {Corpo }}$ & $\mathrm{rad} / \mathrm{s}$ & $\begin{array}{l}\text { Conjunto de velocidades lineares, } \\
\text { referenciadas ao corpo do quadrirotor, } \\
V^{\text {Corpo }}=\left[\begin{array}{lll}P & Q & R\end{array}\right]^{T} \text {. }\end{array}$ \\
\hline$I$ & $K g \cdot m^{2}$ & $\begin{array}{l}\text { Matriz de momentos de inercia do corpo, } \\
I=\left[\begin{array}{ccc}I_{x} & 0 & 0 \\
0 & I_{y} & 0 \\
0 & 0 & I_{z}\end{array}\right]\end{array}$ \\
\hline$x$ & - & $\begin{array}{l}\text { Vetor de estados na representação no } \\
\text { espaço de estados. }\end{array}$ \\
\hline$u$ & - & $\begin{array}{l}\text { Vetor de entradas na representação no } \\
\text { espaço de estados. }\end{array}$ \\
\hline
\end{tabular}




\begin{tabular}{|c|c|c|}
\hline$A$ & - & $\begin{array}{l}\text { Matriz de de estados final, na } \\
\text { representação no espaço de estados. }\end{array}$ \\
\hline$B$ & - & $\begin{array}{l}\text { Matriz de entradas final, na representação } \\
\text { no espaço de estados. }\end{array}$ \\
\hline C & - & $\begin{array}{l}\text { Matriz de saídas final, na representação } \\
\text { no espaço de estados. }\end{array}$ \\
\hline$D$ & - & $\begin{array}{l}\text { Matriz de transmissão direta final, na } \\
\text { representação no espaço de estados. }\end{array}$ \\
\hline$\omega_{\text {set } 1}, \omega_{\text {set } 2}, \omega_{\text {set } 3}, \omega_{\text {set } 4}$ & $\mathrm{rad} / \mathrm{s}$ & $\begin{array}{l}\text { Referências de velocidades para os } \\
\text { motores. }\end{array}$ \\
\hline$f(x, u)$ & - & $\begin{array}{l}\text { Conjunto de funções que representam o } \\
\text { comportamento dos estados do sistema. }\end{array}$ \\
\hline$h(x, u)$ & - & $\begin{array}{l}\text { Conjunto de funções dos sensores, que } \\
\text { representam o comportamento das saídas } \\
\text { do sistema. }\end{array}$ \\
\hline$a_{x}(x), a_{y}(x), a_{z}(x)$ & $\mathrm{m} / \mathrm{s}^{2}$ & $\begin{array}{l}\text { Acelerações do corpo nas direções } X_{c}, Y_{c} \\
\text { e } Z_{c} \text {, respectivamente. Em relação ao seu } \\
\text { centro de massa. }\end{array}$ \\
\hline$a_{s}$ & $m / s^{2}$ & $\begin{array}{l}\text { Vetor de acelerações medidas pelo sensor } \\
\text { acelerômetro, } \\
a_{x}=\left[\begin{array}{lll}a_{x}(x) & a_{y}(x) & a_{z}(x)\end{array}\right]^{T} .\end{array}$ \\
\hline$r_{s}$ & $\mathrm{~m} / \mathrm{s}^{2}$ & $\begin{array}{l}\text { Vetor de posição entre o sensor } \\
\text { acelerômetro e o centro de massa do } \\
\text { corpo, } r_{s}=\left[\begin{array}{lll}r_{s_{x}} & r_{s_{y}} & r_{s_{z}}\end{array}\right]^{T} \text {. }\end{array}$ \\
\hline $\bar{x}$ & - & Vetor ponto de equilíbrio dos estados. \\
\hline $\bar{Z}$ & $m$ & $\begin{array}{l}\text { Altitude nominal do quadrirotor, para o } \\
\text { sistema linearizado. }\end{array}$ \\
\hline $\bar{u}$ & $\mathrm{rad} / \mathrm{s}$ & $\begin{array}{l}\text { Vetor de entradas nominais, para o } \\
\text { sistema linearizado. }\end{array}$ \\
\hline$\overline{\omega_{\text {set } 1}}, \overline{\omega_{\text {set } 2}}, \overline{\omega_{\text {set } 3}}, \overline{\omega_{\text {set } 4}}$ & $\mathrm{rad} / \mathrm{s}$ & $\begin{array}{l}\text { Velocidades angulares nominais de cada } \\
\text { rotor. }\end{array}$ \\
\hline$A_{\text {lin }}$ & - & $\begin{array}{l}\text { Matriz de estados linearizada, na } \\
\text { representação no espaço de estados. }\end{array}$ \\
\hline$B_{\text {lin }}$ & - & $\begin{array}{l}\text { Matriz de entradas linearizada, na } \\
\text { representação no espaço de estados. }\end{array}$ \\
\hline$C_{l i n}$ & - & $\begin{array}{l}\text { Matriz de saídas linearizada, na } \\
\text { representação no espaço de estados. }\end{array}$ \\
\hline$D_{\text {lin }}$ & - & $\begin{array}{l}\text { Matriz de transmissão direta linearizada, } \\
\text { na representação no espaço de estados. }\end{array}$ \\
\hline$\omega_{\text {prop } 1}, \omega_{\text {prop } 2}, \omega_{\text {prop } 3}, \omega_{\text {prop } 4}$ & $\mathrm{rad} / \mathrm{s}$ & Velocidades angulares para cada rotor. \\
\hline$\tau_{1}, \tau_{2}, \tau_{3}, \tau_{4}$ & - & $\begin{array}{l}\text { Constante de tempo para a dinâmica de } \\
\text { primeira ordem de cada rotor. }\end{array}$ \\
\hline$A_{\omega}$ & - & $\begin{array}{l}\text { Matriz de transição de estados linearizada } \\
\text { e com inclusão da dinâmica dos motores, } \\
\text { na representação no espaço de estados. }\end{array}$ \\
\hline
\end{tabular}




\begin{tabular}{|c|c|c|}
\hline$B_{\omega}$ & - & $\begin{array}{l}\text { Matriz de entradas linearizada e com } \\
\text { inclusão da dinâmica dos motores, na } \\
\text { representação no espaço de estados. }\end{array}$ \\
\hline$C_{\omega}$ & - & $\begin{array}{l}\text { Matriz de saídas linearizada e com } \\
\text { inclusão da dinâmica dos motores, na } \\
\text { representação no espaço de estados. }\end{array}$ \\
\hline$D_{\omega}$ & - & $\begin{array}{l}\text { Matriz de transmissão direta linearizada e } \\
\text { com inclusão da dinâmica dos motores, na } \\
\text { representação no espaço de estados. }\end{array}$ \\
\hline$i_{\text {total(rover) }}$ & $A$ & $\begin{array}{l}\text { Corrente necessária nos motores para } \\
\text { igualar a força peso do UAV. }\end{array}$ \\
\hline$Q_{\text {bateria }}$ & $m A h$ & $\begin{array}{l}\text { Capacidade necessária da bateria para } \\
\text { cumprir a especificação de tempo de voo } \\
\text { do UAV. }\end{array}$ \\
\hline$B_{x}, B_{y}, B_{z}$ & gaus & $\begin{array}{l}\text { Valores para as medidas de campo } \\
\text { magnético do sensor magnetômetro. }\end{array}$ \\
\hline$B_{x \text { comp }}, B_{y \text { comp }}, B_{z \text { comp }}$ & gaus & $\begin{array}{l}\text { Valores compensados para as medidas de } \\
\text { campo magnético do sensor } \\
\text { magnetômetro. }\end{array}$ \\
\hline$\theta_{\text {tilt }}$ & $\mathrm{rad}$ & $\begin{array}{l}\text { Posição angular da câmera, na direção de } \\
\text { tilt. }\end{array}$ \\
\hline$\theta_{\text {pan }}$ & rad & $\begin{array}{l}\text { Posição angular da câmera, na direção de } \\
\text { pan. }\end{array}$ \\
\hline $\mathcal{C}$ & - & Matriz controlabilidade do sistema. \\
\hline $\mathcal{O}$ & - & Matriz observabilidade do sistema. \\
\hline$K_{s}$ & - & $\begin{array}{l}\text { Ganho da lei de controle, utilizando a } \\
\text { técnica por alocação direta de polos. }\end{array}$ \\
\hline$K_{L Q R}$ & - & Ganho da lei de controle, utilizando LQR. \\
\hline$s$ & - & $\begin{array}{l}\text { Polo do sistema, no domínio da } \\
\text { frequência. }\end{array}$ \\
\hline$\xi$ & - & Fator de amortecimento do polo. \\
\hline$\omega_{n}$ & $\mathrm{rad} / \mathrm{s}$ & Frequência natural do polo. \\
\hline$(\%) O S$ & - & $\begin{array}{l}\text { Ganho da lei de controle, utilizando a } \\
\text { técnica por alocação direta de polos. }\end{array}$ \\
\hline$T_{\text {acomodação }}$ & $s$ & Tempo de acomodação. \\
\hline$T_{s}$ & $s$ & $\begin{array}{l}\text { Período de amostragem do sistema } \\
\text { discretizado. }\end{array}$ \\
\hline$Z$ & - & $\begin{array}{l}\text { Polo do sistema mapeado no domínio do } \\
\text { tempo discreto. }\end{array}$ \\
\hline$A_{d}$ & - & $\begin{array}{l}\text { Matriz de transição de estados linearizada } \\
\text { e com inclusão da dinâmica dos motores, } \\
\text { na representação no espaço de estados. }\end{array}$ \\
\hline$B_{d}$ & - & $\begin{array}{l}\text { Matriz de entradas linearizada e com } \\
\text { inclusão da dinâmica dos motores, na } \\
\text { representação no espaço de estados }\end{array}$ \\
\hline
\end{tabular}




\begin{tabular}{c|c|l}
\hline$C_{d}$ & - & $\begin{array}{l}\text { discreto. } \\
\text { inclusão da dinâmica dos motores, na } \\
\text { representação no espaço de estados } \\
\text { discreto. }\end{array}$ \\
\hline$D_{d}$ & - & $\begin{array}{l}\text { Matriz de transmissão direta linearizada e } \\
\text { com inclusão da dinâmica dos motores, na } \\
\text { representação no espaço de estados } \\
\text { discreto. }\end{array}$ \\
\hline$J_{L Q R}$ & - & Função custo do controlador LQR. \\
\hline$Q_{L Q R}$ & - & $\begin{array}{l}\text { Matriz de custo-desempenho do } \\
\text { controlador LQR, para os estados. }\end{array}$ \\
\hline$R_{L Q R}$ & - & $\begin{array}{l}\text { Matriz de custo-desempenho do } \\
\text { controlador LQR, para a atuação de } \\
\text { controle. }\end{array}$ \\
\hline$\hat{x}$ & - & Vetor de estados estimados do sistema. \\
\hline$\hat{y}$ & - & Vetor de saídas estimadas do sistema. \\
\hline$L_{e s t}$ & - & $\begin{array}{l}\text { Matriz de ganho do observador de } \\
\text { estados pleno. }\end{array}$ \\
\hline$P(k)$ & - & $\begin{array}{l}\text { Matriz de covariância dos resíduos de } \\
\text { estimação para o filtro de Kalman. }\end{array}$ \\
\hline$K(k)$ & - & $\begin{array}{l}\text { Matriz de ganho filtro de Kalman. } \\
\text { medição. }\end{array}$ \\
\hline$Q_{K a l m a n}$ & - & $\begin{array}{l}\text { Matriz de covariância dos ruídos de } \\
\text { processo. }\end{array}$ \\
\hline Kalman & - & - \\
\hline
\end{tabular}




\section{SUMÁRIO}

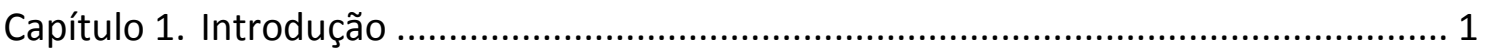

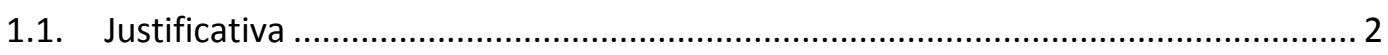

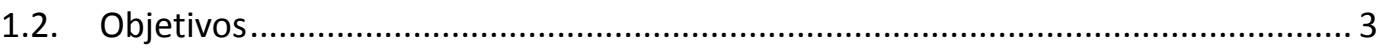

1.3. Revisão da Literatura ....................................................................................... 4

1.3.1. História dos Quadrirotores ....................................................................

1.3.2. Teoria de Operação do Quadrirotor ..............................................................

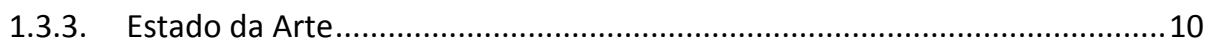

1.4. Metodologia …….......................................................................................... 14

Capítulo 2. Modelagem Matemática do Sistema ...................................................... 16

2.1. Modelagem Dinâmica do Quadrirotor ................................................................ 16

2.1.1. Matrizes de Transformação Terra-Corpo do Quadrirotor ...........................17

2.1.2. Forças e Momentos Gerados Pelos Propulsores.......................................20

2.1.3. Modelo de Newton-Euler para o Quadrirotor ...........................................23

2.1.4. Linearização do Sistema e Descrição no Espaço de Estados...........................25

2.1.4.1. Inclusão da Dinâmica dos Motores no Modelo ......................................30

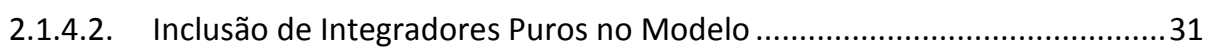

Capítulo 3. Projeto, Ensaios e Seleção de Hardware do UAV ........................................ 33

3.1. Seleção e Ensaio dos Atuadores .............................................................. 33

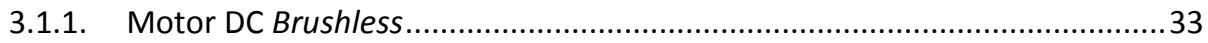

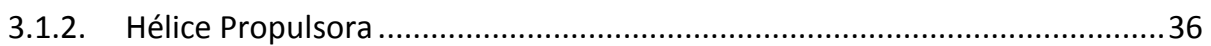

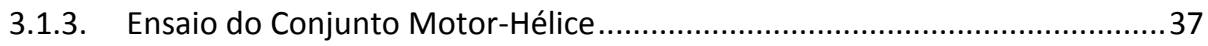


3.3. Projeto Mecânico do Quadrirotor ........................................................... 46

3.4. Seleção e Configuração dos Sensores............................................................. 48

3.4.1. Acelerômetro e Giroscópio ............................................................ 48

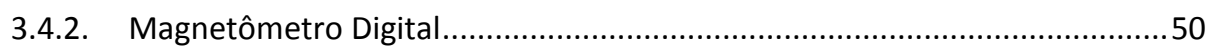

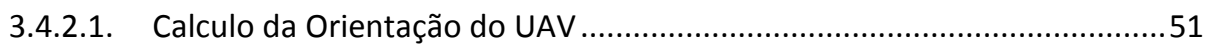

3.4.2.2. Compensação de efeitos de Soft e Hard Iron...........................................52

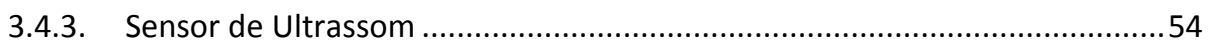

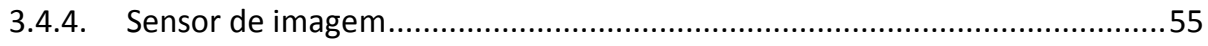

3.4.4.1. Conjunto de Pan e Tilt com Servo-Motores .............................................56

3.4.4.2. Calculo do Deslocamento do UAV a Partir da Câmera...............................58

3.5. Hardware Eletrônico Embarcado................................................................. 58

3.5.1. Módulo Wireless e Protocolo de Comunicação P2P ..................................60

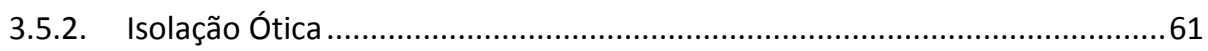

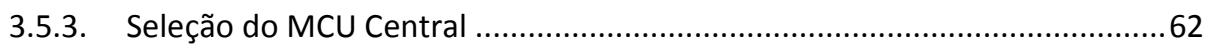

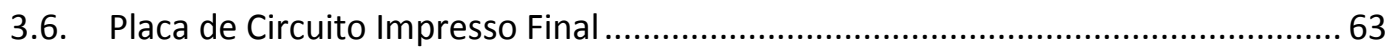

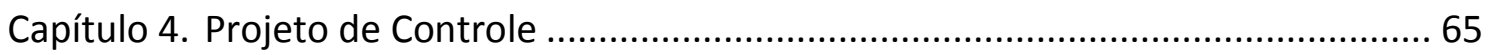

4.1. Verificação de Controlabilidade e Observabilidade ......................................... 65

4.2. Projeto do Controlador Por Alocação de Polos .............................................. 67

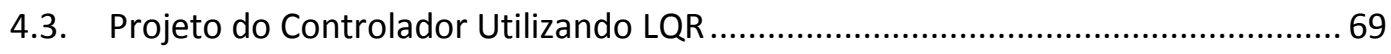

4.4. Observador de Estados de Ordem Plena ................................................... 72

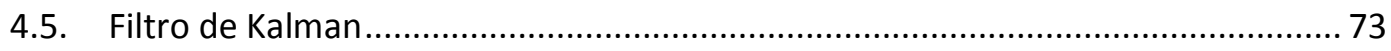

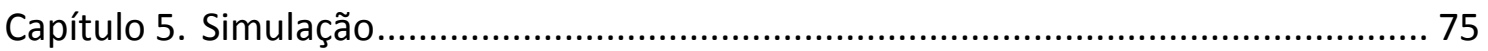


5.1. Construção do Modelo no MATLAB/Simulink ${ }^{\circledR}$

5.1. Simulação do Controle por Alocação de Polos com Observador de Estados de Ordem Plena. 78

5.2. Simulação do Controle LQR com Filtro de Kalman 81

5.3. Simulação do Controle LQR com Introdução de Ruídos de Medição e Processo... 85

Capítulo 6. Implementação e Resultados na Planta Real 94

6.1. Discussões Adicionais quanto à Aplicação da Técnica HIL 99

6.2. Firmware Resultante para Controle Embarcado ao UAV 100

6.3. Ensaios do UAV com Algoritmos de Controle Embarcados...... 103

Capítulo 7. Conclusões e Trabalhos Futuros 106 


\section{Capítulo 1. Introdução}

Desde os primórdios das sociedades, o homem busca soluções para a melhoria de seu ambiente, em termos de conforto e eficiência em tarefas. A cada época da historia humana, diversas inovações tecnológicas foram realizadas e contribuem até hoje para a sociedade.

Dentre os diversos setores da tecnologia, a exploração do voo com uma máquina, sempre incentivou pesquisadores e cientistas. No início do século 20, o cientista e acadêmico Charles Richet criou um helicóptero de pequenas dimensões, não tripulado. Apesar do não sucesso deste projeto, o mesmo inspirou o trabalho seu aluno Louis Bréguet. Por volta do ano de 1906, os irmãos Louis e Jacques Bréguet iniciaram estudos e experimentos na ciência de helicópteros, sob a supervisão de seu professor Richet. Até que em meados do ano de 1907, eles construíram seu primeiro helicóptero tripulado, chamado de Bréguet-Richet Gyroplane No.1, este helicóptero possuía configuração de um quadrirotor, ilustrado na Figura 1 (BOULET, 1982).

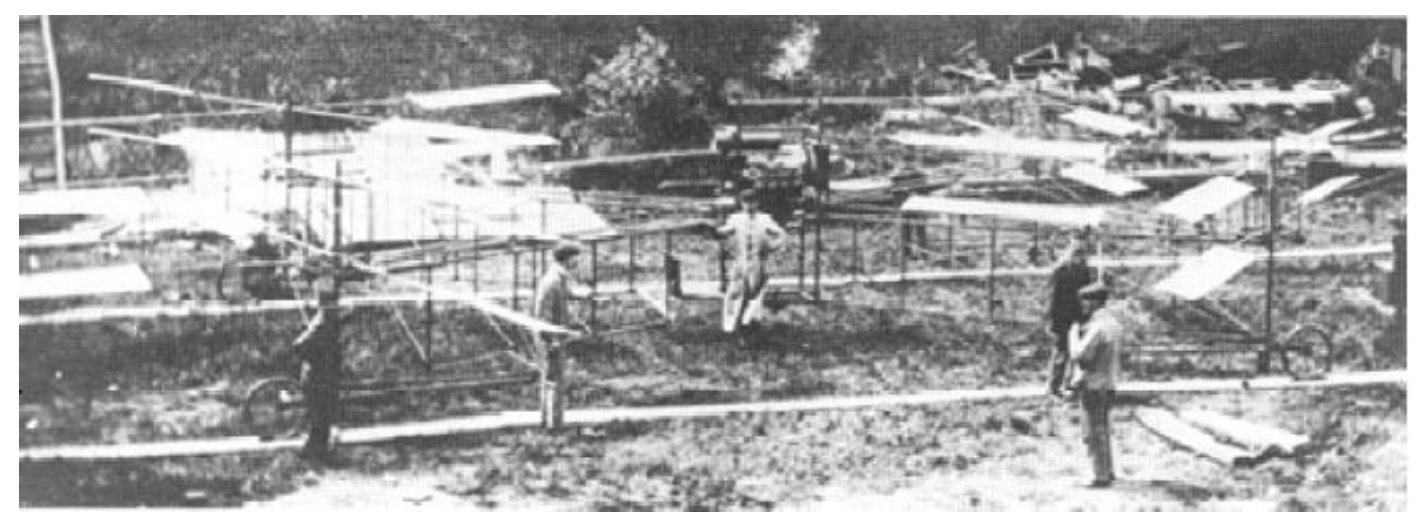

Figura 1. Quadrirotor Bréguet-Richet Gyroplane No. 1.

O Giroplano Bréguet-Richet No. 1 constituiu-se de um grid cruciforme com tubos metálicos. Cada rotor era constituído por oito asas modeladas com panos. Totalizando 32 superfícies de propulsão. O piloto posicionava-se no centro do frame e o motor de propulsão acima desta posição. O motor à combustão interna Antoniette utilizado, constituído por oito cilindros, produzia 40HP $(29,8 \mathrm{~kW})$ de potência. A massa deste quadrirotor se 
totalizou em $578 \mathrm{Kg}$, incluindo o piloto. Entre os meses de agosto e setembro de 1907, testes com o quadrirotor foram conduzidos, e relatórios da época confirmam 1,5m de altitude de voo, com autonomia de 1 minuto (BOULET, 1982).

Desde então, estudos que tangem 0 desenvolvimento de helicópteros receberam cada vez mais incentivos e interesse da academia.

Dentre as várias categorias de aeronaves hoje presentes, os quadrirotores se enquadram na categoria denominada VTOL (Vertical Takeoff and Landing - Decolagem e Aterrissagem Vertical).

Sua característica de pouso e decolagem possibilita flexibilidade para pouso em terreno acidentado ou não preparado para pouso. $O$ avião caça Harrier Jump Jet seria um exemplo de aeronave VTOL, ilustrado na Figura 2.

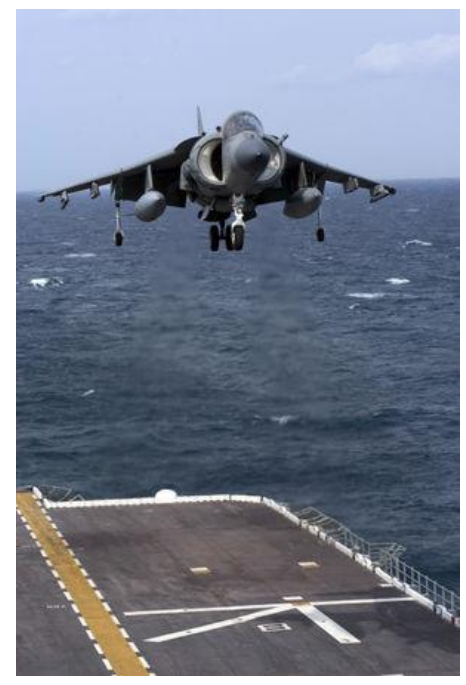

Figura 2. VTOL Harrier Jump Jet.

\subsection{Justificativa}

Com a evolução da automação juntamente com veículos aéreos, surge o conceito dos UAVs (Unmanned Aerial Vehicles - Veículos Aéreos Não Tripulados), onde se procura implementar técnicas de controle e inteligência artificial para a utilização de equipamentos autônomos ou controlados remotamente em cenários de risco para a vida humana ou de 
segurança/vigilância (BRESCIANI, 2008). Os avanços nas teorias de controle, tecnologias de materiais, sensores MEMS (Micro Electromechanical Systems Micro Sistemas Eletromecânicos) e baterias também fomenta esta área de pesquisa oferecendo novas possibilidades para estes sistemas.

A arquitetura de um quadrirotor oferece a opção de decolagem e pouso verticais, bem como o equilíbrio estático no ar quando equipado por um sistema de controle, seja ele manual ou automático. Esta arquitetura possibilita diversas aplicações como vigilância, processamento de imagens, navegação em territórios de risco, navegação em ambientes internos e mapeamento. Todos estes podendo ser implementados de forma a controlar o quadrirotor remotamente, ou de forma autônoma.

É observando este conjunto de características que um quadrirotor pode possuir que este trabalho encontra seu escopo: propondo o projeto mecânico, eletrônico e de controle de um quadrirotor, visando sua estabilização por meio de um controlador linear multivariável. A aeronave por sua vez, será autônoma no ponto de vista da estabilização da sua atitude e deslocamento.

\subsection{Objetivos}

Esta dissertação tem como principais objetivos os projetos mecânico, eletrônico e de controle de um quadrirotor, bem como a confecção de um controlador linear visando o rastreamento dos estados de interesse da aeronave para operação autônoma do mesmo.

O UAV possuirá embarcado ao seu corpo, um conjunto de sensores sendo eles: sensores inerciais com três acelerômetros e giroscópios para estabilização de atitudes juntamente com um magnetômetro, e um sensor de imagem que é utilizado para realizar a realimentação de posição linear via processamento de imagem. Um sensor de ultrassom também é utilizado para aferição de altitude.

Para cumprir os objetivos gerais supracitados, serão contemplados os seguintes objetivos: 
- Projeto e construção mecânica do quadrirotor, visando suportar uma carga útil de até 200 gramas com autonomia de voo de aproximadamente 10 minutos. Nesta etapa serão definidos também os requerimentos de empuxo das hélices, posicionamento dos motores e capacidade estimada de bateria;

- Modelagem dinâmica e cinemática da planta do quadrirotor a partir do corpo mecânico projetado, em conjunto com os atuadores (motores e hélices) e carga útil;

- Criação das malhas de controle, juntamente com a implementação e interface dos sensores para retroação da planta;

- Simulação da planta modelada, juntamente com as malhas de controle para validação do controle com a planta simulada;

- Geração do sistema de controle na planta real para validação do modelo simulado e do sistema de controle. Voo com sistema de controle utilizando a técnica HIL.

\subsection{Revisão da Literatura}

Para realizar o projeto e a implementação do equipamento desejado de modo a maximizar sua eficiência, deve-se fundamentar adequadamente alguns aspectos teóricos que permeiam o tema proposto.

\subsubsection{História dos Quadrirotores}

Como anteriormente citado, o primeiro quadrirotor criado, obteve sucesso parcial em seu voo, contudo devido a grandes avanços ainda pendentes nesta tecnologia, este primeiro trabalho fomentou diversas outras pesquisas.

Em 1920, o engenheiro Etienne Oemichen também realizou pesquisas no campo dos helicópteros, no total ele criou seis diferentes aeronaves VTOL. Devido ao seu primeiro modelo não obter sucesso na 
decolagem, ele utilizou um balão de hélio para prover o empuxo necessário para decolagem, bem como para estabilidade da aeronave.

Seu segundo quadrirotor, o Oemichen No. 2, possuía quatro rotores dispostos de maneira cruciforme para sustentação e mais quatro menores para esterçar a aeronave. Na Figura 3 e Figura 4 observa-se sua configuração.

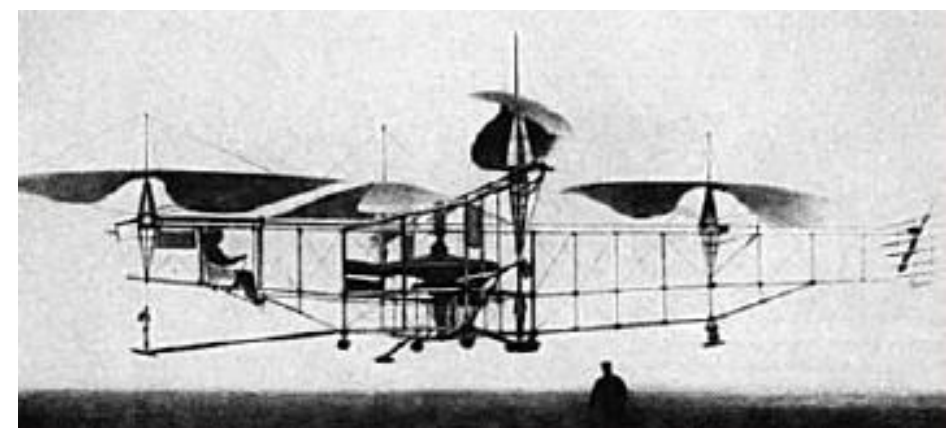

Figura 3. Fotografia da aeronave VTOL Oemichen No. 2.

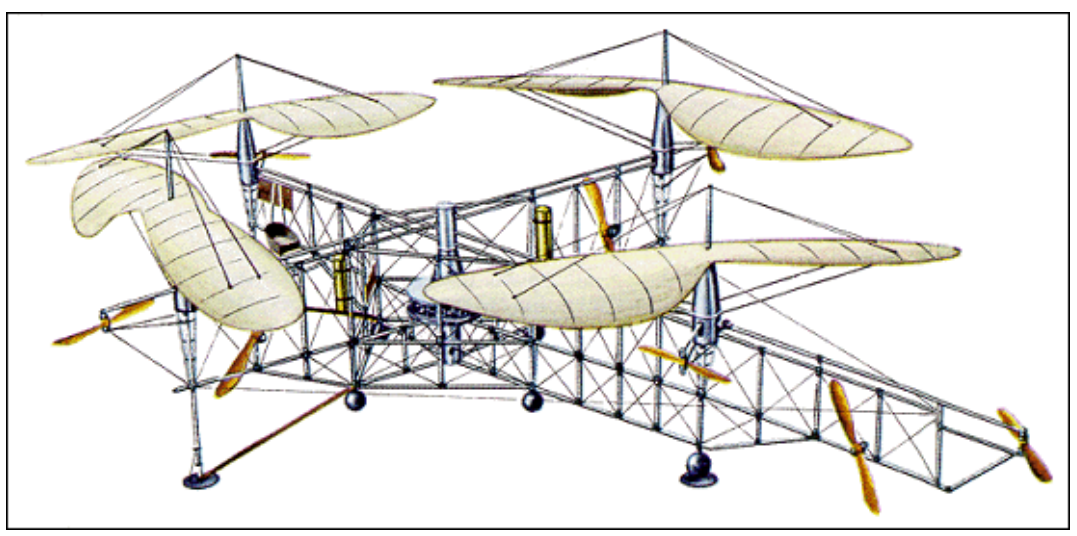

Figura 4. Esboço da aeronave VTOL Oemichen No. 2.

Em 1921, o exército americano obteve interesse por aeronaves VTOL. Um dos requisitos das forças armadas era que a aeronave alcançasse $100 \mathrm{~m}$ de altitude, porém o resultado final consistiu em um máquina com massa de $1678 \mathrm{Kg}$ com o melhor alcance de altitude na faixa dos $5 \mathrm{~m}$. Observa-se uma imagem do quadrirotor desenvolvido pelo Dr. Bothezat e seu colega Ivan Jerome na Figura 5. 


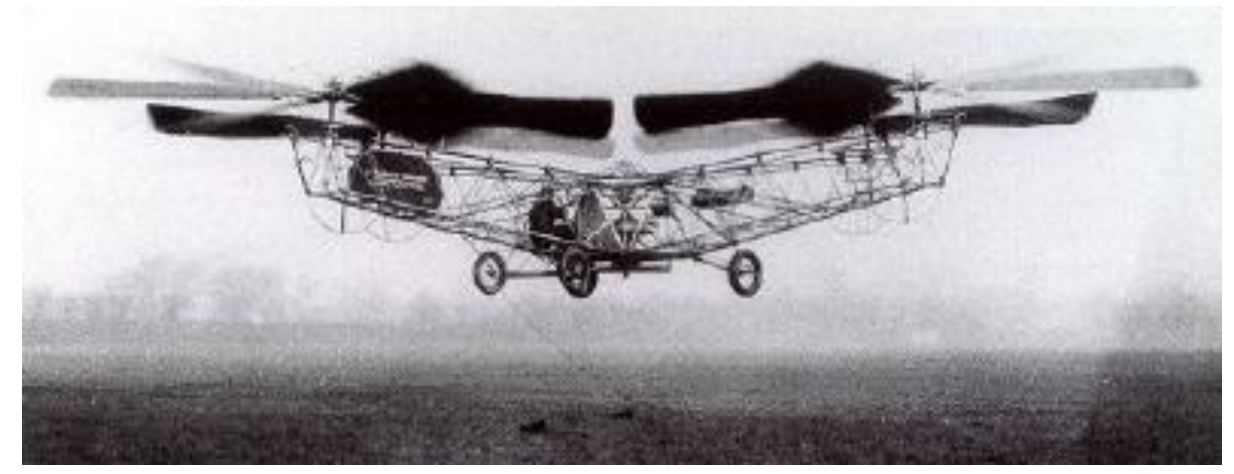

Figura 5. Fotografia da aeronave VTOL produzida para as forças aéreas dos EUA em 1921.

Após a década de 1920, a demanda para quadrirotores diminuiu, mas em 1956, um protótipo chamado Convertawings Model $A$ foi criado e seu desempenho bem sucedido, inclusive para movimentações frontais, entretanto o projeto foi cancelado devido à falta de demanda para este tipo de aeronave.

Com recentes avanços na aeronáutica e engenharia de controle e automação, o interesse nestes equipamentos aumentou novamente. Um exemplo é o Moller Skycar um protótipo para um VTOL para o público consumidor. Como observado na Figura 6, nota-se também que o Skycar possui quatro propulsores protegidos, visando maior segurança.

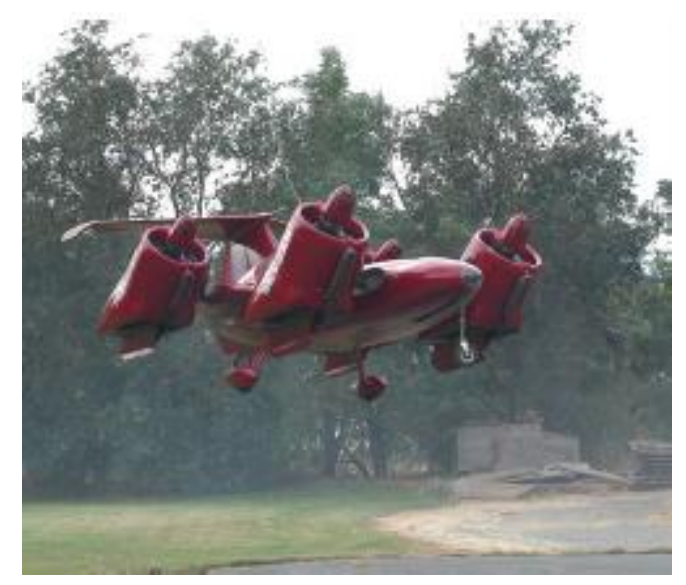

Figura 6. Fotografia da aeronave VTOL Skycar.

Existem ainda nos dias de hoje os quadrirotores UAVs, que normalmente possuem dimensão reduzida e são controlados remotamente ou 
possuem funções autônomas. Muitas vezes são aplicados para fins de entretenimento como, por exemplo, o AR-Drone, um UAV que pode ser controlado remotamente por conexão WiFi. Este modelo está ilustrado na Figura 7.

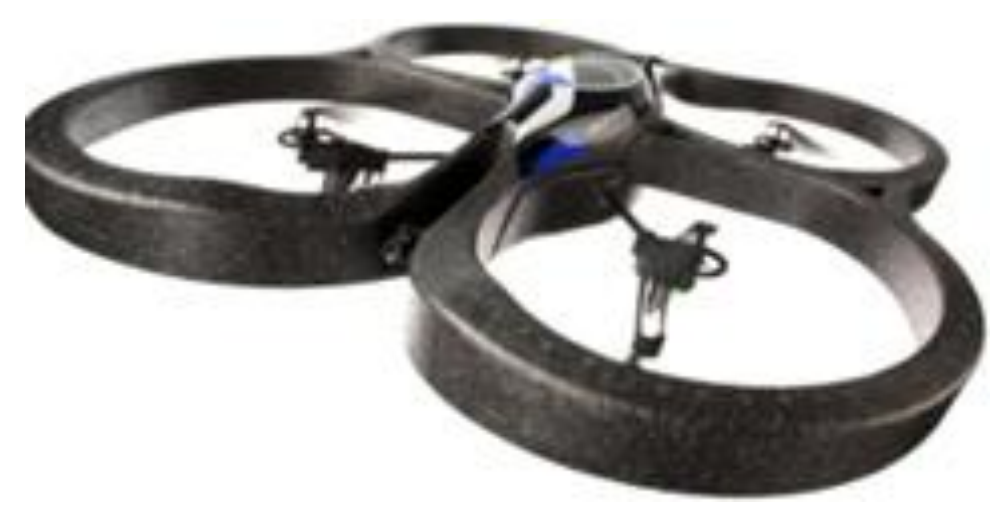

Figura 7. AR-Drone.

\subsubsection{Teoria de Operação do Quadrirotor}

Um quadrirotor é composto basicamente de quatro propulsores comumente organizados de maneira cruciforme. Cada uma das hélices é responsável por uma parcela do empuxo total necessário para decolar e sustentar o quadrirotor.

De forma a equalizar os momentos gerados por cada propulsor, um par propulsor gira no sentido horário e o outro no sentido anti-horário. Desta maneira se todos os propulsores estiverem com velocidades angulares equivalentes, o somatório dos momentos angulares será zero. Aproveitando este efeito, é possível também desequilibrar os torques para criar uma rotação no sentido horário ou anti-horário.

$\mathrm{Na}$ modelagem de um quadrirotor, é comum se aproveitar das convenções utilizadas para as orientações do veículo em relação ao seu centro de gravidade (ou COG - Center of Gravity), também conhecidas como atitudes do UAV. São elas: Guinada (ouYaw, em inglês), Arfagem (ou Pitch, em inglês) e Rolagem (ou Roll, em inglês). Na Figura 8 se exibem estas atitudes. 


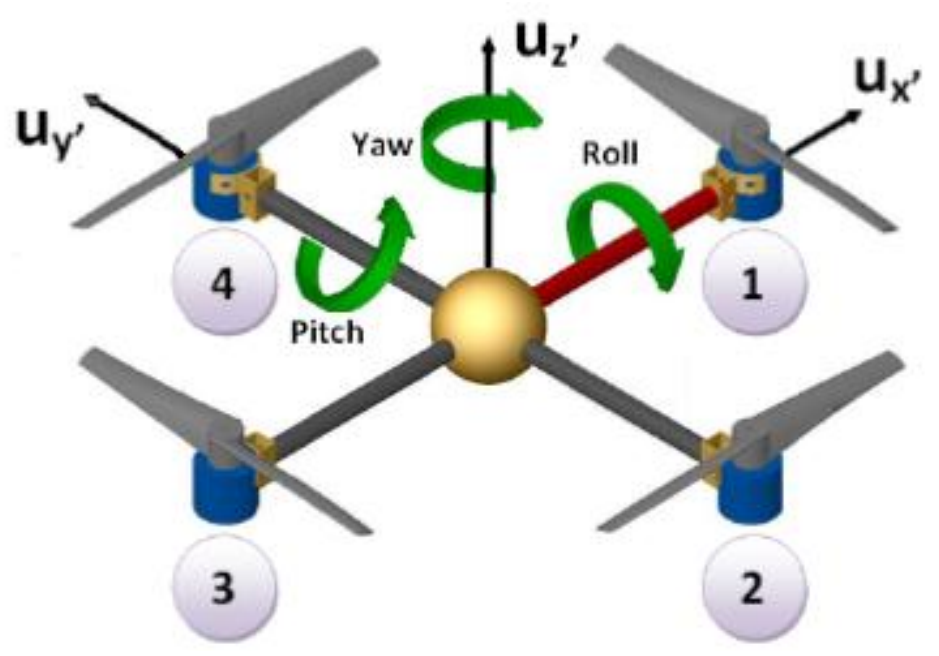

Figura 8. Atitudes do quadrirotor.

Estes ângulos são de suma importância para a implementação das técnicas de controle, pois ao exercer variações nestas atitudes tem-se uma projeção da propulsão de cada hélice para uma direção, assim viabilizando o deslocamento do quadrirotor nos eixos $\mathrm{X}$ e $\mathrm{Y}$.

Com base nos propulsores numerados na Figura 9, ao se elevar a velocidade angular no propulsor 1 e igualmente reduzir-se a velocidade no propulsor 3 , uma variação negativa seria gerada na atitude pitch $\mathrm{e}$ consequentemente um deslocamento negativo no eixo $\mathrm{X}$ seria produzido (como representado no item "a" da Figura 9), ao se reduzir a velocidade no propulsor 1 e aumentar no propulsor 3, uma variação positiva seria gerada na atitude pitch, o que resultaria em um positivo deslocamento no eixo $\mathrm{X}$ (como representado no item "b" da Figura 9). Analogamente, com a variação das velocidades dos propulsores 2 e 4, pode-se gerar movimentos ao longo do eixo $Y$ (itens "c" e "d" da Figura 9), por meio da variação da atitude roll causada pelos propulsores. Para elevar a altitude do quadrirotor, aumenta-se igualmente a velocidade de todos os propulsores (item "e" da Figura 9). Para reduzir a altitude, a redução equilibrada das velocidades é necessária. Por fim, para alterar a orientação, ou yaw, do UAV, um desequilíbrio na somatória dos momentos deve ocorrer (como ilustrado nos itens "g" e "h" da Figura 9). 


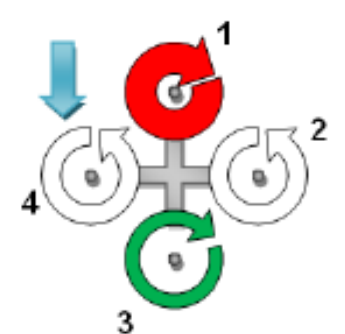

a)

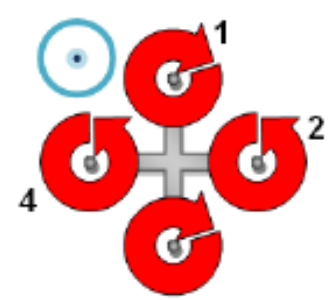

3

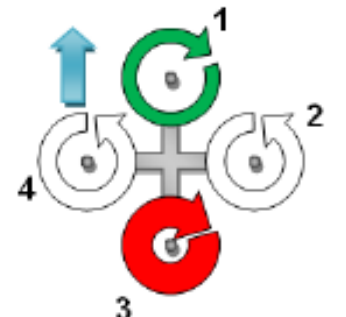

b)

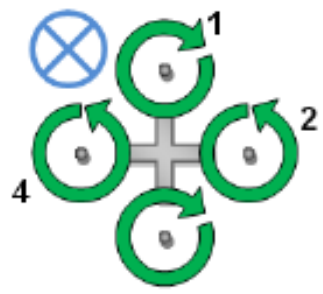

3

f)

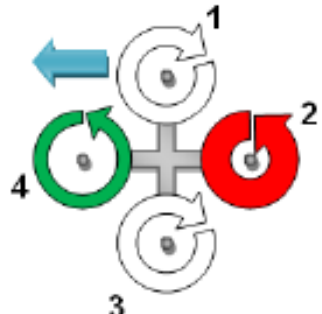

c)

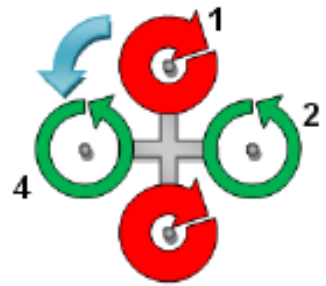

3

в)

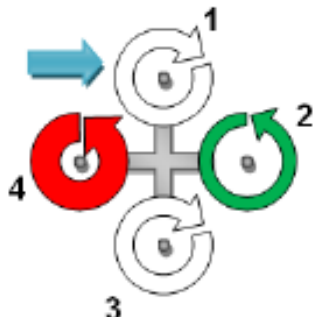

d)

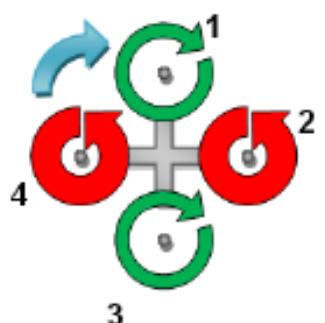

h)

Baixa Velocidade

Alta Velocidade

Figura 9. Variações nas velocidades angulares e respectivos resultados em movimentações lineares e angulares.

Este tipo de configuração do quadrirotor possui diversos contrastes com helicópteros convencionais, podendo gerar vantagens quanto à construção, complexidade de controle e dirigibilidade, como por exemplo (Domingues, 2009):

- Não há necessidade de redução de transmissão de torque entre o motor e o rotor, desde que os motores sejam selecionados adequadamente para as especificações de velocidade e torque;

- Não é necessária hélice com passo variável para controlar o ângulo de ataque da aeronave. A mecânica dos rotores também é simplificada por este motivo;

- Quatro propulsores menores, em oposto a um propulsor centralizado, possuem menos acumulo de energia cinética, reduzindo danos em caso de acidentes;

- Redução de efeitos giroscópios. 


\subsubsection{Estado da Arte}

As características de um quadrirotor são definidas por um conjuntochave de requisitos de desempenho como autonomia de voo, alcance e velocidades máximas, entre outros. A capacidade de alcançar estes requisitos está intimamente relacionada e dependente de sua dirigibilidade e qualidade aerodinâmica (Gessow et al, 1967).

Por se tratar de um problema de controle MIMO (Multiple Input and Multiple Output - Múltiplas Entradas e Saídas), o projeto de um quadrirotor pode ser solucionado por meio da utilização de diversas técnicas de controle lineares ou não lineares.

Nos dias de hoje, diversos trabalhos vêm sendo aplicados na área dos UAVs e especificamente quadrirotores. Diversas universidades, estudantes e pesquisadores trabalham para introduzir novas abordagens de controle, modelagem mecânica e aerodinâmica. Nesta seção serão descritos trabalhos efetuados nesta área nos últimos anos.

O trabalho realizado por Azzram et al. propõe uma abordagem de controle não linear para a estabilização de atitudes e altitude de um quadrirotor, utilizando um modelo dinâmico formalizado a partir de Newton-Euler. Constituiu-se um controlador PD para retroação da atitude yaw e altitude, e PID backstepping para controle das atitudes roll e pitch. Após simulações no modelo formalizado, constatou-se a estabilidade assintótica das atitudes.

A proposta de controle utilizada no trabalho de Erginer et al. se concentrou na estabilização das posições de um quadrirotor UAV a partir de uma câmera, juntamente a um IMU (Inertial Measurement Unit - Unidade de Mensura Inercial) e GPS (Global Position System - Sistema de Posicionamento Global) para controle das atitudes e efeitos giroscópios. A estratégia de controle usa a variação das atitudes para mover o UAV através do espaço de trabalho. Um laço PD secundário foi implementado juntamente com a câmera 
para rastrear o erro de posicionamento. Este trabalho obteve seus resultados a partir de um modelo simulado.

Mouabdallah et al. apresenta uma comparação de performance entre uma abordagem utilizando PID clássico e um controlador linear quadrático para um quadrirotor. Neste trabalho é utilizada uma câmera estática para retroação de posição e um IMU para aquisição de atitudes por meio de um filtro de Kalman já inserido no IMU. Um protótipo nomeado OS4 (Omnidirectional Stationary Flying Outstretched Robot) foi projetado e confeccionado, como observa-se na Figura 10. Os testes comparativos entre técnicas de controle foram realizados em uma bancada de testes com o UAV tendo seus movimentos limitados por cordas, o controle PID implementado foi considerado satisfatório sendo capaz de estabilizar o OS4. O controle linear quadrático foi implementado utilizando um modelo linearizado expresso no espaço de estados, o OS4 por fim não obteve estabilidade utilizando esta metodologia e não pode voar livremente diferentemente da implementação com controle PID.

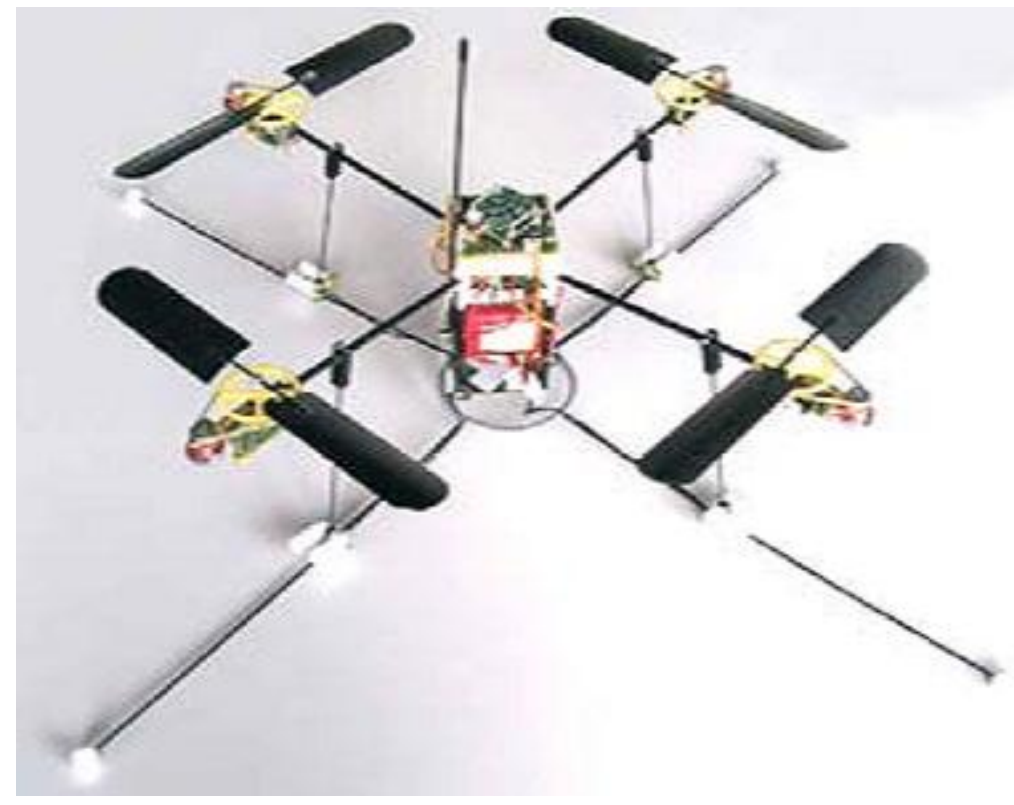

Figura 10. Quadrirotor OS4.

No trabalho de Hoffman et al. uma abordagem de UAVs multiagentes foi tomada. Dentro deste escopo um quadrirotor foi projetado e seu 
protótipo construído, sendo nomeado STARMAC II (Stanford Testbed of Autonomous Rotorcraft for Multi-Agent Control), na Figura 11 pode-se observar uma fotografia deste UAV. Controladores lineares (PID e PD) foram implementados. O trabalho também focou na modelagem dinâmica do quadrirotor para situações de voo em velocidades significantemente diferentes do equilíbrio estático. Foram demonstradas melhorias na performance dos controladores com este modelo.

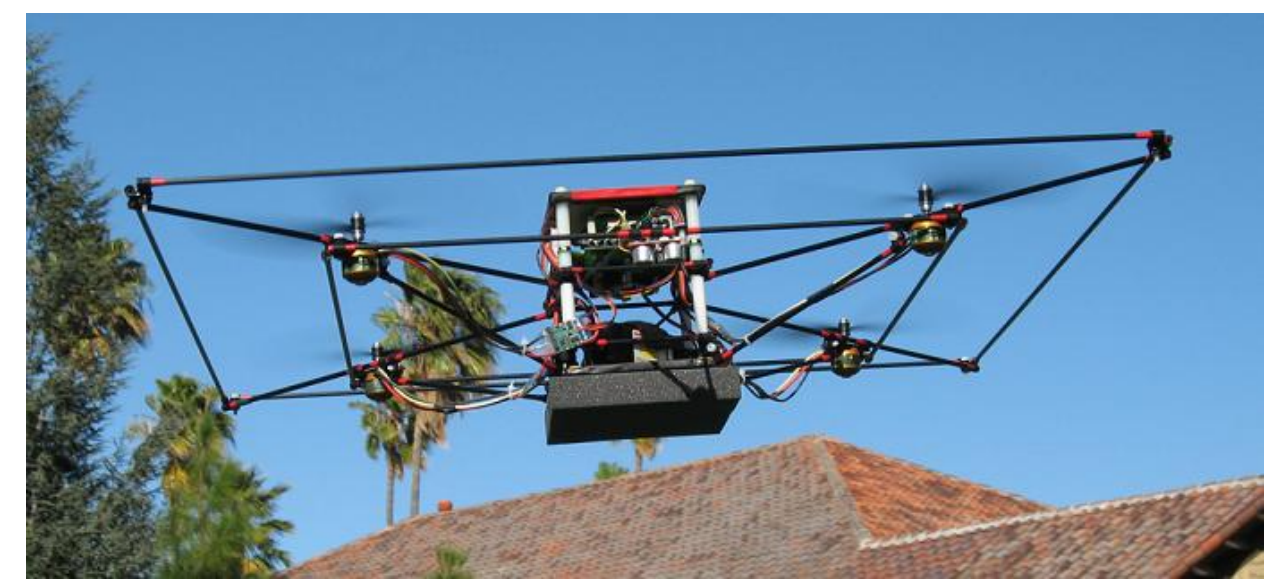

Figura 11. Quadrirotor STARMAC II.

No trabalho realizado por Pounds et al. um UAV quadrirotor nomeado X-4 foi projetado e confeccionado, como observa-se na Figura 12. A proposta deste projeto, além da construção mecânica deste UAV, foi a de criar uma plataforma experimental para variados métodos de controle. Um conjunto de controladores lineares foi implementado para controlar separadamente cada atitude. O modelo totalizou $4,5 \mathrm{~kg}$ de massa, porém obteve sucesso em estabilizar as atitudes em uma bancada de testes. 


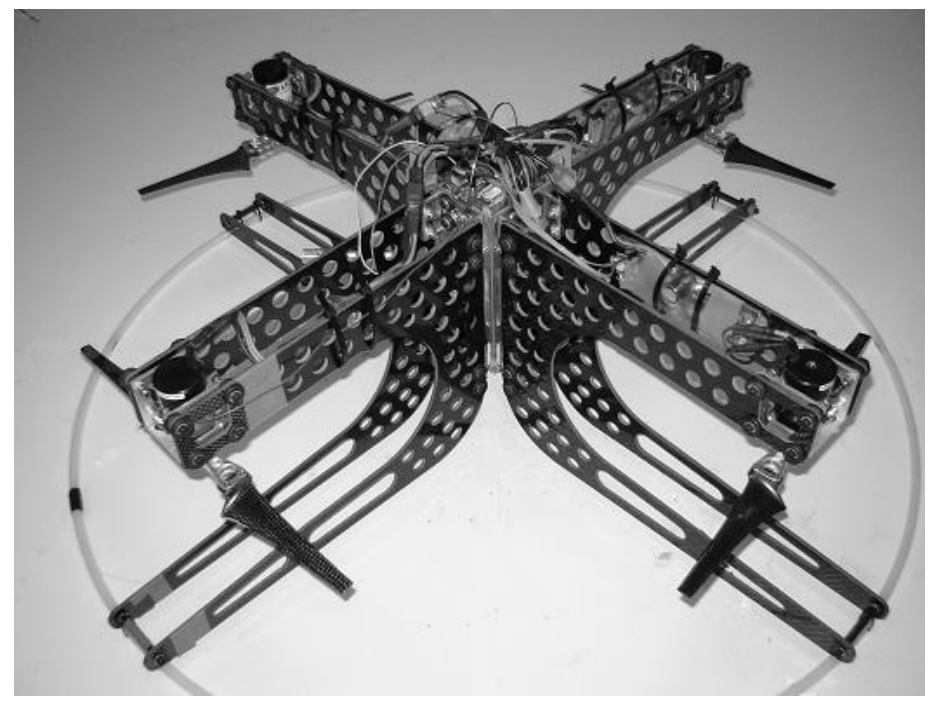

Figura 12. Quadrirotor X-4.

Na dissertação de Sørensen, o modelo X-3D é utilizado para avaliar o desempenho dos controladores LQR e $\mathrm{H}^{\infty}$ robusto, empregando um filtro de Kalman estendido para filtragem dos sensores e observação de estados. 0 principal objetivo deste trabalho foi o de seguir trajetórias de posição com 0 menor atraso possível. O modelo X-3D está ilustrado na Figura 13. Na avaliação realizada dos controladores, o controlador LQR obteve melhor desempenho para o rastreamento de trajetórias rápidas, enquanto $0 \mathrm{H}_{\infty}$ apresentou sobressinais acentuados e instabilidade com a presença de efeito solo, sendo a implementação com LQR mais estável nesta situação também.

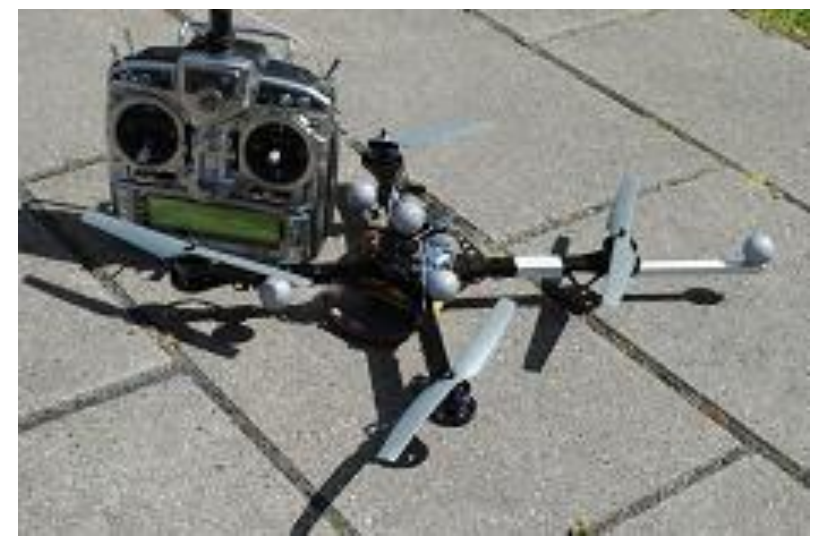

Figura 13. Modelo quadrirotor X-3D. 
Abeywardena et al. analisa a performance de um filtro de Kalman estendido, aplicado a um quadrirotor UAV. Um modelo não-linear é utilizado para realizar a avaliação. Neste trabalho o autor se concentra no desempenho de estimação das atitudes do UAV, a partir de sensores acelerômetros e giroscópios. Constatou-se que o desempenho do filtro é otimizado quando o corpo possui velocidades lineares elevadas, outra característica observada foi a capacidade do filtro em minimizar as flutuações do giroscópio. Adicionalmente, o filtro também não foi capaz de estimar os valores da atitude yaw com os sensores disponíveis.

No trabalho de Plitz et al. é apresentada uma aplicação de controle robusto distribuído para formações de aeronaves quadrirotoras. Na técnica implementada ainda são apresentadas maneiras de incluir requerimentos de performance. Esta técnica é simulada para demonstrar a flexibilidade quanto a relação de membros da formação e topologia de comunicação entre as aeronaves. Cada agente se desloca utilizando um controlador do tipo $\mathrm{H}^{\infty}$ alocado no próprio quadrirotor.

Outras abordagens em diferentes metodologias de controle também são amplamente utilizadas como: Controladores baseados em controle LQR (Domingues, 2009), controladores PID (Johnson, 2002), $\mathrm{H}_{\infty}$ (Chen, 2003), controle Fuzzy (Cosa et al, 2006), redes neurais adaptativas (Johnson, 2002). Como exemplos de implementação de controle não-linear, pode-se citar o UAV da Universidade de Stanford (Jang, 2003) e outro implementado na Universidade da Pensilvânia, utilizando controle baseado em processamento de imagem (Altuğ, 2003).

\subsection{Metodologia}

Os métodos empregados para alcançar os objetivos propostos neste trabalho se caracterizam da seguinte maneira:

- Coleta de informações para a modelagem do quadrirotor, inclusive de seus atuadores propulsores; 
- Projeto mecânico do quadrirotor;

- Seleção de sensores para retroação de estados;

- Modelagem dinâmica da planta do quadrirotor, e versão linearizada para implementação no projeto de controle linear;

- Projeto de controle linear multivariável por alocação de polos e projeto utilizando controlador LQR (Linear Quadratic Regulator - Regulador Linear Quadrático);

- Projeto de observador de estados de ordem plena para utilização juntamente com o controlador por alocação direta de polos e filtro de Kalman para utilização em conjunto com o controlador LQR construído;

- Geração do modelo da planta em MATLAB/Simulink®, juntamente com as malhas de controle criadas;

- Simulação da planta para validação das técnicas de controle implementadas juntamente com seus observadores de estados, para seleção do melhor conjunto para controle para a aplicação do quadrirotor;

- Criação de interface entre os sensores e atuadores do quadrirotor via comunicação wireless, para telemetria de dados e controle do UAV.

- Implementação do projeto de controle utilizando o método HIL (Hardware in the Loop), por meio do MATLAB/Simulink ${ }^{\circledR}$ para validação do projeto de controle no modelo real do sistema. 


\section{Capítulo 2. Modelagem Matemática do Sistema}

Esta seção se dedica à modelagem dinâmica do sistema do quadrirotor como um corpo com seis graus de liberdade. As formulações de Newton-Euler serão empregadas para construir o modelo dinâmico deste sistema.

Posteriormente, este modelo será linearizado em torno de valores nominais de operação juntamente com a inclusão da dinâmica genérica de seus atuadores. Finalmente, integradores puros serão inclusos às entradas do sistema visando a minimização de erros estacionários na futura implementação das malhas de controle.

\subsection{Modelagem Dinâmica do Quadrirotor}

Inicialmente, definem-se dois sistemas de coordenadas, o sistema inercial da terra (sistema T), e o sistema local do corpo do UAV (sistema C) posicionado no centro de massa do corpo. Observa-se na Figura 14 uma representação de ambos.

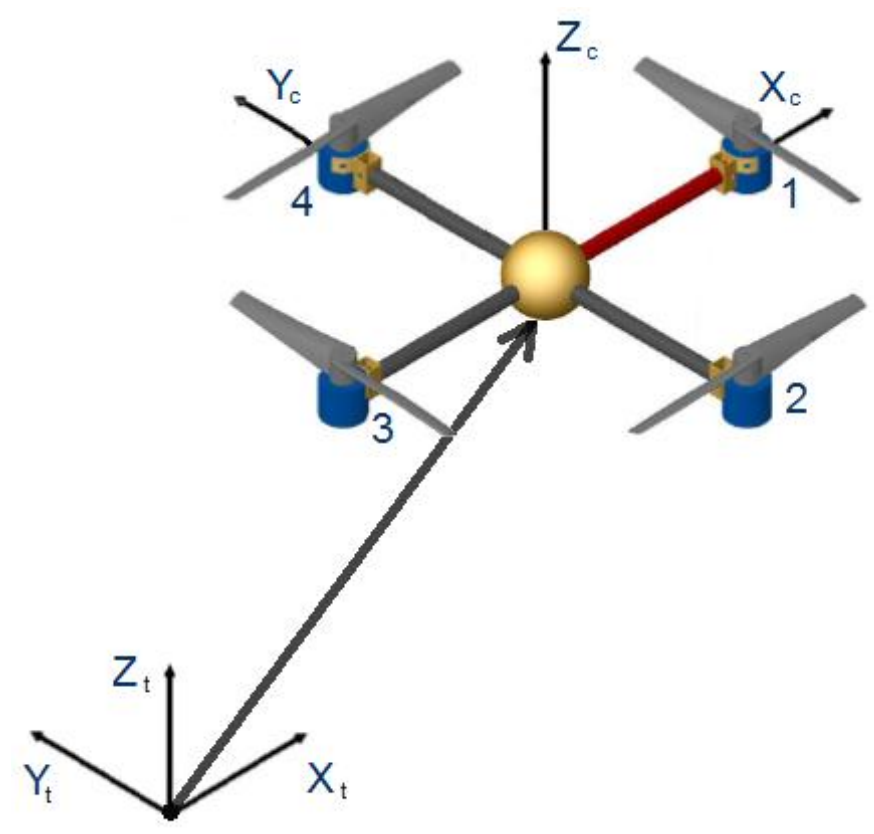

Figura 14. Sistemas de coordenadas inerciais e do quadrirotor. 
A partir das definições dos eixos inerciais, são modeladas as equações que regem os estados de interesse neste trabalho, sendo eles:

- Ângulo de pitch (Arfagem) em relação ao sistema Terra: $\phi$;

- Ângulo de roll (Rolagem) em relação ao sistema Terra: $\theta$;

- Ângulo de yaw (Guinada) em relação ao sistema Terra: $\psi$;

- Velocidade angular de pitch expresso no sistema Corpo: P;

- Velocidade angular de roll expresso no sistema Corpo: Q;

- Velocidade angular de yaw expresso no sistema Corpo: R;

- Posição Linear em X em relação ao sistema Terra: X;

- Posição Linear em Y em relação ao sistema Terra: $Y$;

- Posição Linear em Z em relação ao sistema Terra: Z;

- Velocidade Linear em X expresso no sistema Corpo: U;

- Velocidade Linear em Y expresso no sistema Corpo: V;

- Velocidade Linear em Z expresso no sistema Corpo: W.

Organizados de forma vetorial tem-se

$$
x=\left[\begin{array}{lllllllllllll}
U & V & W & P & Q & R & X & Y & Z & \phi & \theta & \psi
\end{array}\right]^{T} . \quad \text { Equação 1 }
$$

\subsubsection{Matrizes de Transformação Terra-Corpo do Quadrirotor}

A partir do requerimento para as variáveis de interesse é importante descrever a transferência do sistema de coordenadas Terra para o sistema de coordenadas Corpo, por meio da matriz de rotação dos ângulos de Euler, que é composta pela multiplicação das matrizes de rotação de cada ângulo de Euler (Spong, 2006).

Para simplificação das equações, as funções trigonométricas cosseno e seno serão representadas pelos símbolos " $C$ " e " $S$ ", respectivamente. $R_{\phi}, R_{\theta}$ e $R_{\Psi}$ são as matrizes de rotação em torno de cada eixo do sistema de coordenadas Corpo, representadas como 


$$
\left\{\begin{aligned}
R_{\phi} & =\left[\begin{array}{ccc}
1 & 0 & 0 \\
0 & \mathrm{C}(\phi) & \mathrm{S}(\phi) \\
0 & -\mathrm{S}(\phi) & \mathrm{C}(\phi)
\end{array}\right] \\
R_{\theta} & =\left[\begin{array}{ccc}
C(\theta) & 0 & -S(\theta) \\
0 & 1 & 0 \\
S(\theta) & 0 & C(\theta)
\end{array}\right] \\
R_{\psi} & =\left[\begin{array}{ccc}
C(\psi) & S(\psi) & 0 \\
-S(\psi) & \mathrm{C}(\psi) & 0 \\
0 & 0 & 1
\end{array}\right]
\end{aligned}\right.
$$

Equação 2

Visando a geração de uma matriz que transforme a rotação em qualquer eixo do sistema Corpo para o sistema Terra, o produto das três matrizes de rotação supracitadas é realizado e sua resultante é representada pela matriz de rotação $S$, expressa como

$$
S=R_{\phi} \cdot R_{\theta} \cdot R_{\psi} .
$$

Equação 3

Utilizando-se das matrizes expressas na Equação 2, a Equação 3 resulta em

$$
S=\left[\begin{array}{ccc}
C(\theta) \cdot C(\psi) & S(\psi) \cdot C(\theta) & -S(\theta) \\
S(\theta) \cdot S(\psi) \cdot C(\psi)-C(\phi) . S(\psi) & C(\phi) . C(\psi)+S(\phi) \cdot S(\theta) \cdot S(\psi) & S(\phi) \cdot C(\theta) \\
S(\theta) \cdot C(\phi) \cdot C(\psi)+S(\phi) \cdot S(\psi) & S(\theta) \cdot S(\psi) \cdot C(\phi)-S(\phi) \cdot C(\psi) & C(\phi) \cdot C(\theta)
\end{array}\right] . \quad \text { Equação } 4
$$

A partir da matriz $\mathrm{S}$ podem-se relacionar as velocidades lineares do Corpo para o sistema Terra,

$$
S .\left[\begin{array}{c}
\dot{X} \\
\dot{Y} \\
\dot{Z}
\end{array}\right]=\left[\begin{array}{c}
U \\
V \\
W
\end{array}\right]
$$

Equação 5

Como a matriz S é ortogonal, pode-se também escrever

$$
\left[\begin{array}{c}
\dot{X} \\
\dot{Y} \\
\dot{Z}
\end{array}\right]=S^{T}\left[\begin{array}{c}
U \\
V \\
W
\end{array}\right]
$$

Equação 6

Portanto com estas equações, podem-se traduzir movimentos lineares do sistema Terra para o do Corpo e vice-versa.

Semelhantemente as atitudes podem ser traduzidas também, onde a velocidade angular pode ser escrita como: 


$$
\vec{\omega}=P . \hat{\imath}+Q \cdot \hat{\jmath}+R . \hat{k} .
$$

Equação 7

Sendo $\hat{\imath}, \hat{\jmath}$ e $\hat{k}$, os versores do sistema de coordenadas Terra. De modo a expressar as velocidades angulares do corpo em relação ao sistema Terra, novamente a matrizes de transformação da Equação 2 são utilizadas resultando em

$$
\vec{\omega}=R_{\phi} \cdot\left[\begin{array}{c}
\dot{\phi} \\
0 \\
0
\end{array}\right]+R_{\phi} \cdot R_{\theta} \cdot\left[\begin{array}{c}
0 \\
\dot{\theta} \\
0
\end{array}\right]+R_{\phi} \cdot R_{\theta} \cdot R_{\psi} \cdot\left[\begin{array}{c}
0 \\
0 \\
\dot{\psi}
\end{array}\right] .
$$

Equação 8

Resultando finalmente em

$$
\vec{\omega}=\left[\begin{array}{l}
P \\
Q \\
R
\end{array}\right]=\left[\begin{array}{ccc}
1 & 0 & -S(\theta) \\
0 & C(\phi) & S(\phi) \cdot C(\theta) \\
0 & -S(\phi) & C(\theta) \cdot C(\phi)
\end{array}\right] \cdot\left[\begin{array}{c}
\dot{\phi} \\
\dot{\theta} \\
\dot{\psi}
\end{array}\right] .
$$

Expressando os ângulos de Euler em função da velocidade angular do Corpo, escreve-se

$$
\left[\begin{array}{c}
\dot{\phi} \\
\dot{\theta} \\
\dot{\psi}
\end{array}\right]=\left[\begin{array}{ccc}
1 & 0 & -S(\theta) \\
0 & C(\phi) & S(\phi) . C(\theta) \\
0 & -S(\phi) & C(\theta) . C(\phi)
\end{array}\right]^{-1} \cdot\left[\begin{array}{l}
P \\
Q \\
R
\end{array}\right] .
$$

Equação 10

Esta matriz de transformação será denominada "T", portanto

$$
\left[\begin{array}{c}
\dot{\phi} \\
\dot{\theta} \\
\dot{\psi}
\end{array}\right]=T \cdot\left[\begin{array}{l}
P \\
Q \\
R
\end{array}\right] .
$$

Onde,

$$
T=\left[\begin{array}{ccc}
1 & \tan (\theta) . S(\phi) & \tan (\theta) . C(\phi) \\
0 & C(\phi) & -S(\phi) \\
0 & S(\phi) / C(\theta) & C(\phi) / C(\theta)
\end{array}\right] .
$$

É importante ressaltar que esta abordagem por meio da matriz de rotação dos ângulos de Euler possui uma particularidade para alguns tipos de sistemas, tendo em vista que se a atitude pitch chegar a $90^{\circ}$, uma singularidade comumente conhecida como Gimbal Lock ocorrerá. Neste caso, se 0 ângulo sobre o eixo de pitch ou yaw alcançar $90^{\circ}$, perde-se um grau de liberdade. Para tipos de aeronaves onde esta situação pode ocorrer, esta 
abordagem através dos ângulos de Euler é substituída pela abordagem utilizando quaternions. Entretanto, esta situação não é prevista para ocorrer na aplicação deste trabalho, tornando a abordagem dos ângulos de Euler suficiente neste caso.

\subsubsection{Forças e Momentos Gerados Pelos Propulsores}

$\mathrm{Na}$ implementação do quadrirotor, os quatro rotores proporcionam quatro tipos diferentes de forças e torques. Como anteriormente citado, as hélices são contra-rotoras em pares e neste trabalho as hélices dos propulsores 1 e 3 têm sua rotação no sentido horário ou CW (Clockwise), enquanto o par 2 e 4 no sentido anti-horário ou CCW (Counter Clockwise). Na Figura 15, observa-se uma representação gráfica dos sentidos de rotação de cada rotor.

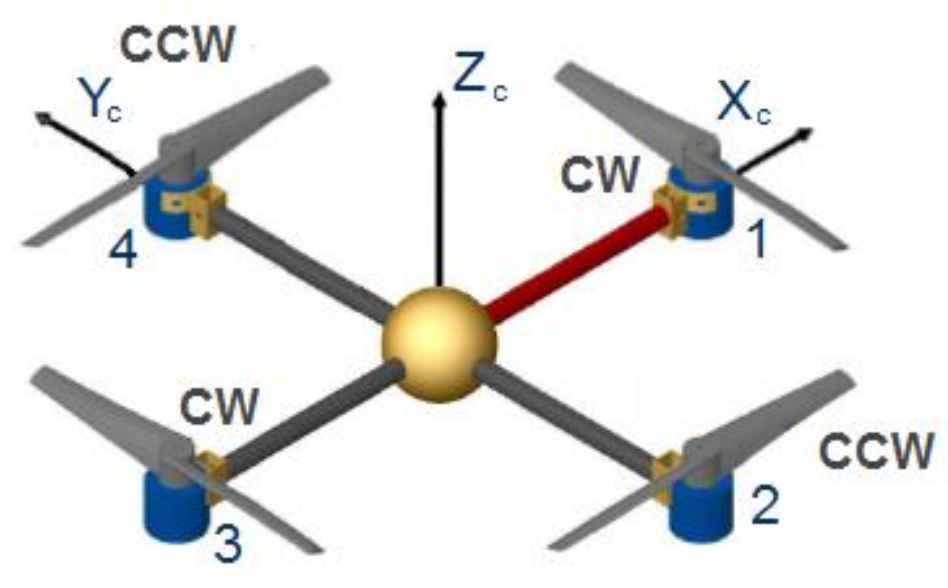

Figura 15. Sentido de rotação para cada propulsor.

Apesar de cada par gerar momentos diferentes, todos os propulsores geram um empuxo positivo no sentido $+Z_{c}$, sendo o empuxo total do quadrirotor neste sentido e direção, a soma destes empuxos individuais.

Note-se que o empuxo realizado por cada hélice depende das características da própria hélice, do desempenho do motor que atua sobre ela e de efeitos de perturbações geradas pelas outras hélices. É importante também ressaltar que em altitudes próximas ao solo, o fenômeno chamado efeito solo, também ocorre e este por sua vez aumenta a eficiência das hélices 
nesta região de altitude, consequentemente aumentando o empuxo de cada conjunto propulsor.

Neste trabalho, as hélices terão uma operação limitada a regiões conhecidas de velocidade, empuxo e fora da zona de efeito solo. Sendo assim, para efeitos de simplificação, o empuxo de cada hélice será considerado como proporcional do quadrado da velocidade angular do rotor. Para a descrição do empuxo que cada hélice imprime no corpo rígido, considera-se a seguinte equação:

$$
\tau_{\text {prop } i}=k_{\text {vprop } i} \cdot \omega_{\text {prop } i}{ }^{2} .
$$

Onde:

- $\tau_{\text {prop } i}$ é o empuxo do propulsor "i" [N];

- $k_{v \text { prop } i}$ é a constante de velocidade-empuxo do propulsor "i", normalmente extraída empiricamente de cada propulsor $\left[\mathrm{N} . \mathrm{s}^{2} / \mathrm{rad}^{2}\right]$;

- $\omega_{\text {prop } i}$ é a velocidade angular da hélice “i” [rad/s].

A primeira força a ser considerada para o controle do UAV é a força de empuxo na direção do eixo $Z_{c}$, e esta será denominada $U_{1}$, que pode ser equacionada como

$$
U_{1}=\sum_{i=1}^{4} \tau_{\text {prop }_{i}}=F_{z}^{\text {Corpo }} .
$$

Equação 14

Além de $U_{1}$, têm-se ainda três outros esforços, sendo eles os momentos referentes à diferença de velocidade de cada par rotor e a haste criada pela dimensão "L" do quadrirotor como observado na Figura 16. 


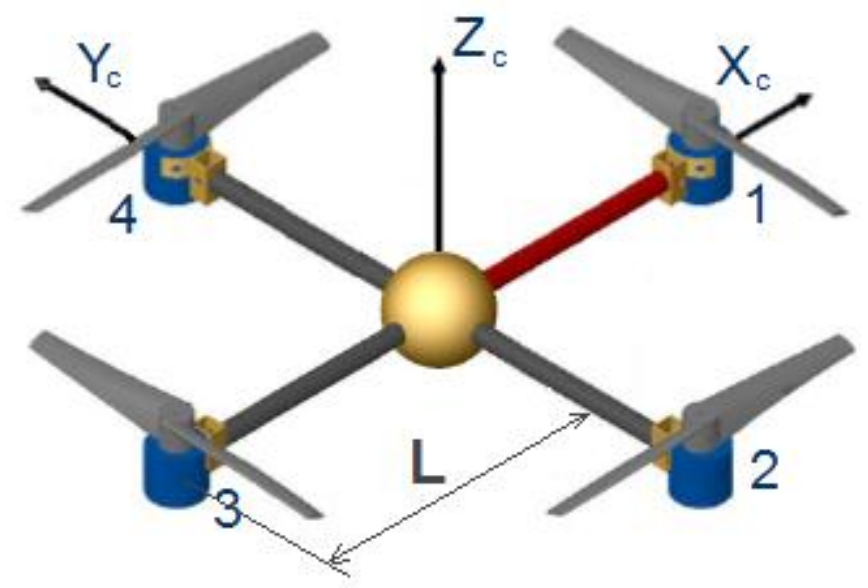

Figura 16. Haste de dimensão "L" no quadrirotor.

Portanto, o momento em torno do eixo $X_{c}$ é:

$$
U_{2}=L .\left(\tau_{\text {prop }_{4}}-\tau_{\text {prop }_{2}}\right)=\tau_{x}{ }^{\text {Corpo }} .
$$

Equação 15

E analogamente no eixo $Y_{c}$, tem-se:

$$
U_{3}=L .\left(\tau_{\text {prop }_{3}}-\tau_{\text {prop }_{1}}\right)=\tau_{y}{ }^{\text {Corpo }} .
$$

Equação 16

Por fim, o esforço $U_{4}$ é considerado como o momento em torno do eixo $Z_{c}$, composto pelos momentos criados pela rotação de cada conjunto rotor. A formulação do momento gerado por cada hélice é análogo ao empuxo, resultando em

$$
M_{\text {prop } i}=k_{\text {mprop } i} \cdot \omega_{\text {prop } i}{ }^{2}=\tau_{z}^{\text {corpo }} .
$$

Equação 17

Onde:

- $M_{\text {prop } i}$ é o momento do propulsor "i" [N.m];

- $k_{m \text { prop } i}$ é a constante de velocidade-momento do propulsor "i", normalmente extraída empiricamente de cada propulsor [N.m.s s $\left.^{2} \mathrm{rad}^{2}\right]$;

- $\omega_{\text {prop } i}$ é a velocidade angular da hélice “i” [rad/s]. 
Portanto $U_{4}$, é apresentado da seguinte forma:

$$
U_{4}=\sum_{i=1}^{4}\left(M_{\text {rrop }_{i}}(-1)^{i-1}\right) \text {. }
$$

Equação 18

É importante ressaltar que os propulsores 1 e 3 causam momentos positivos por terem sua rotação no sentido horário e os propulsores 2 e 4 causam momentos negativos devido a sua rotação no sentido anti-horário.

\subsubsection{Modelo de Newton-Euler para o Quadrirotor}

Definidas as matrizes de transformação entre os sistemas Terra e Corpo e os esforços gerados pelos conjuntos atuadores, pode-se então aplicar as formulações genéricas para modelagem por meio das equações de NewtonEuler.

A equação que descreve a dinâmica genérica para um corpo rígido com seis graus de liberdade referenciados ao corpo é escrita como:

$$
\left[\begin{array}{l}
F^{\text {Corpo }} \\
\tau^{\text {Corpo }}
\end{array}\right]=\left[\begin{array}{cc}
m . I_{3} & 0 \\
0 & I
\end{array}\right] \cdot\left[\begin{array}{l}
\dot{V}^{\text {Corpo }} \\
\dot{\omega}^{\text {Corpo }}
\end{array}\right]+\left[\begin{array}{c}
\omega^{\text {Corpo }} \times\left(m . V^{\text {Corpo }}\right) \\
\omega^{\text {Corpo }} \times\left(I . \omega^{\text {Corpo }}\right)
\end{array}\right] . \quad \text { Equação } 19
$$

Onde:

- $F^{\text {Corpo }}$ é o vetor forças exercidas referenciadas no corpo do Quadrirotor [N];

- $\tau^{\text {Corpo }}$ é o vetor de momentos, em relação ao centro de massa do UAV, exercidos no corpo do Quadrirotor [N.m];

- $m$ é a massa do corpo $[\mathrm{Kg}]$;

- $I_{3}$ é a matriz identidade de dimensão três;

- I é a matriz de inércia do corpo em relação ao sistema fixo ao corpo com origem no centro de massa do mesmo;

- $\dot{V}^{\text {Corpo }}$ é o vetor de acelerações lineares referenciadas ao corpo $[\mathrm{m} / \mathrm{s}]$; 
- $\dot{\omega}^{\text {Corpo }}$ é o vetor de acelerações angulares referenciadas ao corpo $[\mathrm{rad} / \mathrm{s}]$;

Observa-se também a exclusão do termo de Coriolis, que devido à sua insignificância em baixas velocidades, não será considerado nesta modelagem.

A composição da matriz de forças e momentos pode também ser descrita como:

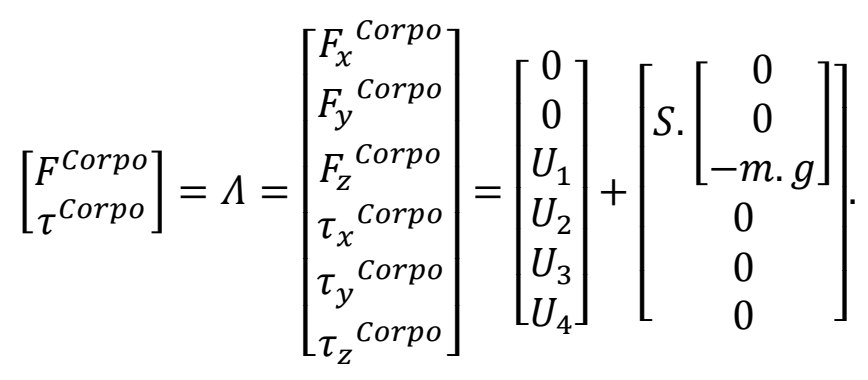

Substituindo o resultado da Equação 20 na Equação 19 se escreve:

$$
\begin{aligned}
& \Lambda=\left[\begin{array}{c}
m \cdot g \cdot S(\theta) \\
-m \cdot g \cdot S(\phi) \cdot C(\theta) \\
U_{1}-m \cdot g \cdot C(\phi) \cdot C(\theta) \\
U_{2} \\
U_{3} \\
U_{4}
\end{array}\right]= \\
& {\left[\begin{array}{cccccc}
m & 0 & 0 & 0 & 0 & 0 \\
0 & m & 0 & 0 & 0 & 0 \\
0 & 0 & m & 0 & 0 & 0 \\
0 & 0 & 0 & I_{x} & 0 & 0 \\
0 & 0 & 0 & 0 & I_{y} & 0 \\
0 & 0 & 0 & 0 & 0 & I_{z}
\end{array}\right] \cdot\left[\begin{array}{c}
\dot{U} \\
\dot{V} \\
\dot{W} \\
\dot{P} \\
\dot{Q} \\
\dot{R}
\end{array}\right]+\left[\begin{array}{l}
W \cdot Q-V \cdot R \\
m \cdot\left[\begin{array}{l}
W \cdot R-W \cdot P \\
U \cdot P-U \cdot Q
\end{array}\right] \\
Q \cdot R \cdot\left(I_{z}-I_{y}\right) \\
P \cdot R \cdot\left(I_{x}-I_{z}\right) \\
P \cdot Q \cdot\left(I_{y}-I_{x}\right)
\end{array}\right] .}
\end{aligned}
$$

Equação 21

Simplificando a Equação 21 e evidenciando as variáveis de interesse, tem-se: Portanto, a Equação 22 possui todas as acelerações necessárias para a modelagem do quadrirotor, referenciadas ao seu próprio corpo. Este conjunto de equações será essencial também para a obtenção do modelo linearizado do UAV, bem como a obtenção das equações de estados para implementação dos algoritmos de controle. 


$$
\left[\begin{array}{c}
\dot{U} \\
\dot{V} \\
\dot{W} \\
\dot{P} \\
\dot{Q} \\
\dot{R}
\end{array}\right]=\left[\begin{array}{c}
(V \cdot R-W \cdot Q)+g \cdot S(\theta) \\
(W \cdot P-U \cdot R)-g \cdot S(\phi) \cdot C(\theta) \\
U_{1} / m+(U \cdot Q-V \cdot P)-g \cdot C(\phi) \cdot C(\theta) \\
U_{2} / I_{x}-Q \cdot R .^{\left(I_{z}-I_{y}\right) / I_{x}} \\
U_{3} / I_{y}-P \cdot R .^{\left(I_{x}-I_{z}\right) / I_{y}} \\
U_{4} / I_{z}-P \cdot Q \cdot\left(I_{y}-I_{x}\right) / I_{z}
\end{array}\right]
$$

Equação 22

2.1.4. Linearização do Sistema e Descrição no Espaço de

\section{Estados}

Tendo em vista as equações deduzidas na seção anterior, nota-se a não-linearidade que o sistema apresenta, ainda que desconsiderando alguns termos da modelagem, como o efeito de Coriolis.

Portanto, vê-se necessária a linearização do modelo e descrição do mesmo na forma de espaço de estados, tendo em vista que o projeto de controle linear será gerado a partir das equações de estados do modelo.

A fim de alcançar a forma do espaço de estados, representado como

$$
\left\{\begin{array}{l}
\dot{x}=A \cdot x+B \cdot u \\
y=C \cdot x+D \cdot u
\end{array}\right.
$$

Equação 23

pode-se considerar o mesmo sistema como

$$
\left\{\begin{array}{l}
\dot{x}=f(x, u) \\
y=h(x, u)
\end{array} .\right.
$$

Onde $x$ é o vetor de estados, previamente definido na Equação 1, e $u$ é o vetor de entradas: 


$$
u=\left[\begin{array}{l}
\omega_{\text {set } 1} \\
\omega_{\text {set } 2} \\
\omega_{\text {set } 3} \\
\omega_{\text {set } 4}
\end{array}\right]
$$

Equação 25

Sendo $\omega_{\text {set }}$ as entradas de referencia de velocidades para os motores. $f(x, u)$ é um conjunto de funções que representam o comportamento do sistema. Este conjunto foi definido pelas variáveis de estado exibidos na Equação 1. Neste trabalho, as derivadas destas variáveis são definidas a partir da Equação 22 em conjunto com as matrizes de transformação Corpo-Terra para as variáveis referenciadas no sistema Terra, sendo este conjunto expresso como

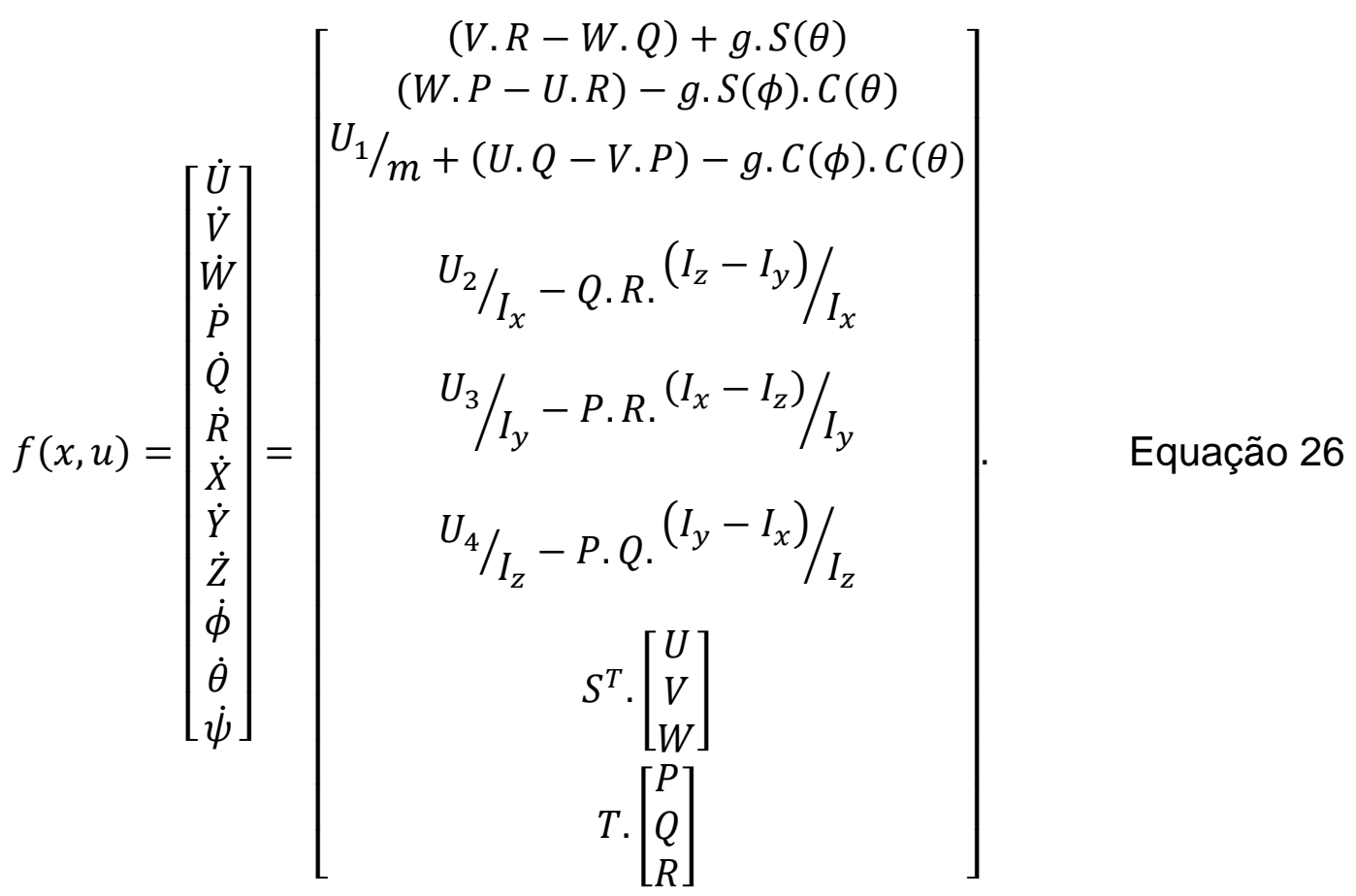

A função $h(x, u)$ na Equação 24 é constituída pelo conjunto de funções dos sensores. Neste trabalho os estados serão medidos por sensores de aceleração linear e velocidade angular, posição linear e magnetômetro para orientação do corpo em relação ao sistema Terra. Organizando-os de forma vetorial tem-se: 


$$
h(x, u)=\left[\begin{array}{c}
a_{x}(x) \\
a_{y}(x) \\
a_{z}(x) \\
P \\
Q \\
R \\
X \\
Y \\
Z \\
\psi
\end{array}\right] .
$$

Equação 27

Os termos de acelerações em função das variáveis de estados e entradas podem ser obtidos de maneira similar à modelagem realizada para 0 Corpo do UAV em relação ao eixo Terra. Como o sensor pode não estar posicionado exatamente no centro de massa do corpo, calcula-se a projeção das medidas do sensor em relação ao centro de massa do corpo, para tanto, modela-se este fenômeno a partir do teorema de Coriolis para acelerações (COSTA, 2008):

$$
a_{s}=a_{C G}+\dot{\omega}^{\text {Corpo }} \times r_{s}+\omega^{\text {Corpo }} \times\left(\omega^{\text {Corpo }} \times r_{s}\right) . \quad \text { Equação } 28
$$

Onde:

- $a_{s}$ é o vetor de acelerações do sensor referido ao seu ponto de medição;

- $a_{C G}$ é o vetor de acelerações do corpo em relação ao seu centro de massa;

- $\quad r_{s}$ é o vetor de posição entre o sensor e o centro de massa do corpo.

Ressalta-se ainda que na Equação 28 se exclui 0 termo de acelerações de Coriolis. Expandindo a equação tem-se: 


$$
\begin{aligned}
& {\left[\begin{array}{l}
a_{x} \\
a_{y} \\
a_{z}
\end{array}\right]} \\
& =\frac{1}{m} \cdot\left[\begin{array}{l}
F_{x}{ }^{\text {Corpo }} \\
F_{y}{ }^{\text {Corpo }} \\
F_{z}{ }^{\text {Corpo }}
\end{array}\right]+g \cdot\left[\begin{array}{c}
S(\theta) \\
-C(\theta) \cdot S(\phi) \\
-C(\theta) \cdot C(\phi)
\end{array}\right] \\
& +\left[\begin{array}{l}
\dot{Q} \cdot r_{s_{z}}-\dot{R} \cdot r_{s_{y}}+Q \cdot\left(P \cdot r_{s_{y}}-Q \cdot r_{s_{x}}\right)-R \cdot\left(P \cdot r_{s_{z}}+R \cdot r_{s_{x}}\right) \\
\dot{R} \cdot r_{s_{x}}-\dot{P} \cdot r_{s_{z}}+R \cdot\left(Q \cdot r_{s_{z}}-R \cdot r_{s_{y}}\right)-P \cdot\left(Q \cdot r_{s_{x}}+P \cdot r_{s_{y}}\right) \\
\dot{P} \cdot r_{s_{y}}-\dot{Q} \cdot r_{s_{x}}+P \cdot\left(R \cdot r_{s_{x}}-P \cdot r_{s_{z}}\right)-Q \cdot\left(R \cdot r_{s_{y}}+Q \cdot r_{s_{z}}\right)
\end{array}\right]
\end{aligned}
$$

Equação 29

Sendo $r_{s_{x}}, r_{s_{y}}$ e $r_{s_{z}}$ as composições do vetor de posições $r_{s}$.

As outras variáveis mensuradas são propriamente variáveis de estados e são extraídas diretamente do sensor de imagem. Finalmente, tem-se para $h(x, u)$ :

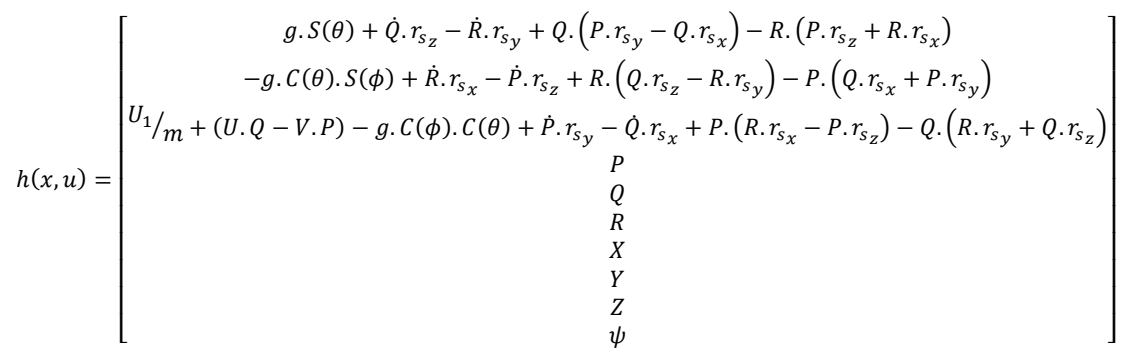

Equação 30

Definidos os conjuntos de equações do sistema e sensores, pode-se então linearizar o modelo para posterior formatação no espaço de estados linear.

Para linearização do modelo, utiliza-se a técnica da série de Taylor (Garcia, 2005). A partir do modelo descrito na Equação 24, a aproximação da série de Taylor de primeira ordem do modelo é:

$$
\left\{\begin{array}{l}
\dot{x} \approx f(\bar{x}, \bar{u})+\left.\frac{\partial f(x, u)}{\partial x}\right|_{(\bar{x}, \bar{u})} \cdot(x-\bar{x})+\left.\frac{\partial f(x, u)}{\partial u}\right|_{(\bar{x}, \bar{u})} \cdot(u-\bar{u}) \\
y \approx h(\bar{x}, \bar{u})+\left.\frac{\partial h(x, u)}{\partial x}\right|_{(\bar{x}, \bar{u})} \cdot(x-\bar{x})+\left.\frac{\partial h(x, u)}{\partial u}\right|_{(\bar{x}, \bar{u})} \cdot(u-\bar{u})
\end{array}\right.
$$


Onde:

- $\bar{x}$ é o vetor ponto de equilíbrio dos estados;

- $\bar{u}$ é o vetor de entradas nominais.

Sendo os pontos de equilíbrio dos estados e valores nominais das entradas definidas respectivamente como:

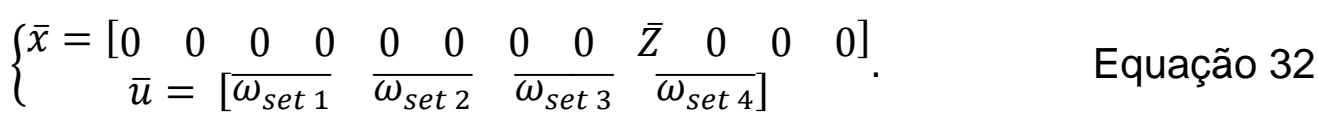

Considerou-se para os pontos de equilíbrio das entradas, todos os estados nulos, com exceção da posição linear $\bar{Z}$, sendo esta a altitude nominal do UAV. Para os esforços de controle, os valores nominais são tais que o somatório dos empuxos individuais gerados igualam a força peso do corpo para mantê-lo em equilíbrio no ar. Estes valores nominais serão definidos nas próximas seções após o conhecimento das características construtivas do quadrirotor

$\mathrm{Na}$ metodologia da linearização, pode-se também expressar (GARCIA, 2005):

$$
\left\{\begin{array}{l}
\tilde{x}=(x-\bar{x}) \\
\tilde{u}=(u-\bar{u})
\end{array}\right.
$$

Sendo $\tilde{x}$ e $\tilde{u}$ as flutuações em torno do ponto de equilíbrio de cada variável ou valor nominal de cada entrada. Substituindo a Equação 33 na Equação 31 tem-se:

$$
\left\{\begin{array}{l}
\dot{\tilde{x}} \approx f(\bar{x}, \bar{u})+\left.\frac{\partial f(x, u)}{\partial x}\right|_{(\bar{x}, \bar{u})} . \tilde{x}+\left.\frac{\partial f(x, u)}{\partial u}\right|_{(\bar{x}, \bar{u})} . \tilde{u} \\
\tilde{y} \approx h(\bar{x}, \bar{u})+\left.\frac{\partial h(x, u)}{\partial x}\right|_{(\bar{x}, \bar{u})} . \tilde{x}+\left.\frac{\partial h(x, u)}{\partial u}\right|_{(\bar{x}, \bar{u})} . \tilde{u}
\end{array}\right.
$$

Por meio da semelhança entre a Equação 34 e Equação 23, definem-se as matrizes do espaço de estados como 


$$
\left\{\begin{array}{l}
A_{\text {lin }}=\left.\frac{\partial f(x, u)}{\partial x}\right|_{(\bar{x}, \bar{u})} \\
B_{\text {lin }}=\left.\frac{\partial f(x, u)}{\partial u}\right|_{(\bar{x}, \bar{u})} \\
C_{\text {lin }}=\left.\frac{\partial h(x, u)}{\partial x}\right|_{(\bar{x}, \bar{u})} \\
D_{\text {lin }}=\left.\frac{\partial h(x, u)}{\partial u}\right|_{(\bar{x}, \bar{u})}
\end{array}\right.
$$

Com estas matrizes, o modelo no espaço de estados do corpo está definido.

\subsubsection{Inclusão da Dinâmica dos Motores no Modelo}

Tendo em vista que os motores que serão utilizados para gerar o empuxo em cada hélice possuem também sua dinâmica própria, vê-se necessária a inclusão desta dinâmica do motor no modelo do sistema.

Para efeitos de simplificação e como o tipo de motor não está definido neste ponto, modelo linear de primeira ordem é utilizada para representar o comportamento dos motores com relação à sua velocidade angular. Esta função é definida como

$$
\omega_{\text {set } i}=\tau_{[i]} \cdot \omega_{\text {prop } \iota}+\omega_{\text {prop } i} . \quad \text { Equação } 36
$$

Onde $\tau_{[i]}$ é a constante de tempo para cada motor.

Incluindo a Equação 36 para cada motor no formato do espaço de estados às matrizes definidas na Equação 35, tem-se 


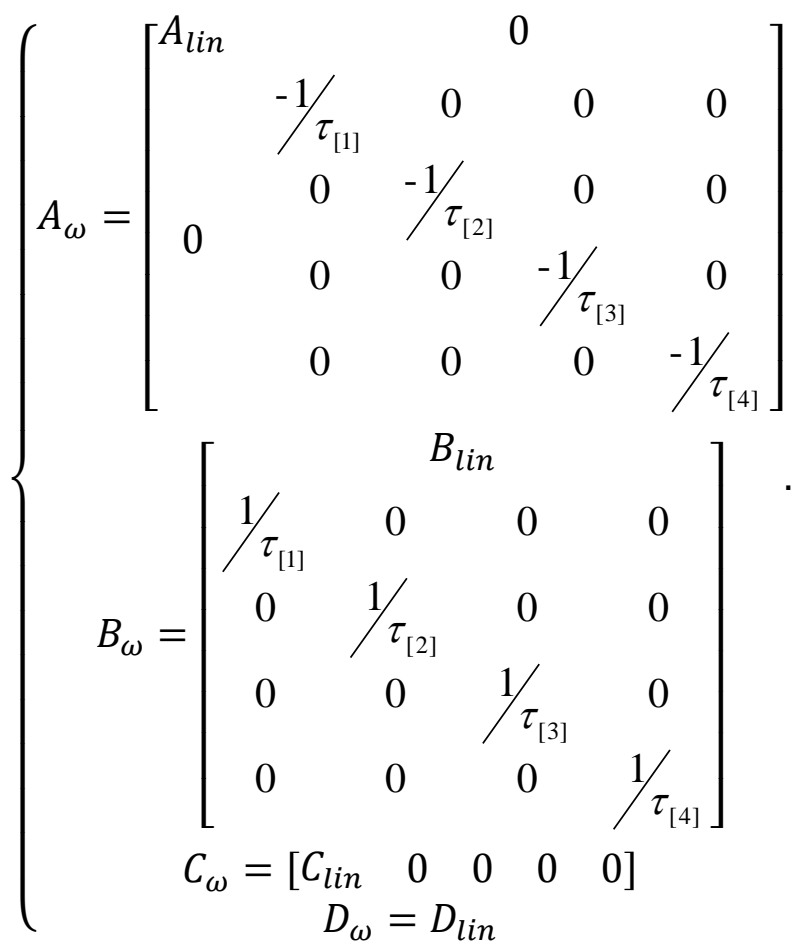

Onde $A_{\omega}, B_{\omega}, C_{\omega}$ e $D_{\omega}$ são as novas matrizes de estados com a inclusão da dinâmica dos motores.

\subsubsection{Inclusão de Integradores Puros no Modelo}

Tendo em vista que o modelo gerado será alimentado com informações paramétricas do projeto mecânico e ensaios para definições empíricas de parâmetros como as constantes dos motores e devido a tolerâncias de projeto, a planta real não terá as mesmas características da planta nominal criada pelo projeto, sobre o qual o projeto de controle será criado.

Visando anular o erro em regime para as referencias de controle na aplicação final, inserem-se integradores puros nas entradas do sistema para alcançar tal requisito (DA CRUZ, 1996).

A partir das matrizes de estados obtidas na Equação 37 inserem-se os integradores e as matrizes finais de estados se caracterizam como 


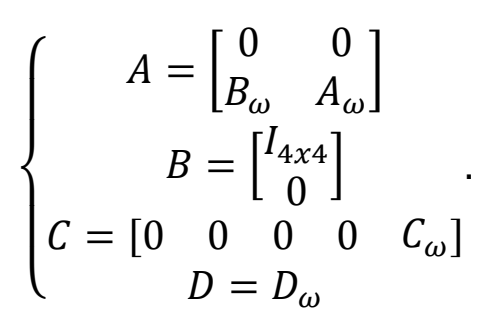

Com as matrizes A, B, C e D estão definidas as matrizes de estados para aplicação das técnicas de controle linear. Estas matrizes incluem as dinâmicas de primeira ordem dos motores bem como integradores na entrada do sistema para eliminação de erros estacionários na aplicação final do controle. Os vetores de estados e entradas finais também se alteraram, e resultam em

$$
x=\left[\begin{array}{lllllllllllllll}
\omega_{\text {set } i} & U & V & W & P & Q & R & X & Y & Z & \phi & \theta & \psi & \left.\omega_{\text {prop }}\right]^{T} & \text { Equação } 39
\end{array}\right.
$$

e

$$
u=\left[\begin{array}{l}
u_{1} \\
u_{2} \\
u_{3} \\
u_{4}
\end{array}\right]
$$

Equação 40

respectivamente. Onde $u_{1}, u_{2}, u_{3}$ e $u_{4}$ são variáveis genéricas de entrada, tendo em vista que estas são entradas para os integradores de entrada da planta, ou seja, a integral destas variáveis resulta fisicamente nos setpoints de velocidade angular na planta real, sendo que estes integradores serão implementados de maneira discreta junto ao controlador. 


\section{Capítulo 3. Projeto, Ensaios e Seleção de Hardware do UAV}

A partir da modelagem dinâmica genérica do quadrirotor, inicia-se o processo de projeto mecânico do corpo do UAV, juntamente com a seleção e ensaio de sensores e atuadores.

Tendo em vista os objetivos de desempenho definidos em seções anteriores, definem-se inicialmente os conjuntos atuadores para o corpo. Seguido pela seleção das baterias necessárias para manter o voo durante 0 período desejado. A partir destes dois componentes básicos, o projeto mecânico do quadrirotor será realizado e finalmente os sensores a serem utilizados serão caracterizados.

\subsection{Seleção e Ensaio dos Atuadores}

Nesta subseção serão definidos os conjuntos atuadores do UAV, sendo eles quatro grupos de propulsão constituídos por motores e hélices. Inicialmente é definido o tipo de motor a ser utilizado seguido pela hélice a ser acoplada aos motores e finalmente ensaios serão realizados para determinar o melhor conjunto propulsor para a aplicação.

Para a definição dos propulsores, considera-se que a massa projetada do UAV será $1,5 \mathrm{Kg}$ já incluindo a carga útil de 200 gramas.

\subsubsection{Motor DC Brushless}

Para a geração do empuxo nas hélices, diversos tipos de motores podem ser utilizados, cada um com seus contrastes. Na Figura 17 ilustra-se um organograma simplificado dos tipos de motores mais comuns hoje utilizados. 


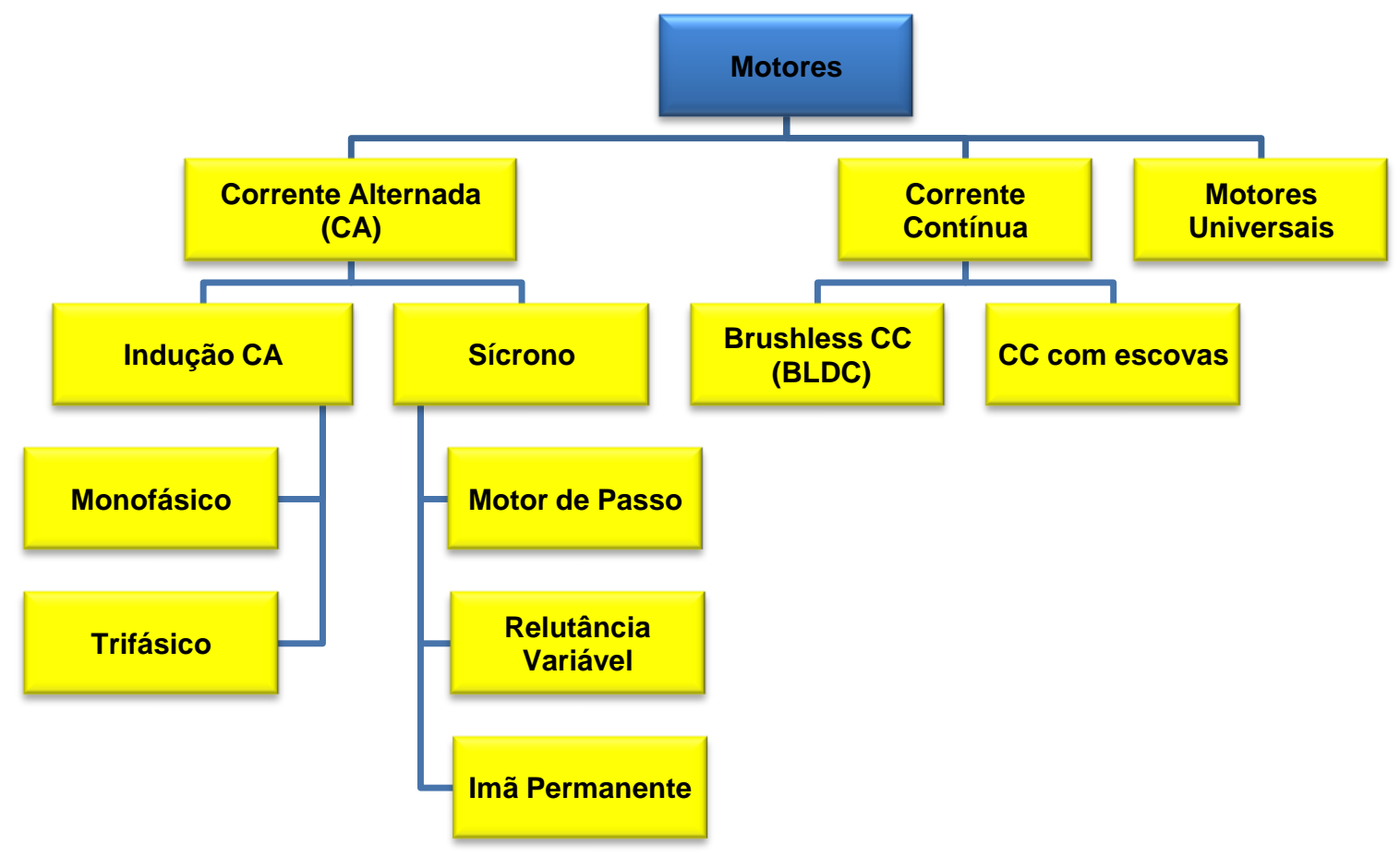

Figura 17. Tipos de motores comumente utilizados.

Dentre os diversos tipos de motores, os mais comuns a serem utilizados em aplicações com UAVs são motores de corrente contínua com escovas (BRESCIANI, 2008) ou sem escovas (Brushless DC Motor - BLDC) (DOMINGUES, 2009; COSTA, 2008). Neste trabalho serão utilizados motores BLDC dadas as seguintes vantagens em relação ao motor CC com escovas (YEDAMALE, 2003):

- Melhores características de curva de velocidade versus torque;

- Rápida resposta dinâmica;

- Alta eficiência;

- Vida operacional prolongada;

- Operação sem ruídos;

- Maiores alcances de velocidade;

- Maior densidade de potência (ou seja, maior razão de torque por unidade de volume físico). 
Posterior à seleção do tipo de motor a ser utilizado, o modelo selecionado foi o AXI 2212-34, ilustrado na Figura 18.

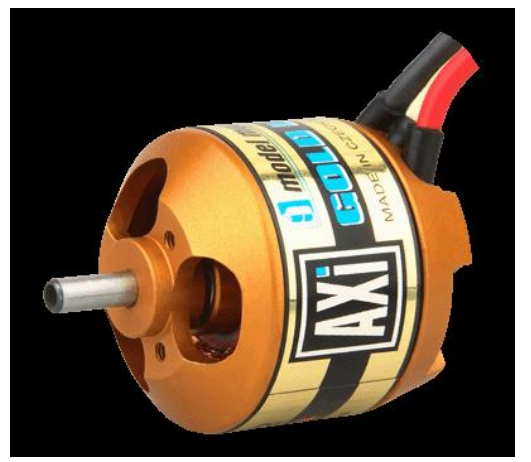

Figura 18. Motor AXI 2212-34

$\mathrm{Na}$ Tabela 1, as especificações genéricas fornecidas pelo fabricante do motor.

\begin{tabular}{|c|c|c|}
\hline Especificação & Valor & Unidade \\
\hline $\begin{array}{c}\text { Tensão de } \\
\text { Operação }\end{array}$ & 12 & $\mathrm{~V}$ \\
\hline $\begin{array}{c}\text { Constante de } \\
\text { Tensão }\end{array}$ & 710 & $\mathrm{RPM} / \mathrm{V}$ \\
\hline $\begin{array}{c}\text { Resistência } \\
\text { Interna }\end{array}$ & 345 & $\mathrm{mOhm}$ \\
\hline Massa & 57 & $\mathrm{~g}$ \\
\hline $\begin{array}{c}\text { Corrente } \\
\text { sem carga }\end{array}$ & 400 & $\mathrm{~mA}$ \\
\hline
\end{tabular}

Tabela 1. Especificações do motor AXI 2212-34

Suas dimensões podem ser observadas na Figura 19.

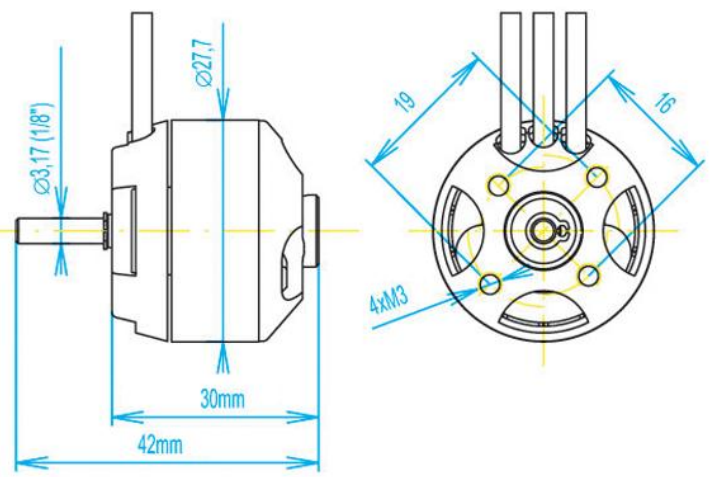

Figura 19. Dimensões (em milímetros) do motor AXI 2212-34. 


\subsubsection{Hélice Propulsora}

De modo a efetivamente gerar o empuxo nos quatro pontos de força do quadrirotor, dois pares de hélices contra-rotoras devem ser selecionadas e neste trabalho dois tipos de hélices foram analisadas.

A primeira fabricante Draganfly Innovations Inc, possuindo duas pás, ilustrada na Figura 20. Esta hélice possui 10" de diâmetro (254 mm) e passo de 4,5" (114,3 mm). As hélices são compostas de plástico e possuem massa desprezível.

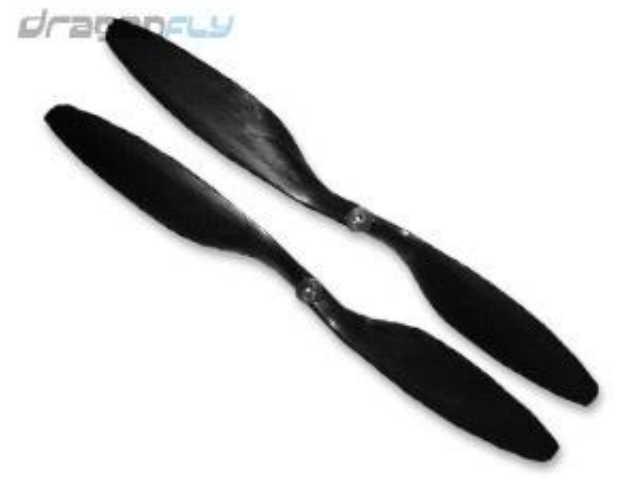

Figura 20. Hélice Draganfly com duas pás.

E a outra do fabricante GWS, com três pás, ilustrada na Figura 21. Esta hélice possui 9" de diâmetro $(228,6 \mathrm{~mm})$ e passo de 5" (127 mm). Sendo também composta de plástico e com massa desprezível.

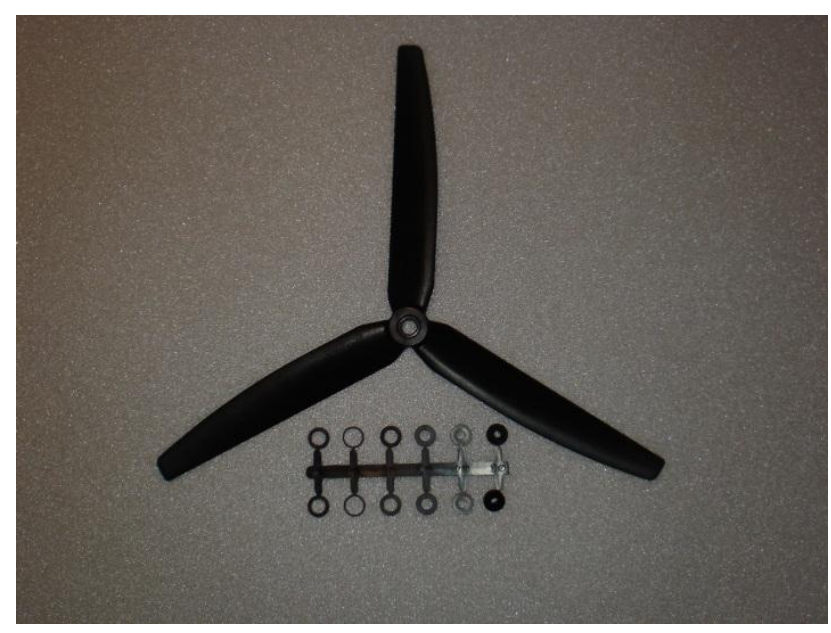

Figura 21. Hélice GWS com três pás. 


\subsubsection{Ensaio do Conjunto Motor-Hélice}

O ensaio do conjunto motor-hélice é condição sine qua non para aplicação final de controle, tendo em vista que com este ensaio as constantes de empuxo e momento referidas em seções anteriores serão aferidas empiricamente, bem como o consumo de corrente para seleção de baterias e previsão de autonomia de voo.

Para este ensaio, foi confeccionado um amplificador de força para aferição via uma célula de carga, utilizando inicialmente um software CAD para desenho técnico mecânico, SolidWorks ${ }^{\circledR}$. A vista em perspectiva do projeto do amplificador pode ser observada na Figura 22.

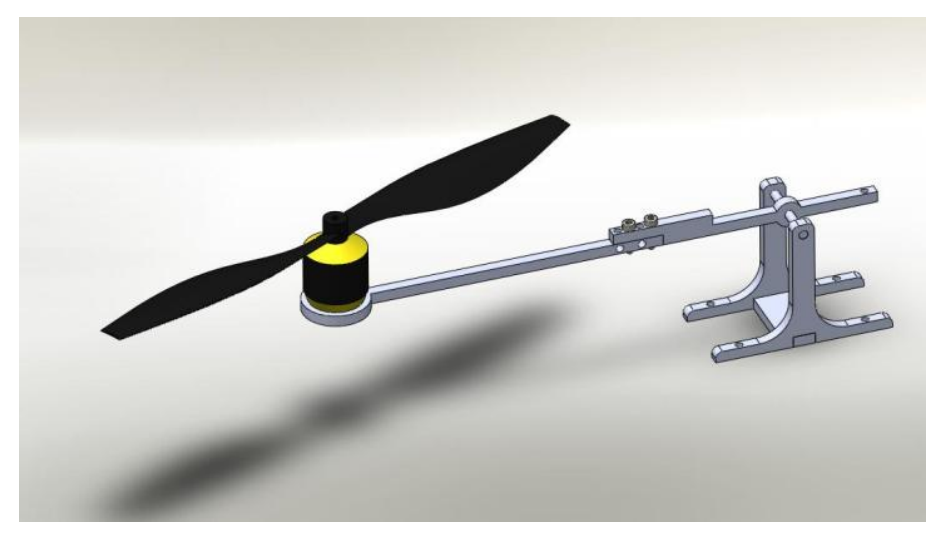

Figura 22. Projeto do amplificador de força para ensaio.

$\mathrm{Na}$ Figura 23 o resultado final utilizando alumínio como material, usinado por corte a laser. 


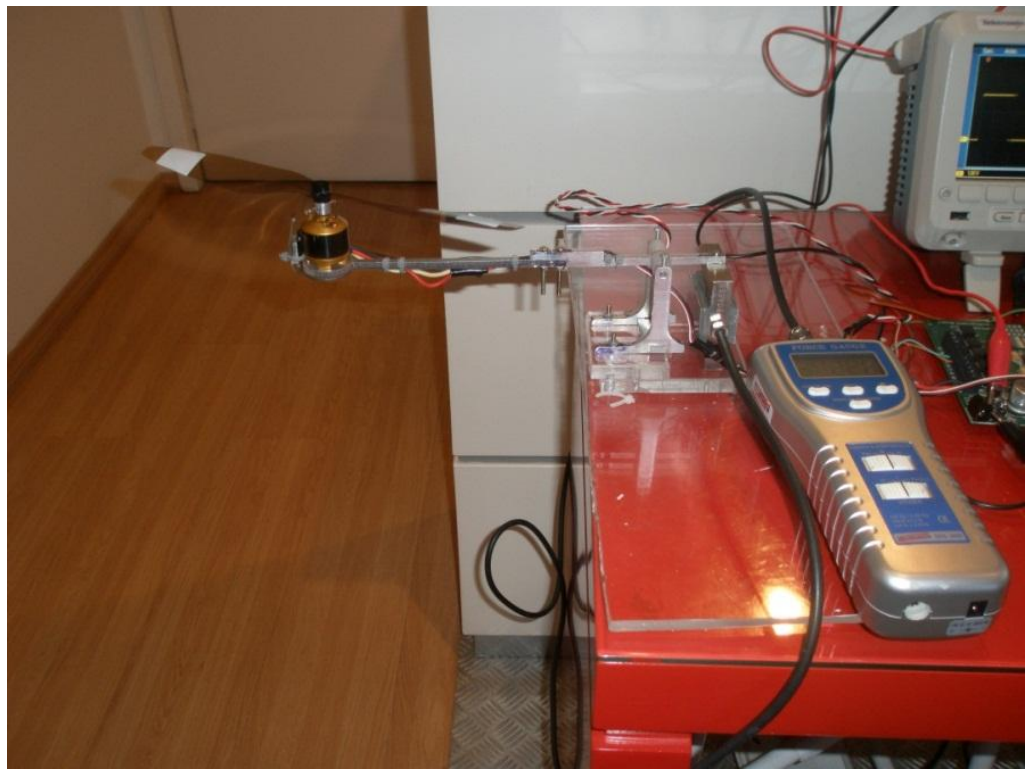

Figura 23. Resultado final da montagem do amplificador de força.

No intuito de mensurar o empuxo realizado pela rotação do conjunto rotor, foi implementado um dinamômetro digital, Instrutherm DD-300, observado na Figura 24.

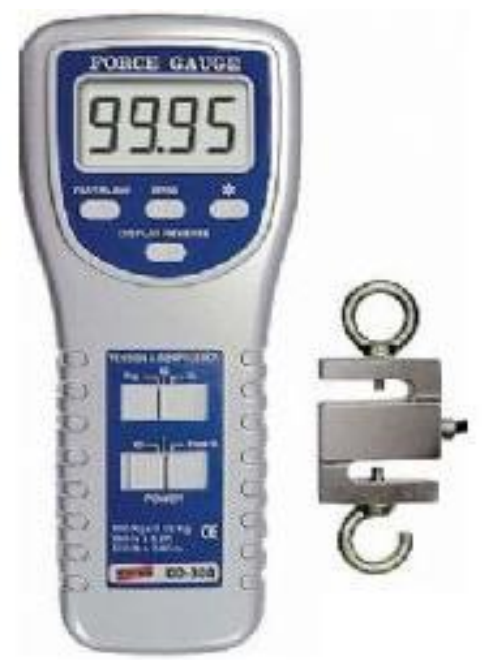

Figura 24. Dinamômetro Instrutherm DD-300.

Na Figura 25, uma imagem de outro ângulo para a configuração do dinamômetro. 


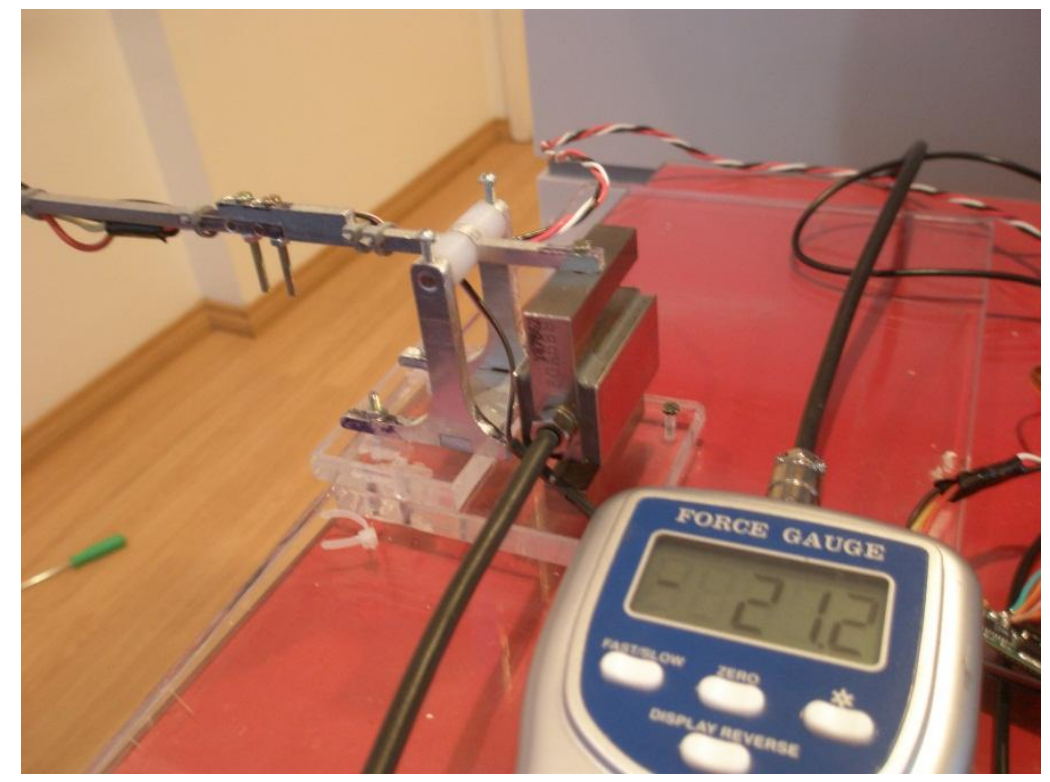

Figura 25. Vista da configuração do dinamômetro em detalhe.

Para aferir a velocidade angular do rotor, um sensor de efeito Hall foi posicionado próximo ao rotor do motor com o objetivo de contar as voltas dos magnetos do rotor. O sensor utilizado foi o SS40A.

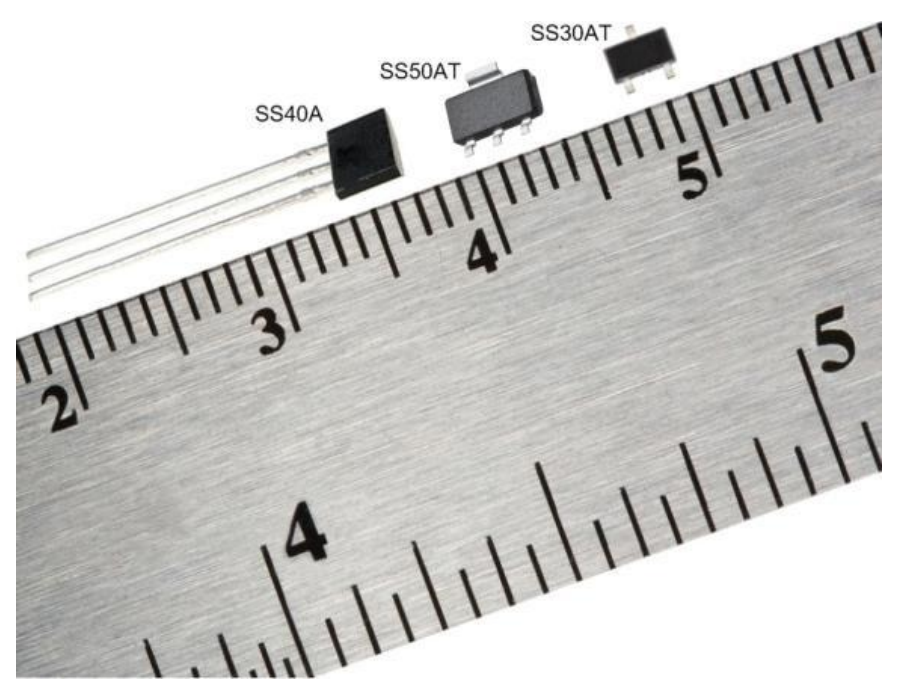

Figura 26. Sensor de efeito hall SS40A.

Os pulsos gerados pelo sensor de efeito Hall foram introduzidos em um osciloscópio para analise de frequência. A configuração total do ensaio pode ser observada na Figura 27. 


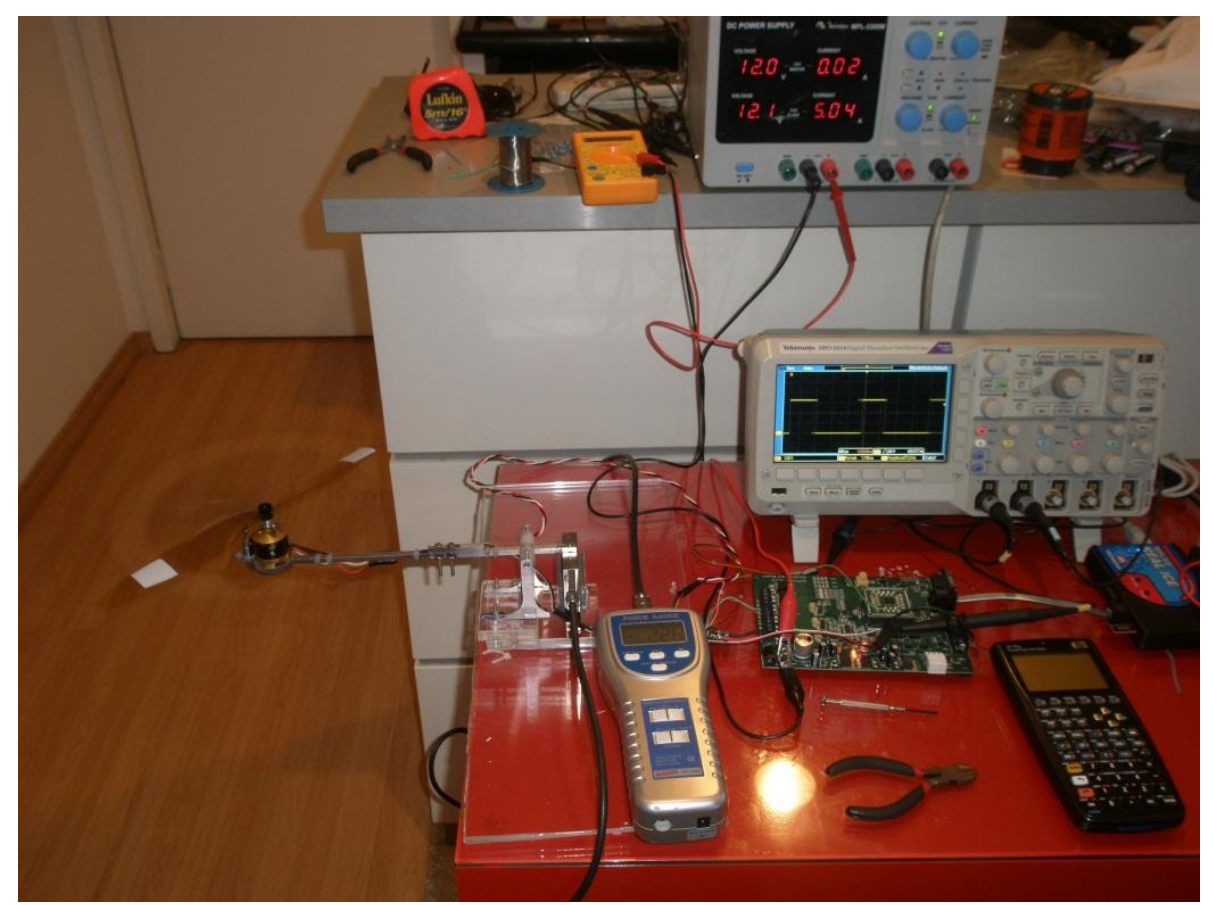

Figura 27. Configuração total do ensaio de empuxo do rotor.

Finalmente para o acionamento e controle de velocidade, um controlador para motores brushless da empresa Hobby King Inc. modelo ESC $30 \mathrm{~A}$ foi utilizado. Este controlador dedicado é acionado via referencias por sinais PWM (Pulse Width Modulation - Modulação por Largura de Pulso) e tem capacidade para controlar um motor com consumo de corrente até 30A. Na Figura 28, uma ilustração do controlador.

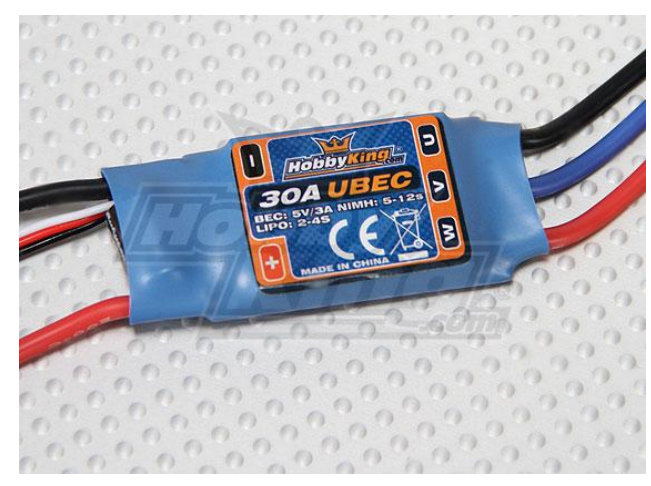

Figura 28. Controlador Hobby King ESC 30A.

Com os componentes de hardware definidos para o ensaio, os seguintes parâmetros serão avaliados: 
- Corrente drenada;

- Velocidade angular do rotor;

- Empuxo aplicado.

A partir destes parâmetros, uma bateria de ensaios foi realizada para cada hélice candidata a utilização. Nestes testes observou-se que 0 modelo de hélice com três pás possui melhores características para a aplicação, por fornecer maior empuxo por faixa de velocidade angular aplicada nos ensaios.

Deste ponto em diante, os ensaios foram focados na identificação das constantes de cada um dos quatro conjuntos motor-hélice que serão utilizados na aplicação final, utilizando as hélices com três pás e tendo em vista que cada conjunto possui constantes diferentes graças a tolerâncias de produção de cada hélice e motor. Os resultados dos ensaios de cada conjunto são exibidos na Tabela 2.

\begin{tabular}{|c|c|c|c|c|c|c|c|c|c|c|}
\hline \multirow{2}{*}{$\begin{array}{l}\text { Setpoint } \\
\text { [\%] }\end{array}$} & \multicolumn{4}{|c|}{$\begin{array}{l}\text { Velocidade média dos } \\
\text { motores [rad/s] }\end{array}$} & \multicolumn{4}{|c|}{$\begin{array}{l}\text { Constante Kv calculada }\left[10^{-5}\right. \\
\left.\text { N.s } \mathrm{s}^{2} / \mathrm{rad}^{2}\right]\end{array}$} & \multirow{2}{*}{$\begin{array}{l}\text { Empuxo total } \\
\text { calculado }[\mathrm{N}]\end{array}$} & \multirow{2}{*}{$\begin{array}{c}\text { Corrente } \\
\text { total dos } \\
\text { motores }[A]\end{array}$} \\
\hline & $\begin{array}{c}\text { Motor } \\
1\end{array}$ & $\begin{array}{c}\text { Motor } \\
2\end{array}$ & $\begin{array}{c}\text { Motor } \\
3\end{array}$ & $\begin{array}{c}\text { Motor } \\
4\end{array}$ & $\begin{array}{c}\text { Motor } \\
1\end{array}$ & $\begin{array}{c}\text { Motor } \\
2\end{array}$ & $\begin{array}{c}\text { Motor } \\
3\end{array}$ & $\begin{array}{c}\text { Motor } \\
4\end{array}$ & & \\
\hline 10 & 283 & 353 & 335 & 287 & 1,130 & 1,078 & 1,065 & 1,109 & 4,37 & 7,58 \\
\hline 15 & 315 & 384 & 358 & 317 & 1,122 & 1,067 & 1,133 & 1,153 & 5,30 & 8,96 \\
\hline 20 & 347 & 411 & 384 & 354 & 1,057 & 1,135 & 1,106 & 1,063 & 6,15 & 10,48 \\
\hline 25 & 376 & 435 & 407 & 376 & 1,053 & 1,059 & 1,091 & 1,118 & 6,88 & 11,56 \\
\hline 30 & 394 & 465 & 428 & 414 & 1,119 & 1,088 & 1,066 & 1,073 & 7,89 & 13,41 \\
\hline 35 & 436 & 497 & 451 & 438 & 1,151 & 1,047 & 1,089 & 1,134 & 9,17 & 15,26 \\
\hline 40 & 455 & 527 & 482 & 497 & 1,081 & 1,068 & 1,104 & 1,102 & 10,50 & 17,71 \\
\hline 45 & 489 & 560 & 510 & 506 & 1,113 & 1,097 & 1,145 & 1,121 & 11,93 & 20,79 \\
\hline 50 & 528 & 592 & 538 & 533 & 1,107 & 1,098 & 1,108 & 1,056 & 13,15 & 22,24 \\
\hline 55 & 559 & 624 & 569 & 564 & 1,150 & 1,141 & 1,046 & 1,096 & 14,90 & 25,10 \\
\hline 60 & 575 & 652 & 592 & 596 & 1,076 & 1,089 & 1,077 & 1,084 & 15,81 & 27,12 \\
\hline 65 & 631 & 682 & 624 & 637 & 1,088 & 1,125 & 1,071 & 1,081 & 18,12 & 30,40 \\
\hline 70 & 652 & 707 & 644 & 660 & 1,152 & 1,124 & 1,073 & 1,117 & 19,83 & 34,05 \\
\hline 75 & 698 & 698 & 666 & 682 & 1,098 & 1,096 & 1,073 & 1,129 & 20,70 & 35,72 \\
\hline 80 & 698 & 698 & 690 & 688 & 1,111 & 1,131 & 1,114 & 1,054 & 21,22 & 36,00 \\
\hline 85 & 698 & 698 & 698 & 698 & 1,121 & 1,088 & 1,075 & 1,056 & 21,15 & 35,38 \\
\hline 90 & 698 & 698 & 698 & 698 & 1,104 & 1,055 & 1,068 & 1,085 & 21,02 & 35,09 \\
\hline
\end{tabular}

Tabela 2. Ensaios de empuxo, velocidade angular e consumo de corrente. 
$\mathrm{Na}$ Tabela 2, foram coletados diversos dados para cada ponto e médias de velocidades angulares e correntes foram calculadas. Com estas informações podem-se estimar as constantes de velocidades de cada conjunto.

Na Figura 29, é apresentado o gráfico do empuxo e corrente drenada total versus as referencias de velocidade definidas.

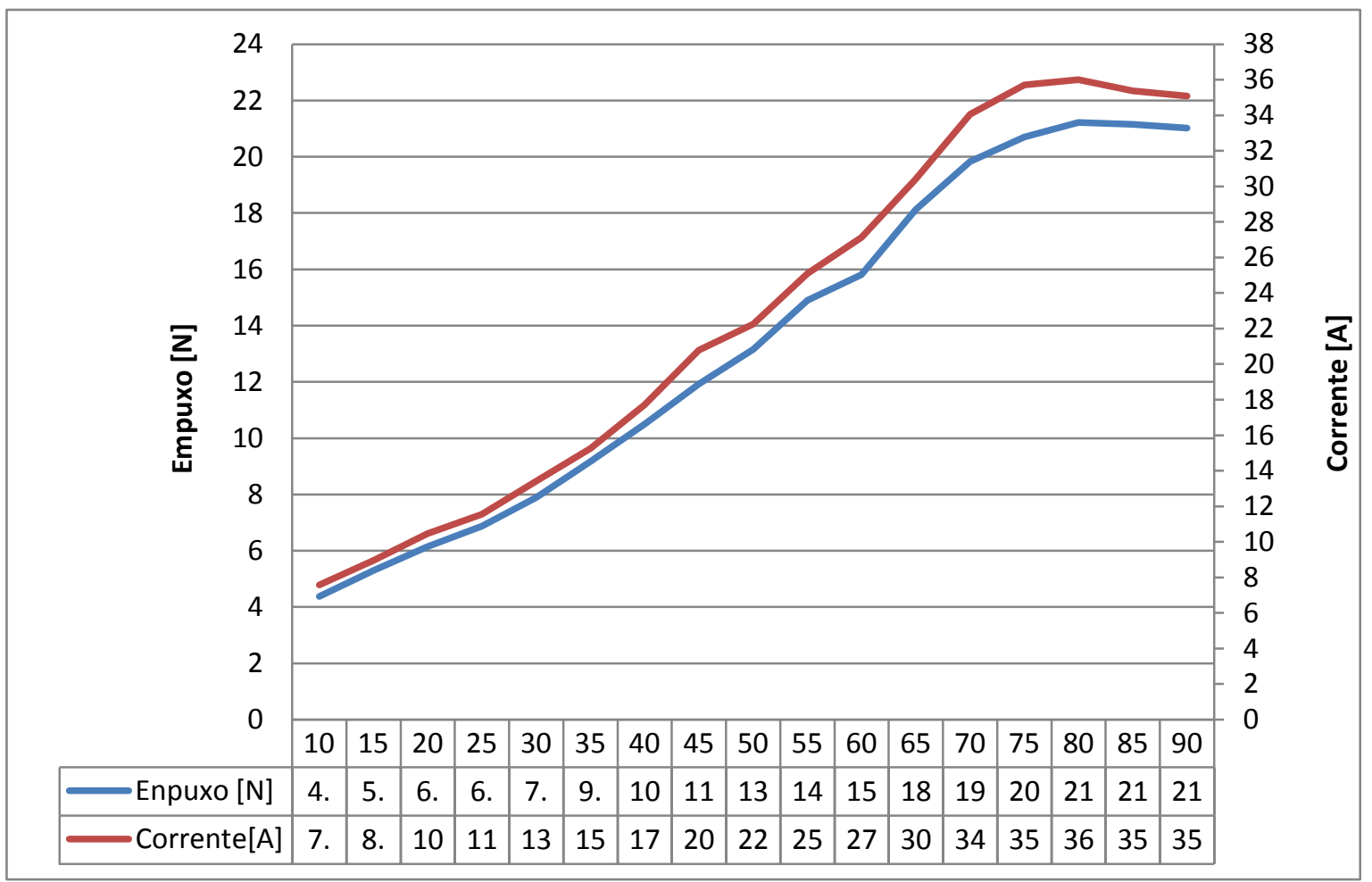

Figura 29. Gráfico de empuxo e corrente dos ensaios.

Observa-se pelo gráfico que o comportamento regular para cada referencia de velocidade é saturado a partir dos $70 \%$, isto é dado pelas proteções internas do controlador ESC que limitam a velocidade angular a partir deste ponto.

Com estes dados do ensaio para os conjuntos motor-hélice, tem-se além das constantes de velocidade de cada motor, também o mapeamento de velocidades para cada referencia de velocidade, bem como a corrente nominal e velocidade angular de cada rotor para manter o UAV em equilíbrio estático no ar (rovering). 


\subsection{Seleção da Bateria}

Após os ensaios com o rotor, pode-se obter uma boa estimativa do consumo do quadrirotor, tendo em vista que os quatro propulsores são os componentes elétricos com maior consumo de corrente neste sistema. Considerando-se uma massa total do quadrirotor igual a $1,5 \mathrm{Kg}$, o peso a ser vencido pelos propulsores é:

$$
\text { Peso }=m \cdot g=1,5 \cdot 9,81=14,715 N . \quad \text { Equação } 41
$$

Como o UAV possui quatro rotores, considerando que cada propulsor seja responsável por vencer um quarto do peso, o empuxo mínimo em cada rotor para manter o UAV estável no ar é:

$$
\tau_{\text {prop } i}=\frac{\text { Peso }}{4}=\frac{14,715}{4}=3,679 \mathrm{~N} . \quad \text { Equação } 42
$$

Efetuando uma interpolação linear nos valores da Tabela 2, observase que a corrente que cada propulsor necessitará para anular a força gravitacional é:

$$
i_{\text {total }(\text { rover })}=24,798 \mathrm{~A} \text {. }
$$

Equação 43

Portanto, para uma duração de bateria de aproximadamente 10 minutos, como requerido nos objetivos, e aplicando um método simples de estimação de vida de bateria, definindo que o final de vida da bateria é $15 \%$ de sua carga original:

$$
Q_{\text {bateria }}=\frac{i_{\text {total }(\text { rover })} \cdot \text { Tempo }}{0,85}=4862 m A h \quad \text { Equação } 44
$$

Enfim, a partir da Equação 44 define-se que a bateria deve ter ao menos 4862 mAh de carga para cumprir as especificações do projeto. 
Tendo esta especificação definida, a bateria Thunder Power RC: eXtreme V2 foi selecionada, possuindo as características apresentadas na Tabela 3.

\begin{tabular}{|c|c|c|}
\hline Parâmetro & Valor & Unidade \\
\hline $\begin{array}{c}\text { Composição } \\
\text { Química }\end{array}$ & Li-Po & N/A \\
\hline Massa & 373 & gramas \\
\hline Tensão Nominal & 11,1 & $\mathrm{~V}$ \\
\hline Capacidade & 5000 & $\mathrm{mAh}$ \\
\hline $\begin{array}{c}\text { Máxima corrente } \\
\text { (contínua) }\end{array}$ & 125 & $\mathrm{~A}$ \\
\hline $\begin{array}{c}\text { Máxima corrente } \\
\text { (pulsada) }\end{array}$ & 250 & $\mathrm{~A}$ \\
\hline
\end{tabular}

Tabela 3. Principais parâmetros da bateria eXtreme V2.

Apesar de a bateria não cumprir o exato requerimento de tensão, sua capacidade é superior e por isso foi selecionada como alimentação geral do quadrirotor. A seguir, uma imagem da bateria.

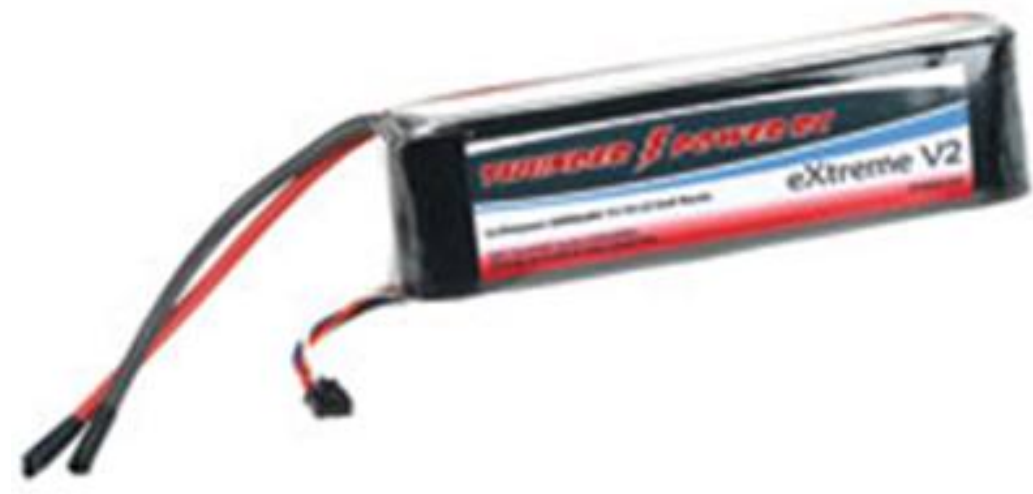

Figura 30. Bateria eXtreme V2.

Por fim, esta bateria possuindo $5000 \mathrm{mAh}$ de carga, obterá um melhor resultado de autonomia, realizando o calculo inverso para estimar a autonomia da aeronave com esta fonte: 


$$
\begin{gathered}
Q_{\text {bat }}=5000 m A h=\frac{i_{\text {total }} \cdot \text { Tempo }}{0,85} \\
\rightarrow \quad \text { Tempo }=10 \mathrm{~min} \mathrm{e} 17 \mathrm{seg} .
\end{gathered} \text { Equação } 45
$$

Tendo em vista a alta corrente drenada pelos motores e a característica indutiva dos mesmos, diversos picos de tensão e corrente estarão presentes durante a operação do UAV. Por este motivo vê-se necessária a inclusão de uma bateria secundaria para alimentar o circuito de controle e baixa corrente, onde estarão presentes o processador e sensores, visando a proteção dos mesmos contra tais surtos. Selecionou-se a bateria Turnigy 1.0 3S, ilustrada na Figura 31.

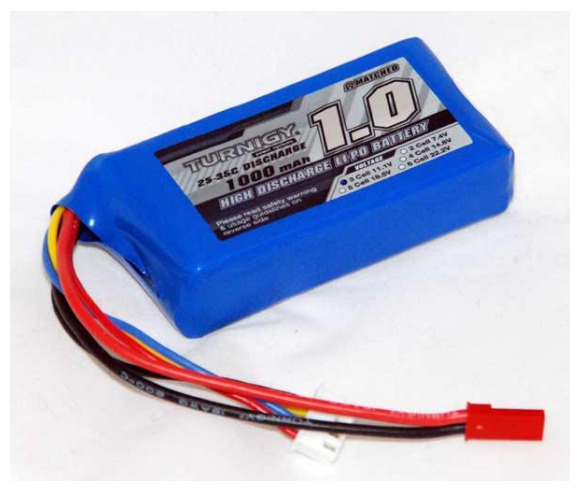

Figura 31. Bateria auxiliar Turnigy $1.03 \mathrm{~S}$.

$\mathrm{Na}$ Tabela 4, encontram-se adicionalmente as principais características da bateria.

\begin{tabular}{|c|c|c|}
\hline Parâmetro & Valor & Unidade \\
\hline $\begin{array}{c}\text { Composição } \\
\text { Química }\end{array}$ & Li-Po & N/A \\
\hline Massa & 94 & gramas \\
\hline Tensão Nominal & 11,1 & $\mathrm{~V}$ \\
\hline Capacidade & 1000 & $\mathrm{mAh}$ \\
\hline $\begin{array}{c}\text { Máxima corrente } \\
\text { (contínua) }\end{array}$ & 25 & $\mathrm{~A}$ \\
\hline $\begin{array}{c}\text { Máxima corrente } \\
\text { (pulsada) }\end{array}$ & 30 & $\mathrm{~A}$ \\
\hline
\end{tabular}

Tabela 4. Principais parâmetros da bateria Turnigy $1.03 \mathrm{~S}$. 


\subsection{Projeto Mecânico do Quadrirotor}

De maneira a comportar o payload requisitado, o rotor e baterias especificados nas seções anteriores, bem como o espaço para os sensores, é necessário um projeto mecânico do chassi do UAV para definição de inércias e outros parâmetros ainda pendentes na modelagem do quadrirotor.

Utilizando o software SolidWorks $\AA^{\circledR}$ foi possível gerar o quadrirotor a partir das especificações de payload e restrições mecânicas das dimensões das hélices, placas de controle e baterias. Na Figura 32, uma imagem do projeto mecânico do quadrirotor, já incluindo a configuração da câmera com pan e tilt (na parte inferior da montagem), a bateria principal (branco), bateria auxiliar (vermelho) e a placa de circuito impresso (verde).

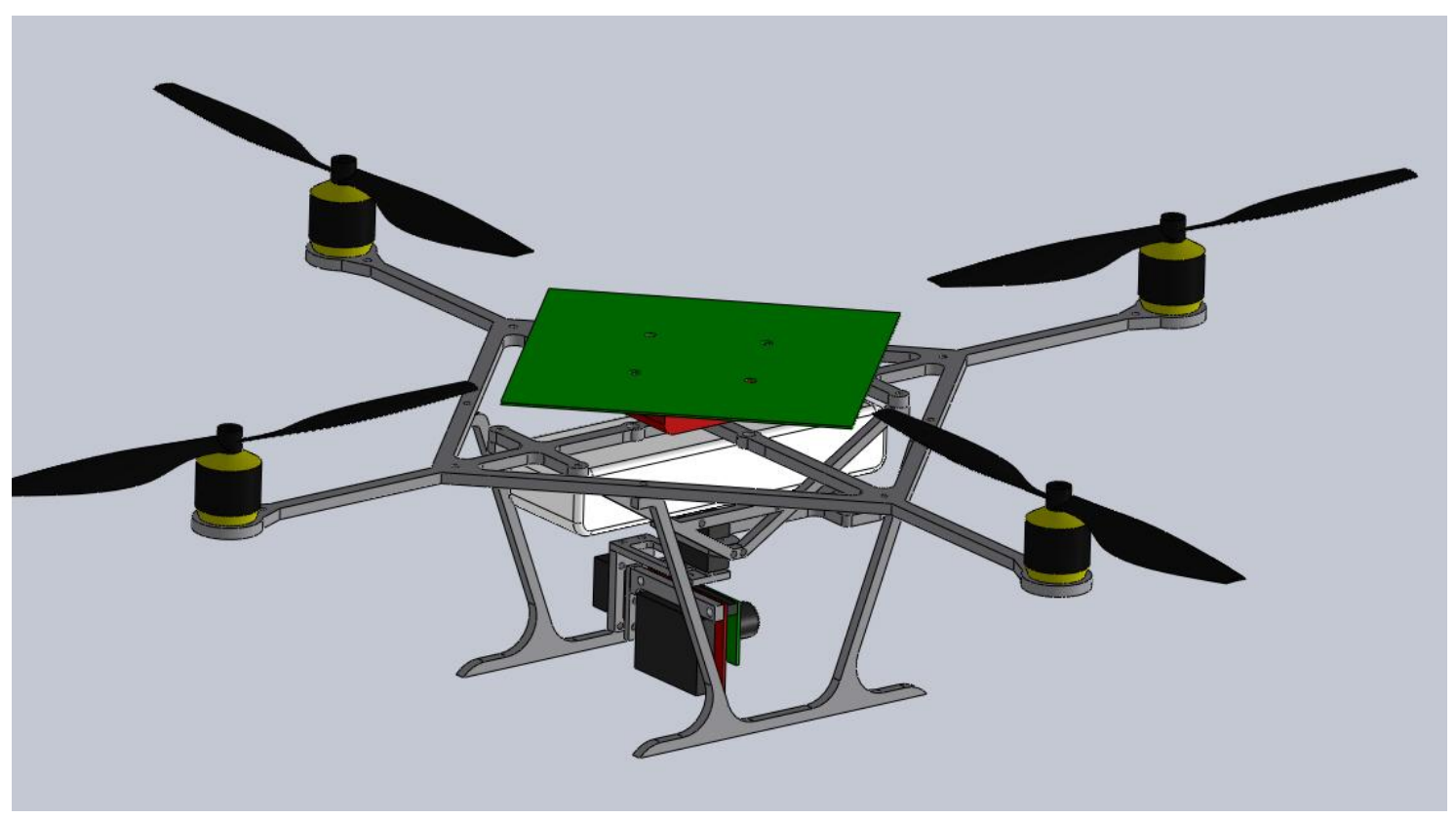

Figura 32. Desenho técnico em software CAD do Quadrirotor.

Com os principais parâmetros exibidos na Tabela 5 . 


\begin{tabular}{|c|c|c|}
\hline Parâmetro & Valor & Unidade \\
\hline $\begin{array}{c}\text { Massa } \\
\text { (com baterias) }\end{array}$ & 1300 & $\mathrm{~g}$ \\
\hline Dimensão L & 0,25 & $\mathrm{~m}$ \\
\hline $\mathrm{Ix}$ & $13,2 \mathrm{E}-03$ & $\mathrm{Kg} \cdot \mathrm{m}^{2}$ \\
\hline $\mathrm{Iy}$ & $12,4 \mathrm{E}-03$ & $\mathrm{Kg} \cdot \mathrm{m}^{2}$ \\
\hline $\mathrm{Iz}$ & $22,7 \mathrm{E}-03$ & $\mathrm{Kg} \cdot \mathrm{m}^{2}$ \\
\hline
\end{tabular}

Tabela 5. Principais parâmetros mecânicos do chassi do UAV.

É importante ressaltar que os valores de massa do chassi e momentos de inércia foram calculados com técnicas de elementos finitos disponível no software CAD utilizado.

Na Figura 33, uma imagem da composição final do quadrirotor com usinagem por corte a laser e montagem da placa de circuito impresso.

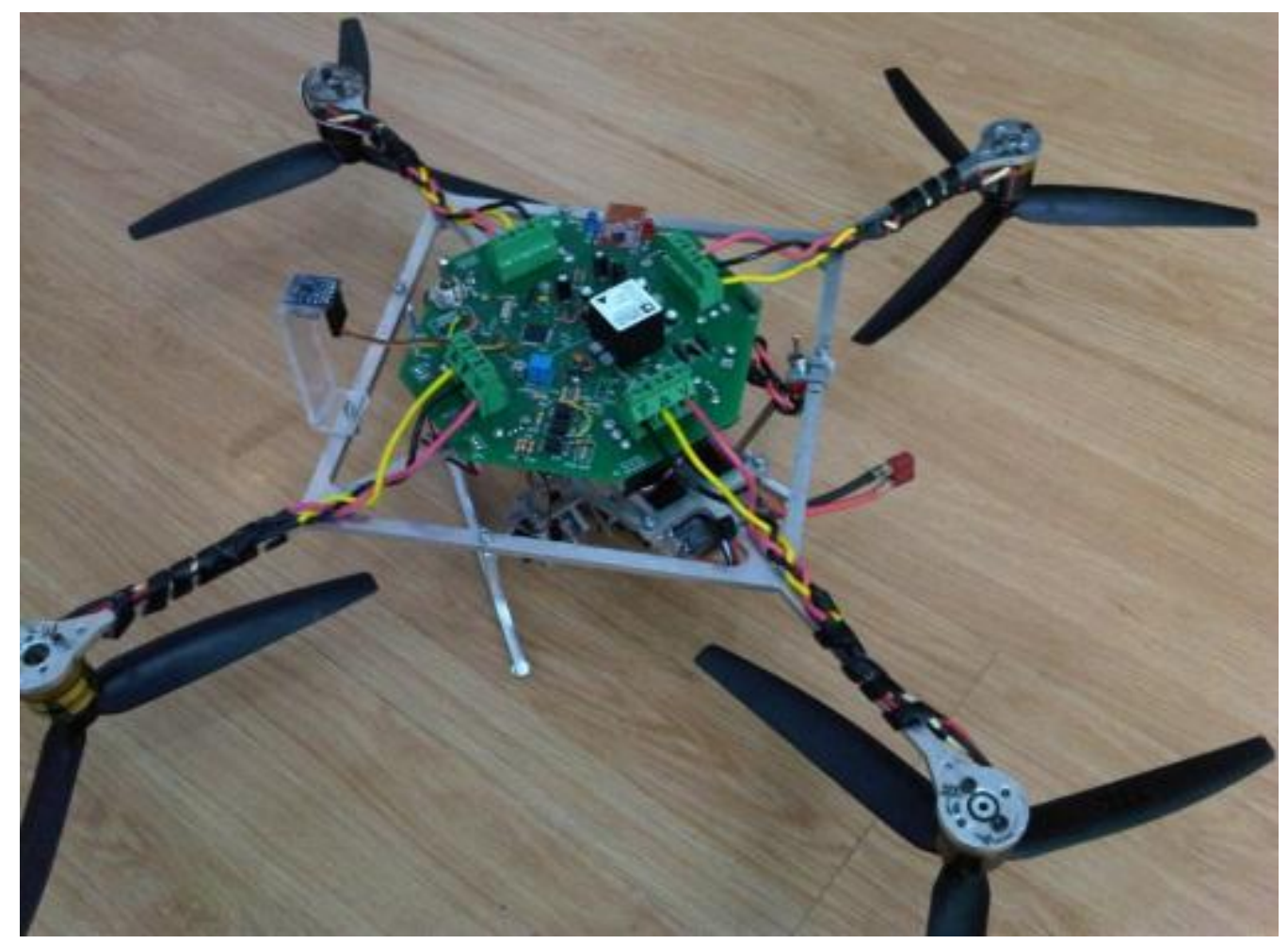

Figura 33. Imagem do UAV concluído. 


\subsection{Seleção e Configuração dos Sensores}

Para obter os feedbacks requeridos na modelagem do sistema, os seguintes sensores serão implementados:

- Acelerômetro: Medição de aceleração;

- Giroscópio: Medição de velocidade angular;

- Magnetômetro: Medição de orientação (Yaw) do UAV;

- Sensor de ultrassom: Medição de altitude do UAV;

- Sensor de Imagem: Processamento de imagem para medição de posição linear.

\subsubsection{Acelerômetro e Giroscópio}

Com o avanço das tecnologias de fabricação e inovação tecnológica em sensoriamento, diversas opções de sensores estão disponíveis nos dias de hoje para implementação em sistemas embarcados.

Atualmente, um tipo de sensor de movimento muito utilizado em projetos acadêmicos e industriais é o sensor do tipo MEMS (Micro ElectroMechanical Systems - Sistemas Micro Eletromecânicos), que possuem a característica de serem muito compactos e leves (ANDREJASIC, 2008), dois fatores muito importantes tendo em vista o desenvolvimento deste trabalho (BRESCIANI, 2008; DOMINGUES, 2009; COSTA, 2008; JOHNSON, 2002; JANG, 2003).

Tendo em vista a necessidade de um acelerômetro e um giroscópio, soluções com os dois sensores integrados se tornam uma opção interessante para compatibilidade na placa de circuito impresso, bem como única interface para aquisição dos dados. Selecionou-se, portanto, o sensor inercial MEMS ADIS16354AMLZ, que possui um acelerômetro e um giroscópio, ambos tridimensionais, na Tabela 6 algumas informações sobre o sensor são apresentadas. 


\begin{tabular}{|c|c|c|}
\hline Parâmetro & Valor & Unidade \\
\hline $\begin{array}{c}\text { Resolução dos } \\
\text { Sensores }\end{array}$ & 14 & bits \\
\hline $\begin{array}{c}\text { Interface de } \\
\text { aquisição }\end{array}$ & $\mathrm{SPI}$ & $\mathrm{N} / \mathrm{A}$ \\
\hline $\begin{array}{c}\text { Máxima taxa de } \\
\text { Comunicação }\end{array}$ & 819.2 & $\mathrm{SPS}$ \\
\hline $\begin{array}{c}\text { Range de medição } \\
\text { do Acelerômetro }\end{array}$ & $\pm 1,7$ & $\mathrm{G}$ \\
\hline $\begin{array}{c}\text { Range de medição } \\
\text { do Giroscópio }\end{array}$ & \pm 300 & $\mathrm{\circ} / \mathrm{s}$ \\
\hline Máximo Impacto & 2000 & $\mathrm{G}$ \\
\hline $\begin{array}{c}\text { Tensão de } \\
\text { operação }\end{array}$ & $4,75 \mathrm{a}$ & $\mathrm{V}$ \\
\hline $\begin{array}{c}\text { Temperatura de } \\
\text { Operação }\end{array}$ & $-40 \mathrm{a} 85$ & ${ }^{\circ} \mathrm{C}$ \\
\hline
\end{tabular}

Tabela 6. Parâmetros característicos do sensor ADIS16354AMLZ.

O diagrama de blocos lógicos do sensor é ilustrado na Figura 34.

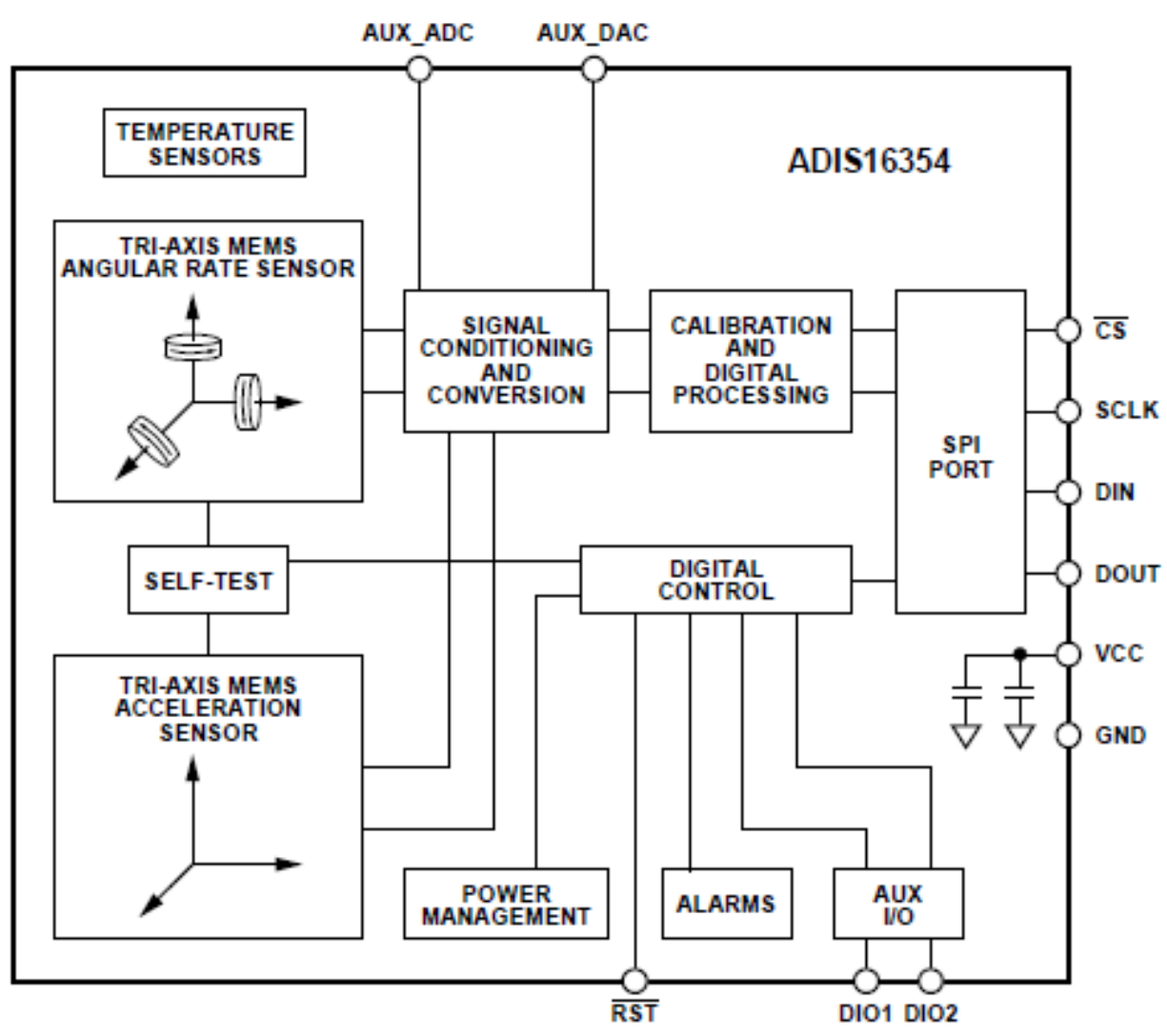

Figura 34. Diagrama de blocos do sensor ADIS16354AMLZ. 
O sensor possui também dimensões reduzidas $(21,41 \times 31,9 \times$ $23,5 \mathrm{~mm}$ ), possibilitando a instalação do encapsulamento na própria placa de controle. Apresenta-se na Figura 35 uma imagem do sensor.

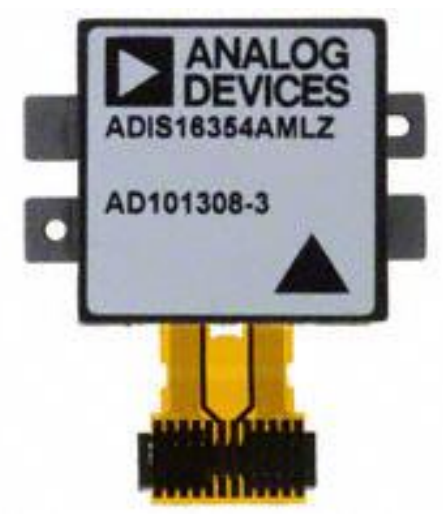

Figura 35. Fotografia do sensor ADIS16354AMLZ.

\subsubsection{Magnetômetro Digital}

Com o objetivo de medir a orientação (Yaw) do UAV um magnetômetro digital é utilizado. Tal sensor mede o campo magnético da terra nos três eixos coordenados e a partir destas medidas é possível estimar a orientação do quadrirotor como uma bússola.

Para realizar esta tarefa o sensor HMC5883L foi selecionado. Ele possui interface ${ }^{2} \mathrm{C}$ para transferência das medidas, o que simplifica a configuração do sensor na PCl (Placa de Circuito Impresso) final. Observa-se na Figura 36 uma imagem do sensor. 


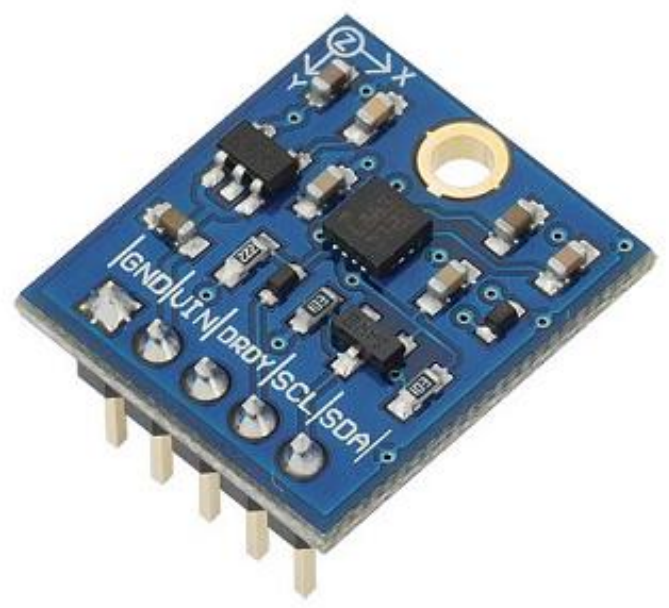

Figura 36. Magnetômetro HMC5883L.

É importante ressaltar que este sensor terá seus eixos coordenados alinhados aos eixos do corpo do UAV na montagem final do mesmo, isto simplificará a aferição do yaw do UAV.

Como este sensor não fornece diretamente os dados de interesse para o sistema (estados ou saídas definidas em seções anteriores) faz-se necessária a estimação da orientação do quadrirotor por meio da projeção do campo magnético medido em cada eixo do sensor.

\subsubsection{Calculo da Orientação do UAV}

Definindo a medida de cada eixo do sensor como $\mathrm{H}_{\mathrm{x}}, \mathrm{H}_{\mathrm{y}}$ e $\mathrm{H}_{z}$, uma maneira simplificada de se calcular a orientação do UAV é pela simples composição dos eixos x e y, sendo

$$
\bar{\psi}=\operatorname{atan} 2(B y, B x) .
$$

Equação 46

Note-se que a Equação 46 não pode ser aplicada quando o corpo possui movimentações angulares além do Yaw, ou seja, se o Pitch ou Roll do corpo forem não nulos esta equação perde sua validade.

Como o UAV não esta restrito possuir Pitch e Roll sempre nulos, uma nova projeção é aplicada para compensar estas inclinações por meio da matriz de rotação. Sendo assim 


$$
\begin{aligned}
& {\left[\begin{array}{l}
B_{x \text { comp }} \\
B_{\text {y comp }} \\
B_{z \text { comp }}
\end{array}\right]} \\
& =\left[\begin{array}{ccc}
C(\theta) & C(\theta) & -S(\theta) \\
S(\theta)-C(\phi) & C(\phi)+S(\phi) \cdot S(\theta) & S(\phi) \cdot C(\theta) \\
S(\theta) \cdot C(\phi) \cdot+S(\phi) & S(\theta) \cdot C(\phi)-S(\phi) & C(\phi) \cdot C(\theta)
\end{array}\right]^{T} \cdot\left[\begin{array}{l}
B_{x} \\
B_{y} \\
B_{z}
\end{array}\right] .
\end{aligned}
$$

Equação 47

Onde $B_{x \text { comp }}, B_{y \text { comp }}$ e $B_{z \text { comp }}$, são os valores compensados para as medidas do campo magnético de cada eixo do sensor. Portanto, aplicando estes valores compensados na Equação 46, obtém-se a orientação do UAV mesmo com movimentações angulares em Pitch e Roll.

\subsubsection{Compensação de efeitos de Soft e Hard Iron}

Outra fonte de erros no sensoriamento por magnetômetros pode ser causada pelos efeitos de soft e hard iron, que causam distorções nas medidas do sensor. Sendo que as distorções por hard iron são causadas por materiais que produzem campo magnético, esta distorção causa um desvio permanente nas medidas do sensor independentemente da orientação do mesmo. O soft iron por sua vez causa alterações e desvios no campo magnético existente, causando um desvio no sensor variante conforme a orientação do corpo.

Para verificar a existência destas interferências, um teste é feito no sensor já acoplado no UAV, aonde é realizada uma rotação completa em torno do eixo $Z_{\mathrm{c}}$ do sistema de coordenadas do corpo e um gráfico dos valores $B_{x \text { comp }}$ e $B_{y \text { comp }}$ é gerado.

Neste ensaio, espera-se que o gráfico resultante exiba um circulo com o centro na origem. Caso o resultado não possua centro coincidente com a origem do gráfico é atestada a presença de interferência por hard iron, dado que o campo está constantemente deslocado por um valor fixo. Caso o formato do resultado seja uma elipse, considera-se que existem efeitos de soft iron presentes nas proximidades do sensor. Ressalta-se também que ambos os efeitos podem ocorrer simultaneamente. 
$\mathrm{Na}$ Figura 37 exibe-se tal ensaio realizado no sensor já implementado no UAV para verificação de interferências.

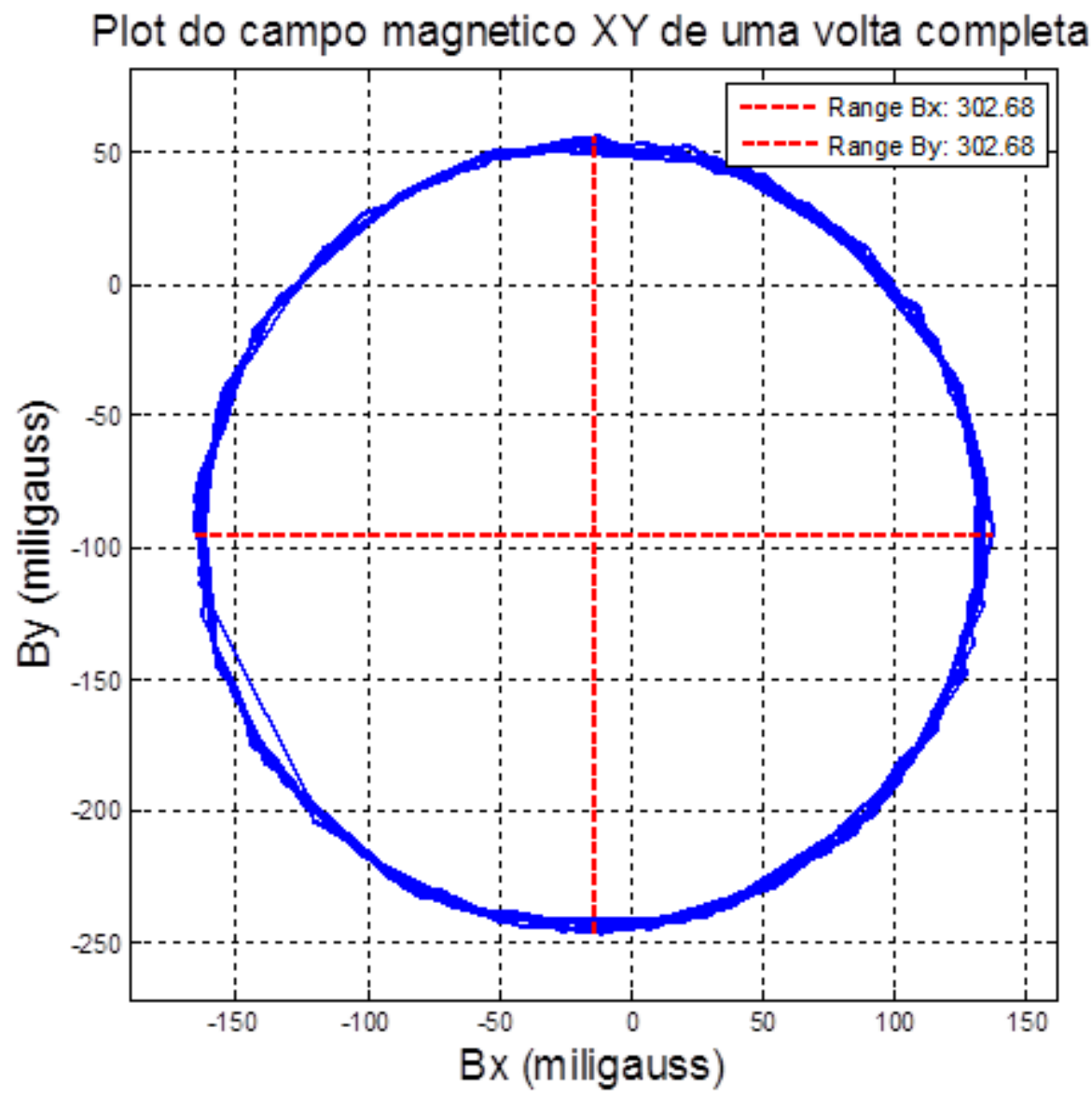

Figura 37. Gráfico para verificação de interferências por hard ou soft iron.

Observa-se na Figura 37 que o gráfico resultou em um circulo com o centro deslocado da origem do gráfico, o que acusa distúrbios por hard iron, por outro lado, não há evidencia expressiva de distorções por soft iron e por isso não haverá compensação para tal efeito.

Para compensar os distúrbios observados, uma subtração é agregada às medidas do sensor, sendo -19 miligauss para $B_{x \text { comp }}$ e -79 miligauss para $B_{x \text { comp }}$.

Aplicando estas correções, um novo ensaio é realizado e seu resultado exibido na Figura 38. 


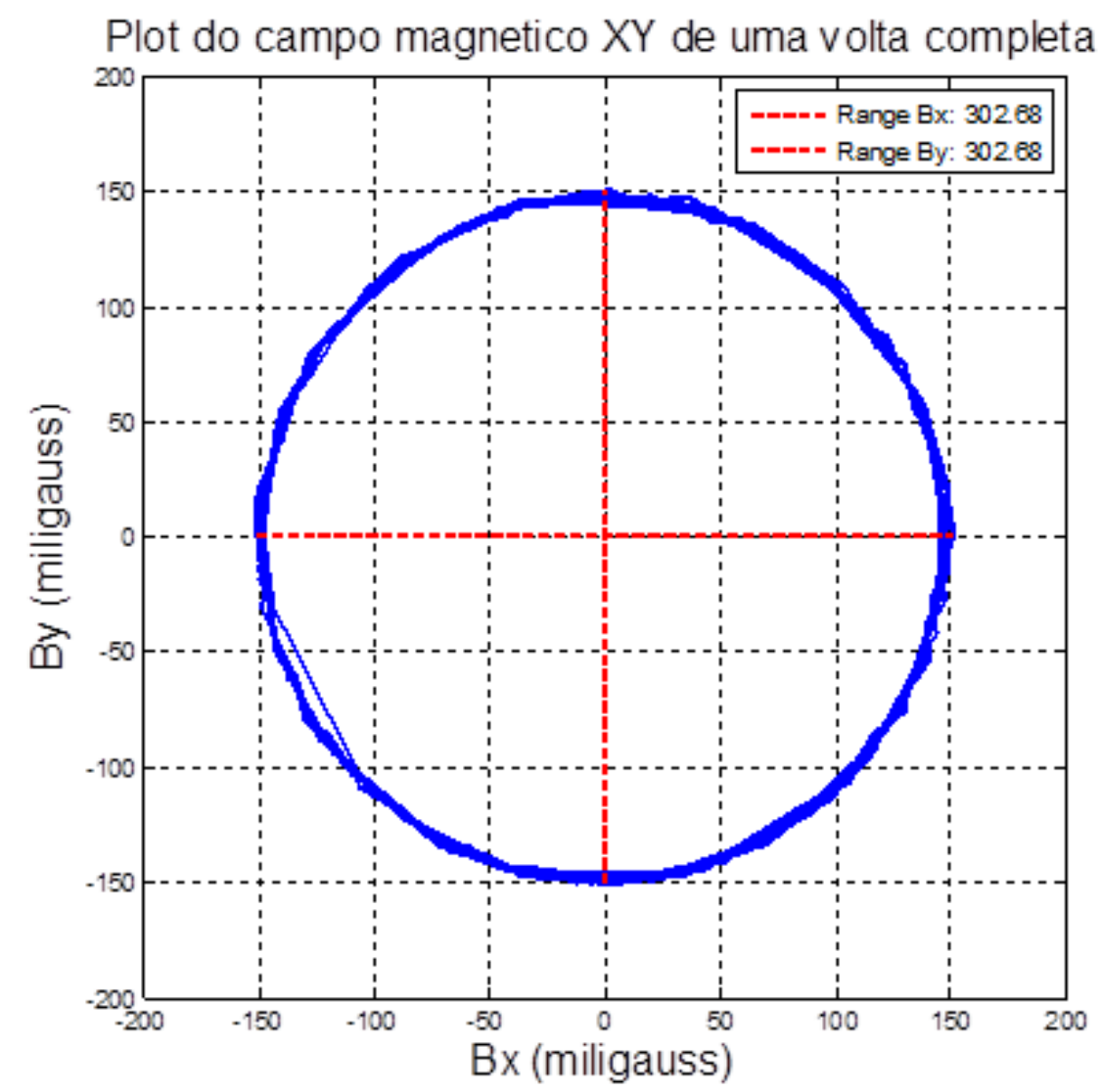

Figura 38. Gráfico compensado para verificação de interferências por hard ou soft iron.

Pelo gráfico observa-se que a compensação foi bem sucedida, eliminando o deslocamento antes presente e sem a presença expressiva de deformações na circunferência do circulo.

Finalmente, com a implementação destas medidas para 0 magnetômetro, o mesmo está calibrado para operação e aplicação no UAV, sendo a equação final para aquisição do yaw:

$$
\psi=\operatorname{atan} 2\left(\left(B_{y \text { comp }}+79\right),\left(B_{x \text { comp }}+19\right)\right) . \quad \text { Equação } 48
$$

\subsubsection{Sensor de Ultrassom}

Também será aplicado ao quadrirotor um sensor de ultrassom, para realizar a medida direta da altitude do corpo. Este sensor também será utilizado 
no calculo da triangulação para estimação das posições lineares do corpo X e $\mathrm{Y}$.

O sensor selecionado é o modelo PING))) da empresa Parallax Inc., este sensor possui sua interface aplicada a partir da emissão de pulsos de um controlador para geração e aguardo do retorno da onda ultrassônica, o tempo entre o envio e recebimento da onda é calculado pelo controlador e a altitude é calculada a partir deste valor. Uma imagem do sensor é apresentada na Figura 39.

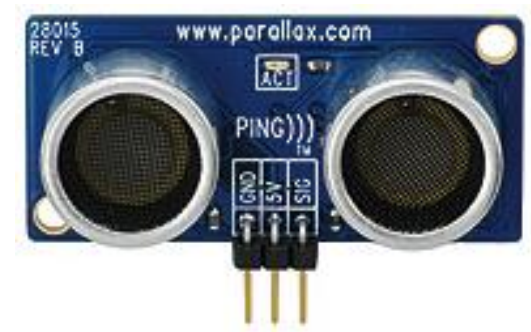

Figura 39. Sensor de ultrassom PING))).

\subsubsection{Sensor de imagem}

Visando a estimação da posição linear do quadrirotor em relação à origem do sistema de coordenadas Terra, um sensor de imagem é utilizado para processar imagens que indicam o deslocamento do quadrirotor. Para este fim o sensor de imagem OV6620 será utilizado. Suas principais características se encontram na Tabela 7.

\begin{tabular}{|c|c|c|}
\hline Parâmetro & Valor & Unidade \\
\hline $\begin{array}{c}\text { Quantidade de } \\
\text { Pixels }\end{array}$ & 101.376 & Pixels \\
\hline Formato de dados & YCrCb/RGB & N/A \\
\hline $\begin{array}{c}\text { Formato da } \\
\text { Imagem }\end{array}$ & $352 \times 288$ & Pixels \\
\hline $\begin{array}{c}\text { Tensão de } \\
\text { operação }\end{array}$ & 5 & $\mathrm{~V}$ \\
\hline
\end{tabular}

Tabela 7. Principais características do sensor OV6620.

Na Figura 40, uma imagem do módulo sensor de imagem. 


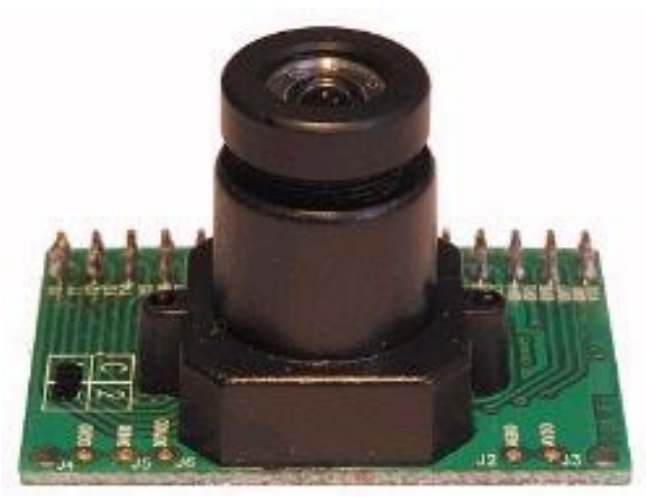

Figura 40. Sensor OV6620.

Para implementar o sistema estimador de posição linear com a câmera, um ponto de referencia é posicionado no espaço de trabalho do UAV para que a câmera sempre centralize sua visada a este ponto, desta forma e com a utilização do sensor de altitude é realizada uma triangulação dos valores para o calculo da posição.

\subsubsection{Conjunto de Pan e Tilt com Servo-Motores}

Para realizar a movimentação angular da câmera, dois servomotores são utilizados. Os servo-motores utilizados são do modelo S3114 do fabricante Futaba. Uma imagem do S3114 é apresentada na Figura 41.

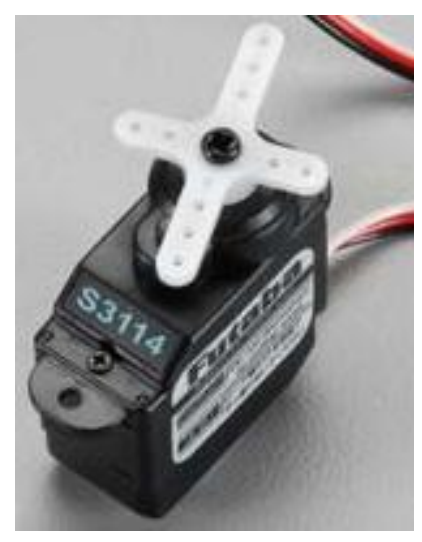

Figura 41. Servo-motor S3114.

Este modelo de servo-motor é acionado por meio de modulação por largura de pulsos (PWM - Pulse Width Modulation), onde o duty do PWM 
fornece a referência de posição para o servo-motor, sendo frequência de operação especificada pelo fabricante para o PWM igual $50 \mathrm{~Hz}$.

Exibe-se na Figura 42 o projeto em CAD para o mecanismo de orientação da câmera.

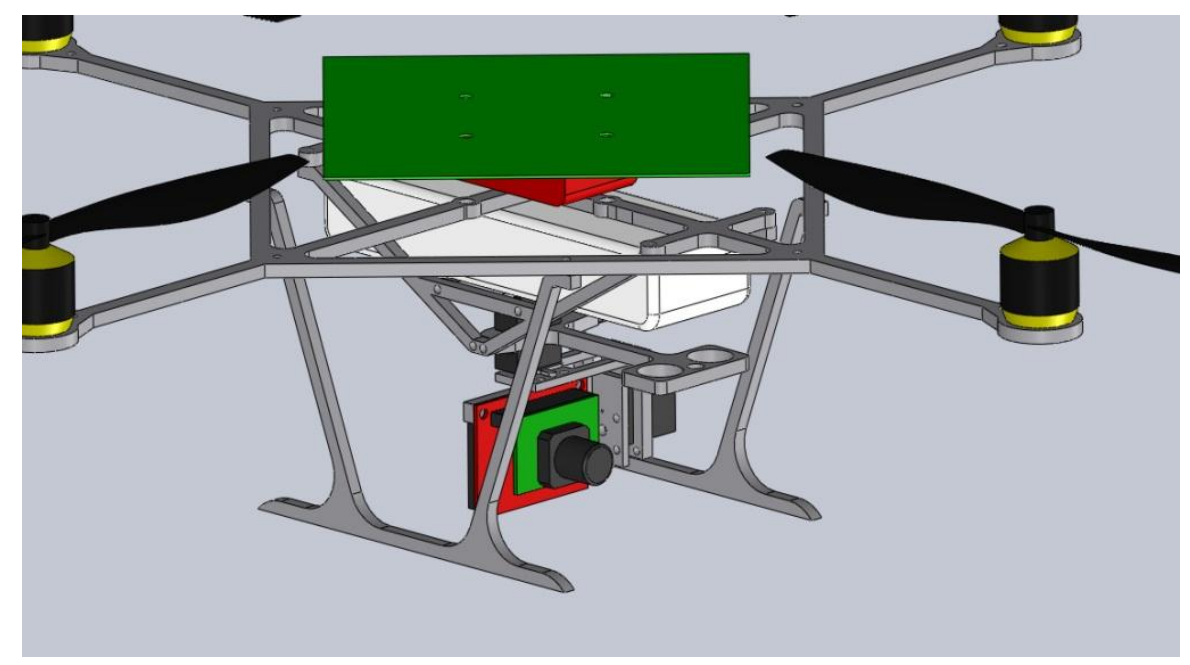

Figura 42. Projeto do mecanismo de pan e tilt da câmera.

$\mathrm{Na}$ Figura 43, apresenta-se o mecanismo de orientação já manufaturado e montado com a câmera e servo-motores.

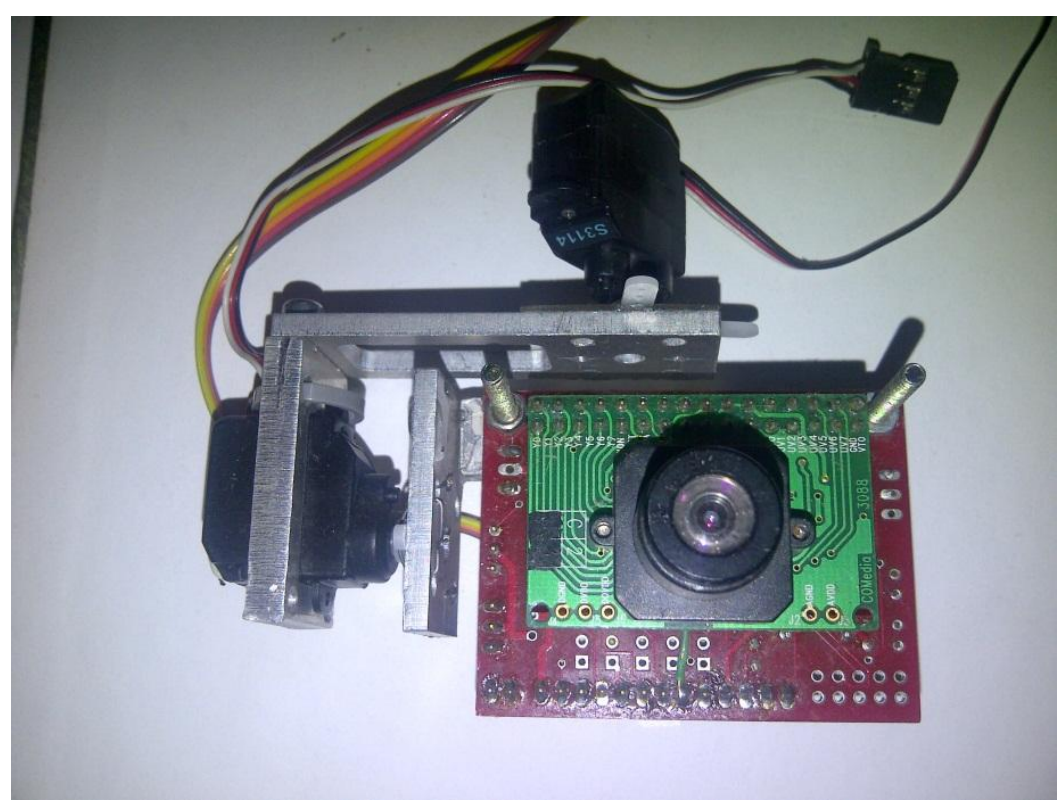

Figura 43. Mecanismo de orientação da câmera. 
É importante ressaltar que os servo-motores que realizam a movimentação da câmera possuem uma dinâmica mais rápida que o deslocamento do corpo, sendo assim esta dinâmica não será introduzida ao modelo do UAV.

\subsubsection{Calculo do Deslocamento do UAV a Partir da Câmera}

Com o mecanismo de orientação da câmera já definido, uma simplificada malha de controle PI (Proporcional-Integrador) é implementada no controlador do UAV para que a câmera esteja sempre orientada para o ponto de referencia no espaço de trabalho.

A partir da posição angular de cada servo-motor e a altitude medida pelo sensor de ultrassom calcula-se a posição linear do UAV em relação ao ponto de referência citado anteriormente, por cinemática inversa. Para o deslocamento na direção $\mathrm{X}$ tem-se

$$
X=\frac{Z}{\tan \left(\theta_{\text {tilt }}\right)} \cdot \operatorname{sen}\left(\theta_{\text {pan }}-\psi\right)
$$

Equação 49

e na direção $Y$, tem-se

$$
Y=\frac{Z}{\tan \left(\theta_{\text {tilt }}\right)} \cdot \cos \left(\theta_{\text {pan }}-\psi\right) .
$$

Para a Equação 49 e Equação $50, \theta_{\text {pan }}$ é a posição angular da câmera para o pan e $\theta_{\text {tilt }}$ é a posição angular da câmera para o tilt. A altitude Z e ângulo yaw $\psi$, são medidos diretamente por sensores previamente definidos.

\subsection{Hardware Eletrônico Embarcado}

Visando a integração dos sensores, atuadores, comunicação wireless e controle, a eletrônica embarcada do UAV é definida segundo o diagrama de blocos exibido na Figura 44. O sistema é organizado por meio da utilização de um Microcontrolador (MCU - Microcontroler Unit) central, que será 
responsável pela aquisição dos sensores, bem como comunicação wireless. 0 MCU central também implementa o controle dos motores e servo-motores, juntamente com suas respectivas malhas de controle.

Um bloco isolador ótico também é inserido entre a eletrônica de potência (controle dos rotores e servo-motores) e a eletrônica de controle (lógica de controle do UAV, monitoramento da bateria, sensores e comunicação wireless).

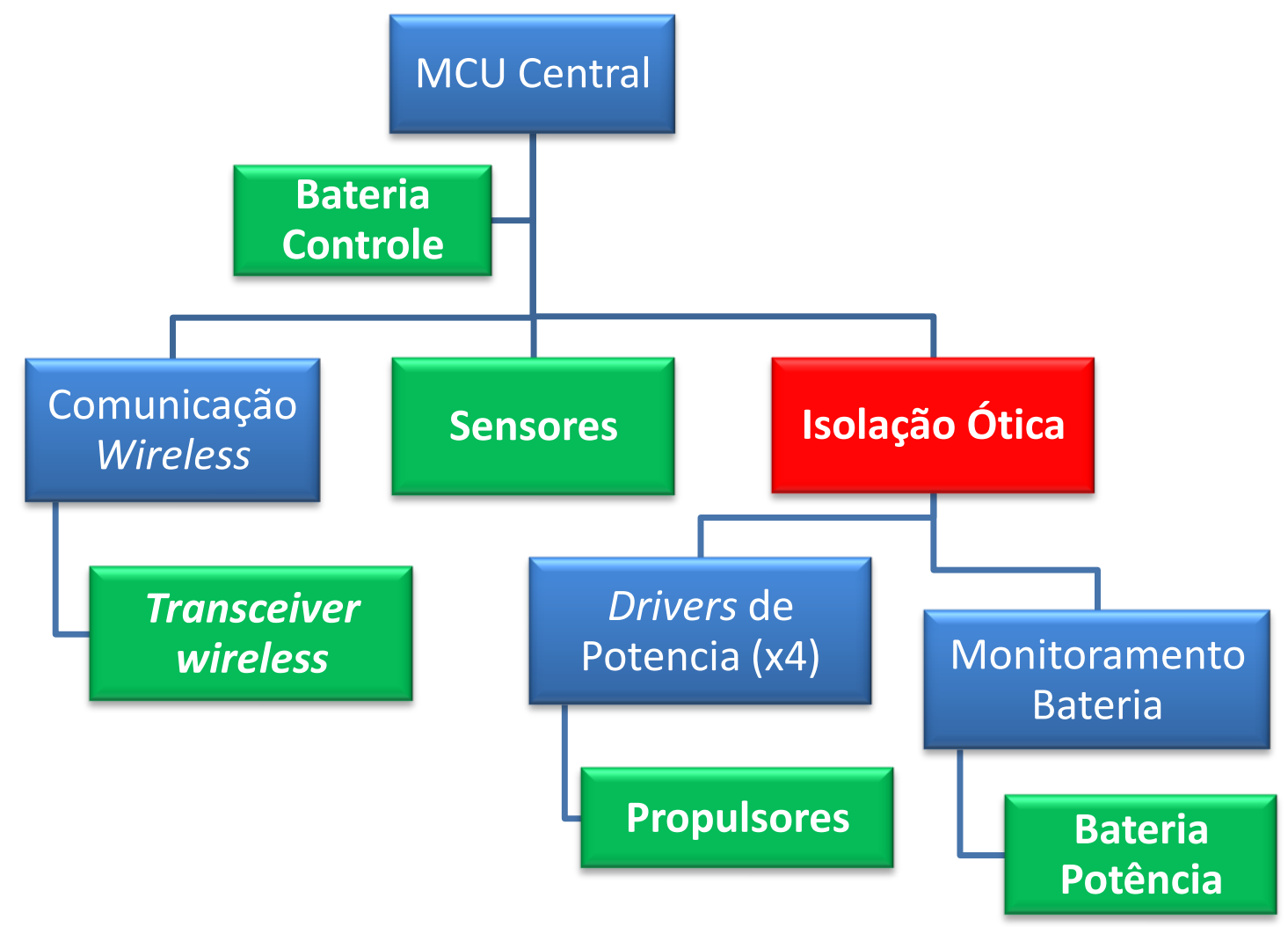

Figura 44. Diagrama de blocos da eletrônica embarcada a partir do MCU central

Ressalta-se também que os barramentos de conexão entre o MCU central e seus inferiores serão todos implementados utilizando comunicação SPI (Serial Peripheral Interface - Interface Serial Periférica) e ${ }^{2} \mathrm{C}$ (Inter- 
Integrated Circuit - Circuito Inter-Integrado), com exceção do sensor de imagem que possui um protocolo particular proprietário do fabricante.

\subsubsection{Módulo Wireless e Protocolo de Comunicação P2P}

Como o escopo do projeto não tem foco acentuado no desenvolvimento da solução de comunicação wireless optou-se por uma solução modularizada e de comunicação simples, porém confiável, tendo em vista que em alguns casos, a perda de comunicação pode causar a falha do UAV ou acidentes.

A Microchip Inc. oferece uma solução interessante para este problema: O módulo MRF89XAM9A, que possui antena integrada e interface de comunicação via SPI, o que é importante para a arquitetura proposta previamente. Na Tabela 8, os parâmetros principais deste módulo.

\begin{tabular}{|c|c|c|}
\hline Parâmetro & Valor & Unidade \\
\hline Interface & SPI & $\mathrm{N} / \mathrm{A}$ \\
\hline $\begin{array}{c}\text { Formato de } \\
\text { Transmissão }\end{array}$ & $\mathrm{FSK}$ & $\mathrm{N} / \mathrm{A}$ \\
\hline $\begin{array}{c}\text { Frequencia de } \\
\text { Operação }\end{array}$ & 915 & $\mathrm{MHz}$ \\
\hline $\begin{array}{c}\text { Potência de } \\
\text { Transmissão }\end{array}$ & 12,5 & $\mathrm{dBm}$ \\
\hline $\begin{array}{c}\text { Potência de } \\
\text { Recepção }\end{array}$ & -105 & $\mathrm{dBm}$ \\
\hline $\begin{array}{c}\text { Corrente de } \\
\text { Transmissão }\end{array}$ & 30 & $\mathrm{~mA}$ \\
\hline $\begin{array}{c}\text { Corrente de } \\
\text { Transmissão }\end{array}$ & 3,5 & $\mathrm{~mA}$ \\
\hline $\begin{array}{c}\text { Tensão de } \\
\text { Operação }\end{array}$ & 2,1 a 3,6 & $\mathrm{~V}$ \\
\hline
\end{tabular}

Tabela 8. Principais parâmetros do transceiver MRF89XAM9A.

A seguir, na Figura 45 uma imagem do módulo. 


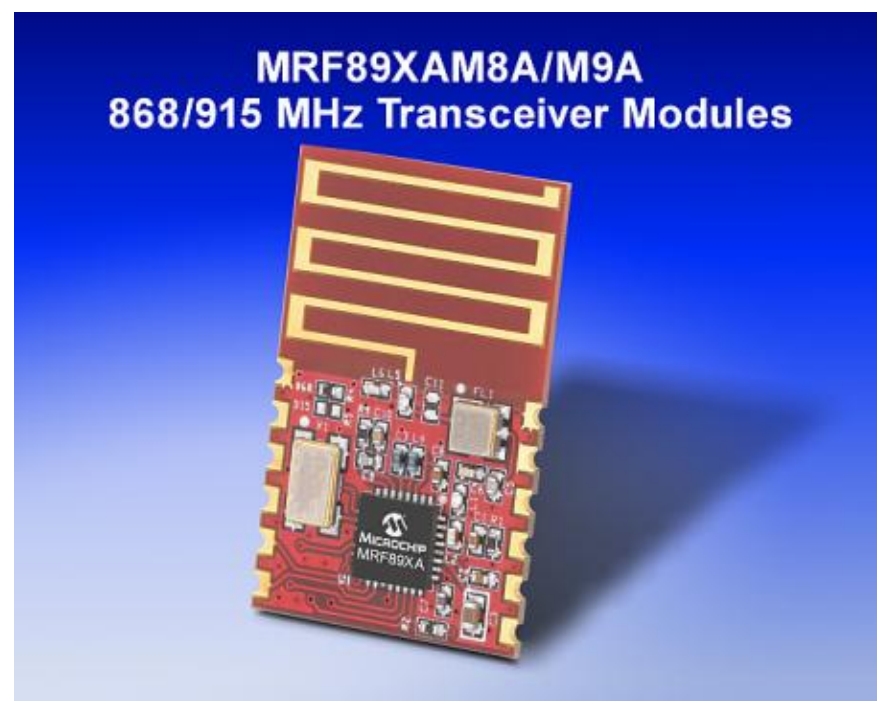

Figura 45. Módulo MRF89XAM9A.

Ressalta-se que este trasceiver possui apenas a camada física da comunicação, ou seja, nenhum protocolo é embarcado no módulo, portanto o protocolo deve ser inserido no MCU central. Seguindo a lógica de simplificação da solução de comunicação, selecionou-se também o protocolo proprietário desenvolvido pela Microchip Inc., o MiWi (FLOWERS, 2010), este protocolo é similar ao ZigBee. Neste trabalho será utilizado o MiWi P2P (YANG, 2010). Ambos os protocolos são baseados no padrão Wireless Personal Area Network (WPAN) IEEE 802.15.4 (YANG, 2010).

O protocolo MiWi pode consumir até $25 \mathrm{~KB}$ do memória Flash do MCU central, e 2KB de memória RAM. Este protocolo é aberto, portanto podese alterar a pilha para melhor encapsular mensagens.

\subsubsection{Isolação Ótica}

Para isolação ótica entre o sistema de potência de controle, optoacopladores são introduzidos. O optoacoplador HCPL-0630 do fabricante AVAGO Technologies será utilizado, tendo em vista sua banda de frequência de $10 \mathrm{MBd}$ e dois canais por encapsulamento, visando melhor aproveitamento de espaço em placa. Na Figura 46 ilustra-se o diagrama de conexões do componente. 


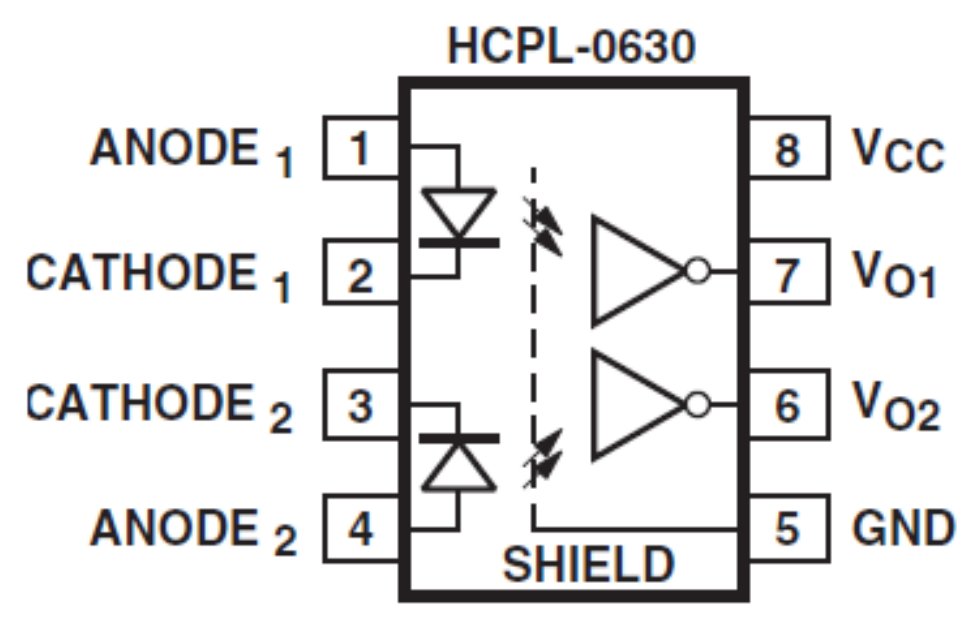

Figura 46. HCPL-0630.

\subsubsection{Seleção do MCU Central}

Com todos os periféricos definidos, podem-se então definir as características necessárias para a seleção do MCU central.

Iniciando pelos requisitos de memória, os módulos que geram maior necessidade de memória RAM são: o módulo de comunicação wireless, algoritmos de controle e processamento de imagem. Sabe-se que o consumo de RAM do protocolo MiWi é de aproximadamente $2 \mathrm{~KB}$, enquanto estima-se que a memória RAM consumida pelos algoritmos de controle não seja maior que $2 \mathrm{~KB}$ e por fim, o sensor de imagem irá consumir em torno de 8KB para carregar imagens e entre outras tarefas. Totalizando uma necessidade de $12 \mathrm{~KB}$ para a memória RAM.

Sendo os requerimentos de memória Flash:

- Endereçamento de módulos periféricos e algoritmos de acesso: 1KB;

- Rotinas de leitura dos sensores: 10KB;

- Protocolo MiWi: 5KB.

Sendo assim, a demanda de memória Flash é de 16KB. Ressalta-se ainda que estes valores são estimados. 
Em relação aos requerimentos de periféricos, o mecanismo de comunicação SPI e I2C, módulos PWM e conversores analógicos-digitais são os de maior importância.

Tendo em vista estes requisitos, selecionou-se 0 dsPIC33FJ128GP804, que atende a todos os requerimentos supracitados. Adicionalmente, o MCU possui 128KB de memória flash e 16KB de memória RAM, visando flexibilidade para possíveis expansões de funcionalidades.

\subsection{Placa de Circuito Impresso Final}

A partir das definições de hardware e sensores, $\mathrm{PCl}$ foi confeccionada e adicionada ao UAV. Ressalta-se que a massa da $\mathrm{PCl}$ já foi inclusa no projeto mecânico do quadrirotor, previamente abordado neste trabalho. Na Figura 47, uma imagem da placa já montada no quadrirotor.

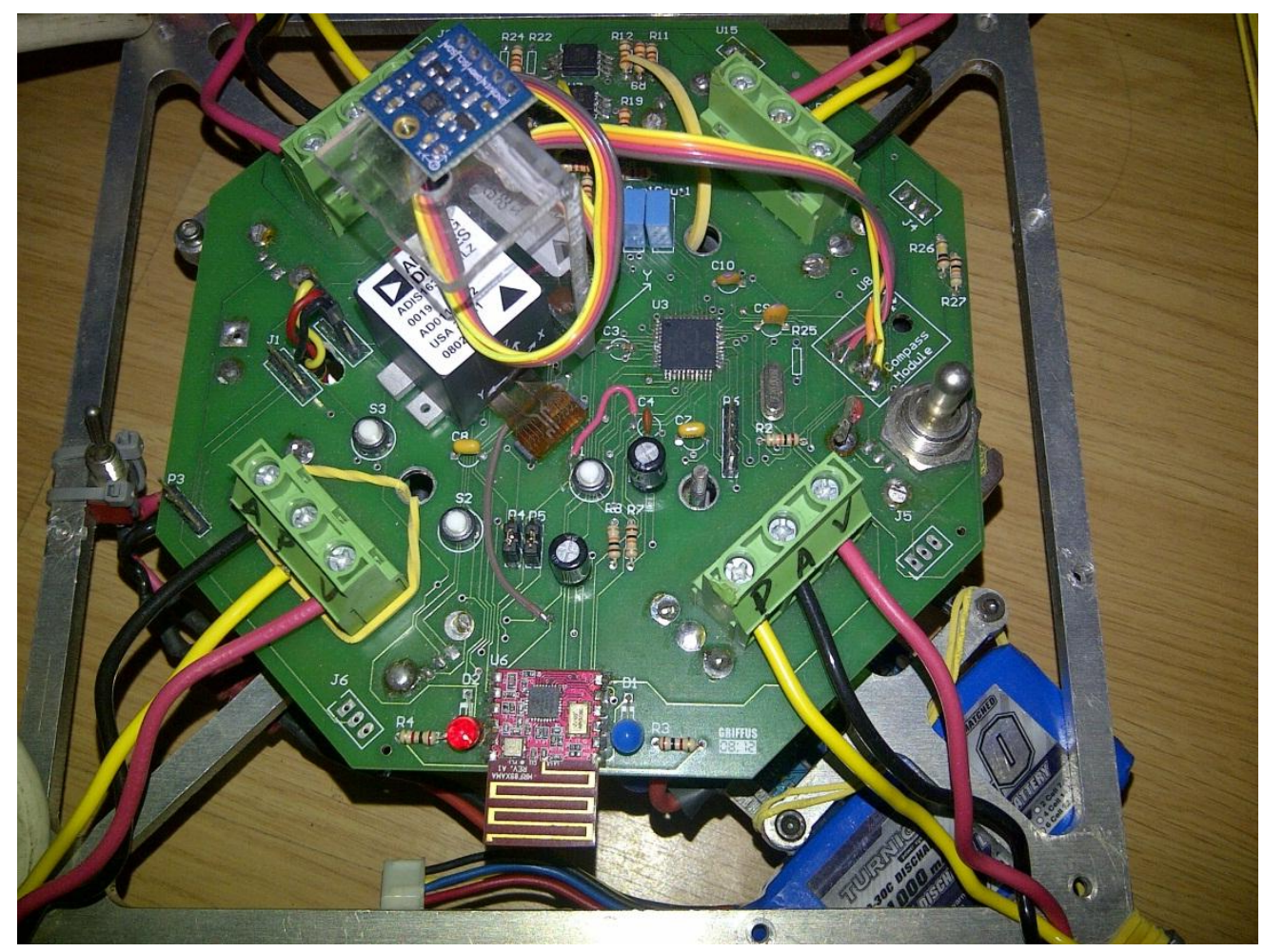

Figura 47. PCI montada no corpo do UAV. 
Com a montagem final da $\mathrm{PCl}$ no UAV, um importante parâmetro para o projeto é definido, sendo ele a posição do sensor inercial em relação ao centro de massa do corpo que resulta em

$$
r_{s}=\left[\begin{array}{c}
0 \\
0 \\
0,04
\end{array}\right] .
$$

Equação 51 


\section{Capítulo 4. Projeto de Controle}

Após a modelagem dinâmica genérica do quadrirotor, seu projeto mecânico e elétrico, pode-se então criar o projeto de controle da aeronave.

Inicialmente substituem-se os valores definidos na seção do projeto mecânico nas matrizes de estados deduzidas anteriormente, desta forma obtém-se o modelo no espaço de estados com todos os valores definidos.

Neste trabalho duas técnicas de controle linear serão aplicadas para abordar o problema do controle proposto: controle por alocação direta de polos e LQR. Para recuperar os estados não medidos, duas soluções serão também avaliadas, sendo elas um observador de estados de ordem plena e um filtro de Kalman discreto. Os desempenhos destas duas técnicas serão comparados em simulação para definir qual é mais adequada para solucionar o problema.

As equações do sistema e o projeto de controle serão implementados no domínio do tempo discreto, com período de amostragem de $20 \mathrm{~ms}$, como já mencionado anteriormente.

\subsection{Verificação de Controlabilidade e Observabilidade}

Para poder impor polos em malha fechada, inicialmente deve-se testar se o sistema é controlável (FRANKLIN, 2010). Um sistema é dito completamente "controlável" se existir um vetor $u(t)$ que leve o sistema de qualquer estado inicial $x\left(t_{0}\right)$ a qualquer estado final $x\left(t_{1}\right)$, onde $t_{1}>t_{0}$.

Pelo critério algébrico,

$$
\mathcal{C}=\left[\begin{array}{llll}
B & A . B & \ldots & A^{n-1} \cdot B
\end{array}\right] \quad \text { Equação } 52
$$

e

$$
\operatorname{posto}(\mathcal{C})=n_{\text {posto }} \quad \text { Equação } 53
$$


Onde $\mathcal{C}$ é a matriz de controlabilidade, $n$ é a dimensão do vetor de estados e $n_{\text {posto }}$ é o resultado do posto, onde o sistema é dito completamente controlável quando $n_{\text {posto }}$ é igual a $n$. A ordem do subsistema não controlável é

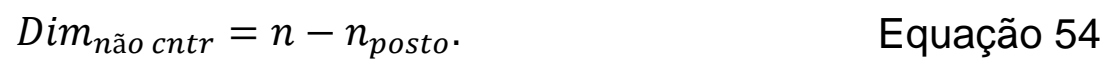

Utilizando o software MATLAB®, obtêm-se o posto da matriz $\mathcal{C}$, por meio do seguinte comando:

$$
\operatorname{rank}(\operatorname{ctrb}(A, B))=16 . \quad \text { Equação } 55
$$

Como anteriormente descrito (Equação 39), o total de variáveis de estado é 20, portanto

$$
n=20 .
$$

Equação 56

Ou seja, o sistema não é completamente controlável, tendo 4 estados não controláveis, sendo eles $0 \omega_{\text {set } i}$ de cada entrada do sistema. Entretanto isto não é um problema, tendo em vista que estes valores são impostos pelas entradas do sistema e de fato não podem ser controlados como estados.

Como será implementado um sistema de controle por retroação de estados, deve-se possuir todos os estados disponíveis para realizar o controle, o que não é o caso neste modelo. Têm-se os três estados de velocidade angular do corpo ( $P, Q$ e $R$ ), as posições lineares do corpo em relação ao sistema Terra (X, Y e Z), o ângulo de yaw $(\psi)$ e as velocidades angulares dos motores $\left(\omega_{\text {set } i}\right.$ e $\left.\omega_{\text {prop } i}\right)$. Restam ainda cinco outros estados que não são medidos diretamente (as velocidades lineares, pitch e roll).

Pode-se, todavia, aplicar técnicas para estimar os estados não medidos, utilizando um observador de estados. E similarmente ao controle dos estados, a observação de um estado só pode ser feita se este é observável, e 
para verificar se os estados são observáveis, utiliza-se a avaliação da matriz de observabilidade:

$$
\mathcal{O}=\left[\begin{array}{c}
C \\
C . A \\
\vdots \\
C . A^{n-1}
\end{array}\right]
$$

Exatamente como na avaliação da matriz de controlabilidade, 0 posto da matriz $\mathcal{O}$ indica se o sistema é completamente observável. E o comando no MATLAB® para realizar esta avaliação é:

$$
\operatorname{rank}(\operatorname{obsv}(A, C))=20
$$

Equação 58

Como o posto da matriz observabilidade é igual à dimensão $\mathrm{n}$ do sistema, o sistema em questão é completamente observável, deste modo pode-se implementar um observador de ordem completa para estimar todos os estados da planta.

Com as avaliações de controlabilidade e observabilidade efeituadas, as técnicas de controle previstas podem ser aplicadas. Sendo que ambas irão fornecer um ganho de retroação segundo a lei de controle

$$
u=-K_{\text {s ou } L Q R} \cdot\left(x-x_{\text {referências }}\right) . \quad \text { Equação } 59
$$

Onde $K_{S \text { ou } L Q R}$ é o ganho que será obtido de cada uma das técnicas que serão aplicadas nas subseções a seguir.

\subsection{Projeto do Controlador Por Alocação de Polos}

Como já provado, a planta do quadrirotor é controlável para os estados de interesse, desta forma pode-se alocar os polos, teoricamente, de forma arbitrária. Sendo definidos a partir de especificações de tempo de acomodação e percentual de sobressinal.

Cada polo, no domínio da frequência, é definido por: 


$$
s=-\xi . \omega_{n} \pm \omega_{n} \cdot \sqrt{1-\xi^{2}} i . \quad \text { Equação } 60
$$

Onde,

- $\xi$ é o fator de amortecimento.

- $\omega_{n}$ é a frequência natural.

As relações entre os parâmetros do polo e seu impacto no sobressinal e tempo de assentamento são, respectivamente para os polos dominantes:

$$
(\%) O S=e^{-\left(\xi \cdot \pi / \sqrt{1-\xi^{2}}\right)} \cdot 100 \quad \text { Equação } 61
$$

e o tempo necessário para acomodação a $2 \%$ do ponto de referencia

$$
T_{\text {acomodação }}=\frac{4}{\xi \cdot \omega_{n}} \text {. }
$$

É importante ressaltar que a Equação 60 apresenta os polos no tempo contínuo, e como o projeto de controle será criado no tempo discreto, os polos serão convertidos. Para tal, utiliza-se

$$
z=e^{s T_{S}} .
$$

Equação 63

Onde z é o polo mapeado no domínio do tempo discreto e $\mathrm{T}_{\mathrm{s}}$ é o período de amostragem, considerado como 0,02s. Este período de amostragem foi selecionado levando em consideração o tempo necessário para envio e recepção dos dados pelo canal $\mathrm{RF}$, aquisição dos sensores utilizados. Ressalta-se ainda que esta frequência de amostragem é aproximadamente dez vezes maior que a frequência natural mais alta do sistema. 
Na Tabela 9 apresentam-se as especificações de controle para os estados de interesse, que podem sofrer alterações durante os testes práticos.

\begin{tabular}{|c|c|c|c|c|}
\hline \multirow{2}{*}{$\begin{array}{c}\text { Variável de } \\
\text { Estado }\end{array}$} & \multicolumn{2}{|c|}{ Requerimentos } & \multicolumn{2}{c|}{$\begin{array}{c}\text { Polo a ser alocado } \\
\text { (discretizado) }\end{array}$} \\
\cline { 2 - 5 } & $\mathrm{T}_{\text {acomodação }[\mathrm{s}]}(\%) \mathrm{OS}$ & Real & Imaginário \\
\hline$X$ & 5,000 & 2,000 & 0,9840 & $\pm 0,0126$ \\
\hline$Y$ & 5,000 & 2,000 & 0,9840 & $\pm 0,0126$ \\
\hline$Z$ & 5,000 & 5,000 & 0,9840 & $\pm 0,0165$ \\
\hline$\phi$ & 6,000 & 1,000 & 0,9867 & $\pm 0,009$ \\
\hline$\theta$ & 6,000 & 1,000 & 0,9867 & $\pm 0,009$ \\
\hline$\psi$ & 6,000 & 1,000 & 0,9867 & $\pm 0,009$ \\
\hline
\end{tabular}

Tabela 9. Especificação da Alocação de Polos.

Utilizando o comando place() do MATLAB, extrai-se a matriz de ganhos multivariável:

$$
K_{s}=\operatorname{place}\left(A_{d}, B_{d},[\text { polos discretos }]\right) . \quad \text { Equação } 64
$$

Onde $A_{d}$ e $B_{d}$ são as matrizes de estados no domínio do tempo discreto, considerando um segurador de ordem zero e período de amostragem de 0,02s como já especificado anteriormente.

Com este ganho de realimentação selecionado, os polos do sistema em malha fechada devem coincidir com os polos especificados no projeto. É importante também ressaltar que estes polos foram impostos levando em consideração o sistema linear obtido em seções anteriores, portanto espera-se que nas simulações do sistema as respostas transitórias se aproximem das imposições realizadas, entretanto sabe-se que elas não serão exatamente iguais tendo em vista que o sistema no qual o controlador esta sendo aplicado não é idêntico ao sistema linear, mesmo nas regiões nominais definidas na linearização do sistema.

\subsection{Projeto do Controlador Utilizando $L Q R$}

No projeto de controle ótimo, busca-se um controlador que forneça o melhor desempenho possível dado um conjunto de limitações, com o 
compromisso entre desempenho e esforço de controle, o que é interessante para este trabalho tendo em vista economia de bateria.

Será aplicado nesta seção do trabalho um controlador ótimo do tipo LQR onde a energia de controle é balanceada por uma função custo com os fatores definidos pelo projeto de controle.

Para um sistema no domínio do tempo continuo a função custo $J_{L Q R}$ é definida como (FRANKLIN, 2010)

$$
J_{L Q R}=\int_{0}^{\infty}\left(x^{T} \cdot Q_{L Q R} \cdot x+u^{T} \cdot R_{L Q R} \cdot u\right) d t . \quad \text { Equação } 65
$$

Onde $Q_{L Q R}$ e $R_{L Q R}$ são as matrizes de compromisso custodesempenho, sendo elas ambas simétricas positiva-definidas.

Para definir o ganho de retroação $K_{L Q R}$ utiliza-se

$$
K_{L Q R}=R_{L Q R}{ }^{-1} \cdot B^{T} \cdot P, \quad \text { Equação } 66
$$

onde P é calculado a partir da equação de Riccati:

$$
B^{T} \cdot P+P \cdot A-P \cdot B \cdot R_{L Q R}{ }^{-1} \cdot B^{T} \cdot P+Q_{L Q R}=0 . \quad \text { Equação } 67
$$

A partir deste ponto, definem-se as matrizes de compromisso. Selecionam-se inicialmente matrizes $Q_{L Q R}$ e $R_{L Q R}$ diagonais. Os valores para estas matrizes serão definidos a partir do método de Bryson, onde cada elemento da matriz diagonal é

$$
Q_{L Q R_{i}}=\frac{1}{x_{i, \max }^{2}}
$$




$$
R_{L Q R_{i}}=\frac{1}{u_{i, \max }^{2}}
$$

Onde $x_{i, \max }$ é o valor máximo desejável do estado $x_{i}$, e similarmente $u_{i}$, max é o valor máximo desejável do controle $u_{i}$. Considera-se a utilização desta técnica apenas uma primeira iteração para gerar o controlador, adicionalmente, testes com o controlador e a planta irão gerar novos valores para os elementos da matriz.

Como anteriormente citado, para gerar as matrizes, é necessária a definição dos valores máximos dos estados e entradas do sistema, sendo eles definidos na Tabela 10 e Tabela 11. Ressalta-se que os valores para as velocidades angulares dos motores são incrementais aos seus valores nominais de operação.

\begin{tabular}{|c|c|c|c|c|c|c|c|}
\hline wset 1 & 149,30 & $\mathbf{V}$ & 2,00 & $\mathbf{X}$ & 2,00 & $\mathbf{\Psi}$ & 1,57 \\
\hline wset 2 & 149,30 & $\mathbf{W}$ & 2,00 & $\mathbf{Y}$ & 2,00 & wprop 1 & 149,30 \\
\hline wset 3 & 149,30 & $\mathbf{P}$ & 1,57 & $\mathbf{Z}$ & 1,50 & wprop 2 & 149,30 \\
\hline wset 4 & 149,30 & $\mathbf{Q}$ & 1,57 & $\mathbf{\phi}$ & 1,57 & wprop 3 & 149,30 \\
\hline U & 2,00 & $\mathbf{R}$ & 1,57 & $\boldsymbol{\theta}$ & 1,57 & wprop 4 & 149,30 \\
\hline
\end{tabular}

Tabela 10. Máximos valores de cada estado do sistema.

\begin{tabular}{|l|l|}
\hline $\boldsymbol{\omega} 1$ & 149,30 \\
\hline $\boldsymbol{\omega} 2$ & 149,30 \\
\hline $\boldsymbol{\omega 3}$ & 149,30 \\
\hline $\boldsymbol{\omega 4}$ & 149,30 \\
\hline
\end{tabular}

Tabela 11. Máximos valores de cada entrada do sistema.

Com estes valores definidos, utiliza-se da Equação 68 e Equação 69 para gerar as matrizes $Q_{L Q R}$ e $R_{L Q R}$. A partir da definição destas matrizes, utiliza-se o comando do MATLAB® para gerar o ganho do controlador LQR, sendo

$$
K_{L Q R}=\operatorname{lqrd}\left(A, B, Q, R, T_{S}\right) . \quad \text { Equação } 70
$$


Este comando já retorna o ganho para o controlador LQR no domínio do tempo discreto.

\subsection{Observador de Estados de Ordem Plena}

Tendo em vista a falta da medição direta de algumas variáveis de estado e a não ciência de condições iniciais destas, pode-se utilizar um observador de estados de ordem plena. O pré-requisito para aplicação deste método é a completa observabilidade do sistema, que já foi testada e confirmada anteriormente.

A implementação de um observador de estados se baseia na reconstrução do vetor de variáveis de estados a partir de medidas de sensores (FRANKLIN, 2010). Para identificar o vetor de estados estimados, utiliza-se $\hat{x}$ como simbologia. Portanto, as equações de estados e lei de controle se alteram para

$$
\left\{\begin{array}{c}
\dot{\hat{x}}=A \cdot \hat{x}+B \cdot u \\
y=C \cdot x+D \cdot u \\
u=-K_{s} \cdot \hat{x}
\end{array}\right.
$$

O mecanismo da observação se baseia no feedback do erro entre $y$ e $\hat{y}$ (estimado a partir do modelo dinâmico do sistema). Este erro é então introduzido no equacionamento de estados (FRANKLIN, 2010)

$$
\left\{\begin{array}{cc}
\dot{\hat{x}}=A \cdot \hat{x}+B \cdot u+L_{e s t} \cdot(y-\hat{y}) . & \text { Equação } 72 \\
\hat{y}=C \cdot \hat{x}+D \cdot u &
\end{array}\right.
$$

Onde $L_{e s t}$ é a matriz de ganho do observador e pode ser escolhida de maneira a acelerar a convergência da estimativa. Continuando a manipulação da Equação 72 tem-se

$$
\dot{\hat{x}}=A \cdot \hat{x}+B \cdot u+L_{e s t} \cdot(y-C . \hat{x}) . \quad \text { Equação } 73
$$

Por fim, o ganho do estimador é realizado de forma dual ao processo da lei de controle, e a dinâmica do estimador precisa convergir para baixo erro 
rapidamente, e para isto alocam-se os polos do observador mais rápidos que os polos do sistema em malha fechada (FRANKLIN, 2010).

De forma dual ao processo de obtenção do ganho $K_{S}$, a matriz de ganhos do observador é definida a partir da função do MATLAB®:

$$
L_{\text {est }}=\operatorname{Place}\left(A^{\prime}, C^{\prime},[\text { polos do observador }]\right)^{\prime} . \quad \text { Equação } 74
$$

Com o observador definido, o projeto de controle utilizando o observador de estados de ordem plena se conclui e simulações podem ser realizadas para validar o controle e estimação de estados no modelo dinâmico do UAV.

\subsection{Filtro de Kalman}

O filtro de Kalman é um filtro recursivo criado pelo engenheiro Rudolf Emil Kalman no ano de 1960. Este filtro tem como uma de suas principais características a estimação de estados de sistemas lineares a partir de leituras de sensores corrompidos por ruídos de processo e medição. Em termos teóricos o filtro de Kalman é um estimador para o problema Gaussiano-linearquadrático (KALMAN, 1960). A filtragem de Kalman é utilizada nos dias de hoje por diversos setores da indústria e pesquisas, estando presente na área de visão computacional, navegação, aeroespacial, entre outros. Neste trabalho o filtro de Kalman discreto será utilizado, sendo ele um algoritmo linear, recursivo, não polarizado e de ordem mínima, para a observação de estados.

Aplicando as equações do filtro de Kalman de forma algorítmica, tem-se a sequência para a implementação do filtro, que se repete a cada instante de amostragem (GREWAL, 1993):

1. Calculo dos estados estimados a priori:

$$
\hat{x}^{-}(k)=A_{d} \cdot \hat{x}(k-1)+B_{d} \cdot u(k-1) . \quad \text { Equação } 75
$$


2. Calculo da covariância dos resíduos de estimação a priori:

$P^{-}(k)=A_{d} \cdot P(k-1) \cdot A_{d}^{T}+Q_{\text {kalman }}$.

Equação 76

3. Obtenção do ganho de Kalman:

$$
K(k)=P^{-}(k) \cdot C_{d}{ }^{T} \cdot\left[C_{d} \cdot P^{-}(k) \cdot C_{d}{ }^{T}+R_{\text {kalman }}\right]^{-1} \cdot \quad \text { Equação } 77
$$

4. Estimação do vetor de estados:

$$
\hat{x}(k)=\hat{x}^{-}(k)+K(k) \cdot\left[y(k)-C_{d} \cdot \hat{x}^{-}(k)\right] . \quad \text { Equação } 78
$$

5. E finalmente o calculo da covariância dos resíduos de estimação:

$$
P(k)=\left[I-K(k) \cdot C_{d}\right] \cdot P^{-}(k) . \quad \text { Equação } 79
$$

Onde o índice $\mathrm{k}$, representa $\mathrm{o}$ instante de amostragem atual e as matrizes de $Q_{\text {kalman }}$ (matriz simétrica semi-definida positiva) e $R_{\text {kalman }}$ (matriz simétrica definida positiva) são as matrizes de covariância dos ruídos de processo e medição, respectivamente. A determinação destas matrizes é comumente realizada de forma empírica, sendo realizadas de forma iterativa com os ensaios no modelo. 


\section{Capítulo 5. Simulação}

A partir do projeto de controle e o modelo dinâmico não-linear definidos em seções anteriores, simulações sobre os modelos são realizadas para validar o controle sobre o modelo e fornecerem parâmetros iniciais para os ensaios com o modelo real. Inicialmente, os modelos dinâmicos são inseridos no MATLAB/Simulink® para análise e simulação. Validando o controle linear por alocação de polos em conjunto com um observador de estados pleno e o controlador LQR em conjunto com o filtro de Kalman. Adicionalmente, serão introduzidos os ruídos de processo e medição previamente aferidos diretamente da planta real para verificação de estabilidade e desempenho com a presença de tais efeitos.

As simulações serão realizadas utilizando as seguintes referências de posições lineares:

- Um degrau de +0,5m no tempo 30 s será acionado como referência para a posição linear Z;

- Um degrau de +0,5m no tempo 60 s será acionado como referência para a posição linear $\mathrm{X} \mathrm{e} \mathrm{Y \text {; }}$

- Todas as referências dos estados restantes serão mantidas nulas durante as simulações.

O comportamento do UAV será avaliado e comparações serão feitas entre os dois métodos de controle e observação de estados selecionados.

\subsection{Construção do Modelo no MATLAB/Simulink®}

Para realizar as simulações da planta e controle, inicialmente constrói-se um modelo no MATLAB/Simulink® para a verificação do desempenho das técnicas de controle. Neste modelo, os dois principais blocos são o bloco das equações dinâmicas que regem o corpo e o bloco de controle do sistema. Na Figura 48 observa-se a organização do diagrama principal. 


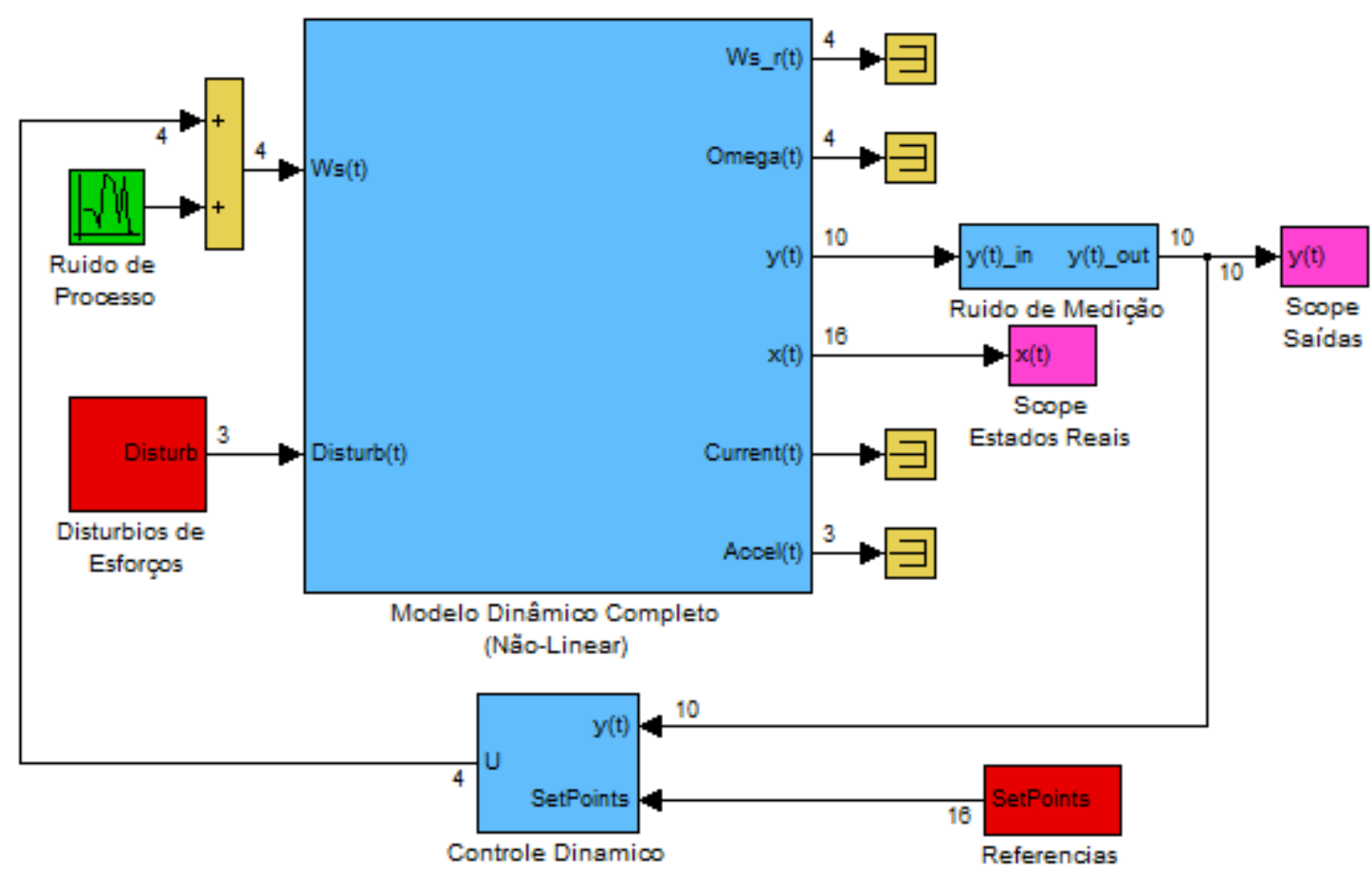

Figura 48. Diagrama principal no MATLAB/Simulink® para o modelo e controle.

Além dos blocos principais, outros blocos auxiliares também são exibidos na Figura 48, sendo eles os blocos de ruídos de processo e medição, um bloco de distúrbios de esforços, o bloco de referência para as variáveis de estados e blocos para visualização das variáveis de interesse.

No bloco da dinâmica do UAV estão ainda inclusos parâmetros adicionais como o vetor de saída $\mathrm{y}(\mathrm{t})$ para a implementação do controle e o consumo de corrente do UAV estimado a partir de uma tabela lookup. O conteúdo do bloco da dinâmica do UAV pode ser observado na Figura 49. 


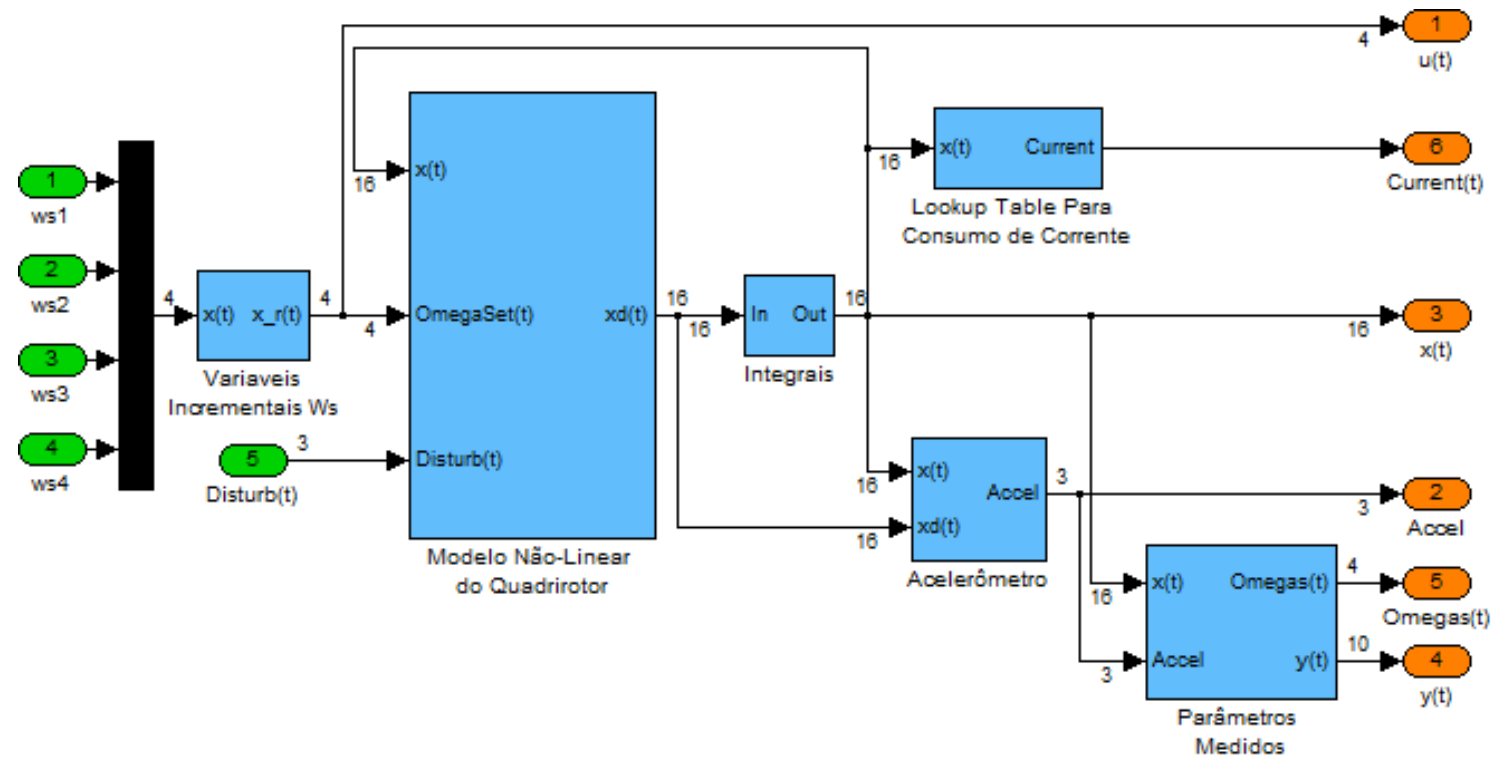

Figura 49. Bloco da dinâmica do UAV.

O bloco de controle por sua vez, possui o ganho de controle e um bloco para o observador de estados e filtro de Kalman, na Figura 50 observa-se em detalhe o conteúdo do bloco de controle.

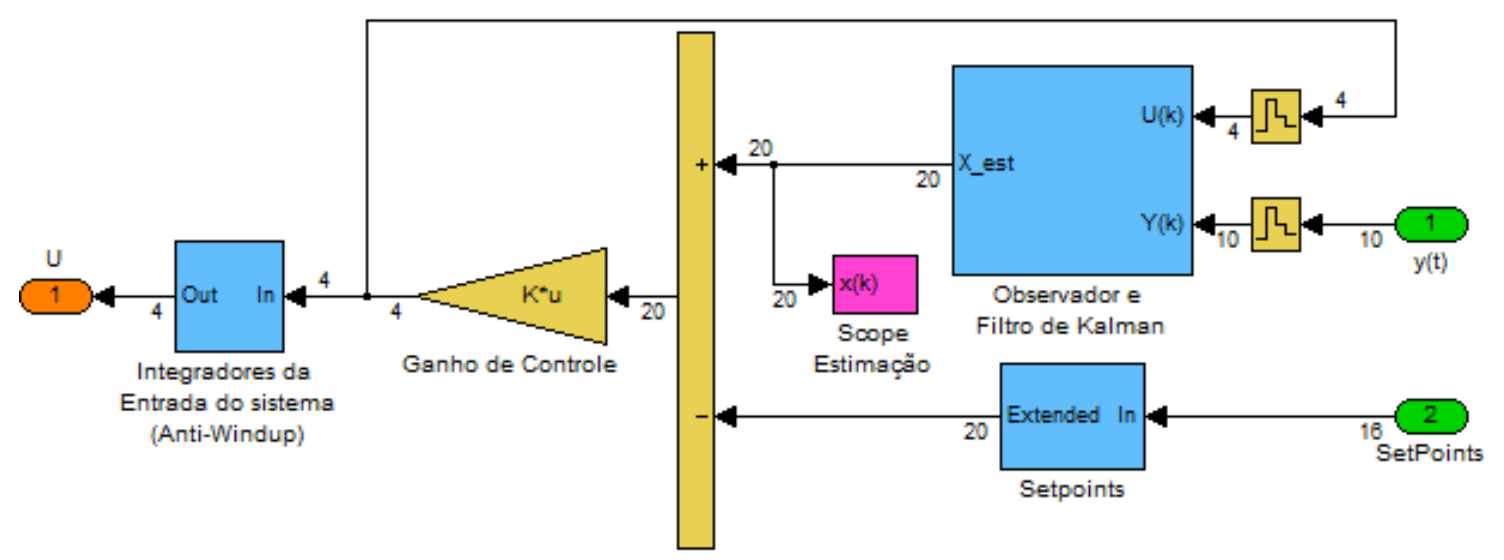

Figura 50. Diagrama do bloco de controle do UAV.

Observa-se adicionalmente que o integrador de entrada do sistema descrito na seção de modelagem dinâmica do UAV se encontra no bloco de controle, dado que eles não estão fisicamente inclusos no modelo do corpo. Ressalta-se ainda que para os ensaios, o ganho de controle será alterado para os valores gerados a partir do LQR ou alocação de polos. 
Finalmente, o bloco do observador de estados de ordem plena e filtro de Kalman fornece os estados estimados para atuação de controle. O tipo de observador é selecionado por uma chave manual, como ilustrado na Figura 51.

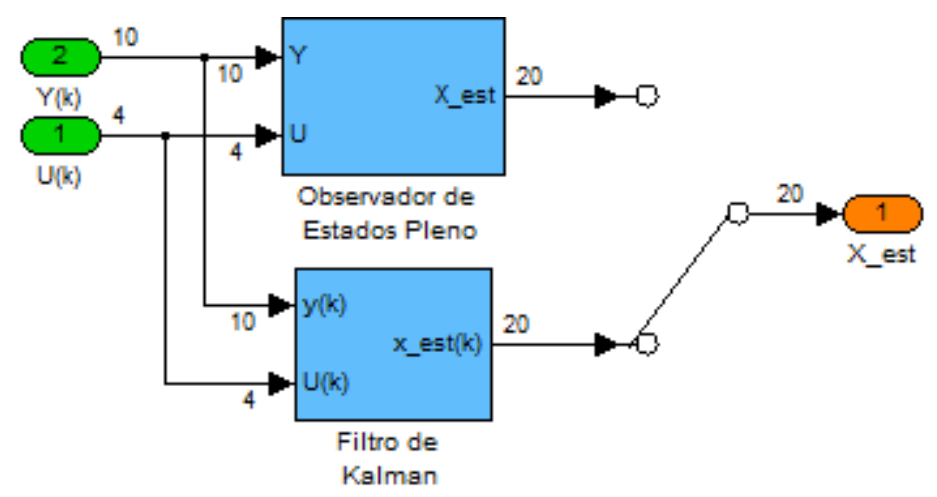

Figura 51. Diagrama para o bloco de observação de estados.

5.1. Simulação do Controle por Alocação de Polos com Observador de Estados de Ordem Plena

Tendo o diagrama para simulações definido, iniciam-se as simulações da implementação do controle por alocação de polos em conjunto com um observador de estados de ordem plena.

A partir dos requerimentos definidos anteriormente para 0 desempenho do controlador, simulações são realizadas. Ilustra-se na Figura 52 a resposta para referências de posição linear do corpo. 

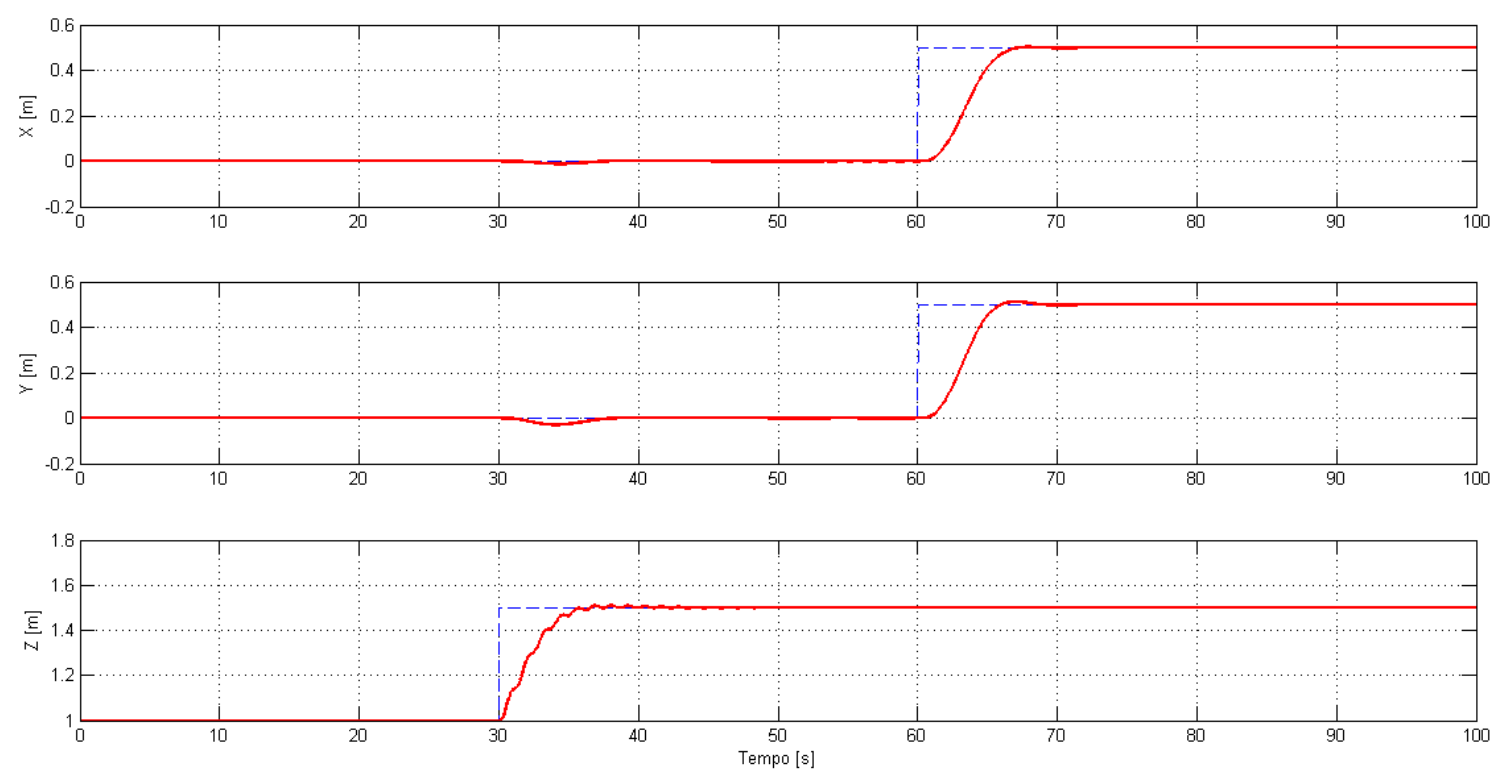

Figura 52. Referências e respostas para as posições lineares do UAV, utilizando controle por alocação de polos.

A partir das respostas observadas nos gráficos da Figura 52 observa-se que a imposição dos polos dominantes do sistema linearizado foi bem sucedida, mantendo o sobressinal e tempo de acomodação aproximadamente equivalente ao projeto de controle.

Adicionalmente, ilustra-se na Figura 53 o comportamento das atitudes do corpo para as mesmas referências utilizadas nos gráficos da Figura 52. 

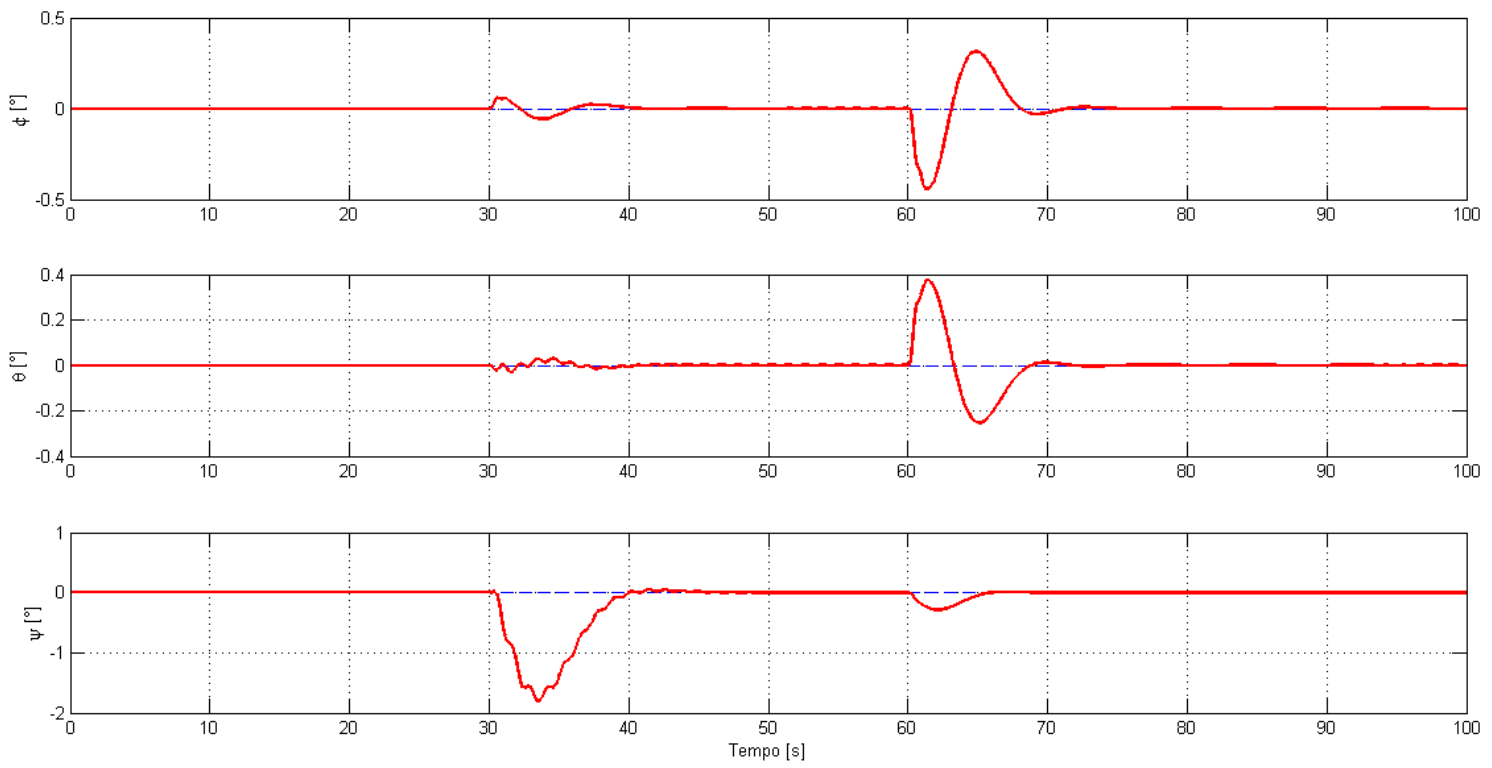

Figura 53. Referências e respostas para as posições angulares do UAV, utilizando controle por alocação de polos.

Finalmente, observa-se na Figura 54 os esforços de controle de cada rotor do UAV para a simulação executada.
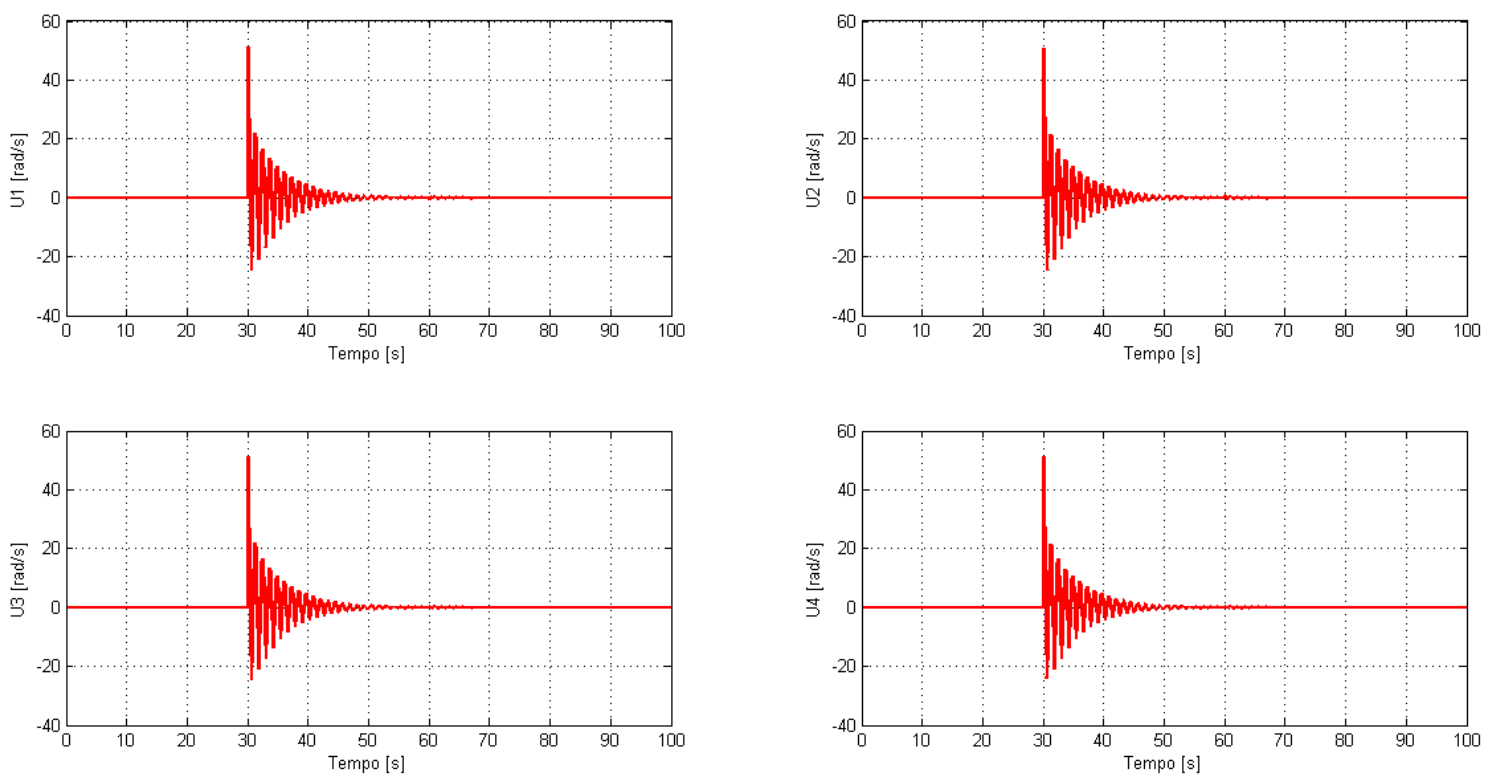

Figura 54. Esforços de controle nos rotores, utilizando alocação de polos.

Como o sistema foi linearizado para implementação do controle, a saída do controlador representa o valor incremental à rotação nominal dos motores $\overline{\omega_{\text {set } \iota}}$, que é definida a partir do empuxo necessário de cada hélice 
para manter o UAV em equilíbrio estático no ar, calculado na Equação 42. Interpolando os valores da Tabela 2 para cada motor, extraem-se as velocidades angulares para cada rotor,

$$
\left[\begin{array}{l}
\overline{\omega_{\text {set } 1}} \\
\frac{\omega_{\text {set } 2}}{\omega_{\text {set } 3}} \\
\overline{\omega_{\text {set } 4}}
\end{array}\right]=\left[\begin{array}{l}
584 \\
579 \\
586 \\
581
\end{array}\right] .
$$

Verifica-se adicionalmente o perfil de consumo de corrente utilizando o controle por alocação direta de polos, podendo ser observado na Figura 55.

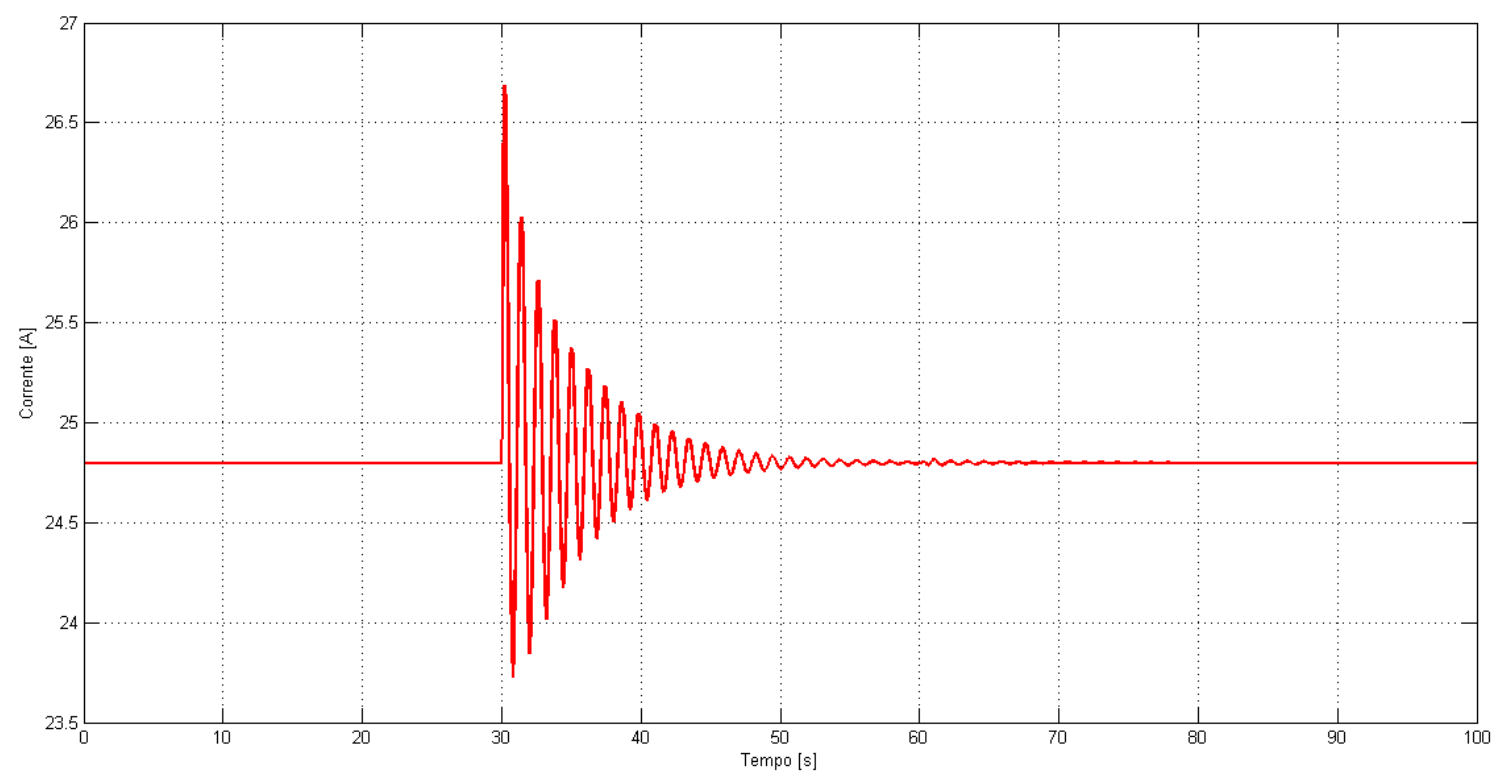

Figura 55. Consumo de corrente utilizando controle por alocação de polos.

Para a simulação realizada, utilizou-se o ganho de controle gerado pela imposição de polos descrita anteriormente, em conjunto com um observador de ordem plena com sua dinâmica definida como três vezes mais rápida que os polos impostos.

\subsection{Simulação do Controle LQR com Filtro de Kalman}

Em sequencia às simulações com o controlador por imposição de polos, realiza-se a simulação utilizando o controlador LQR em conjunto com o filtro de Kalman. As mesmas referências impostas na simulação com o 
controlador por alocação de polos serão utilizadas, visando manter consistência para comparar o desempenho de cada método.

Na Figura 56, um gráfico com as respostas para as referências de posições lineares impostas.
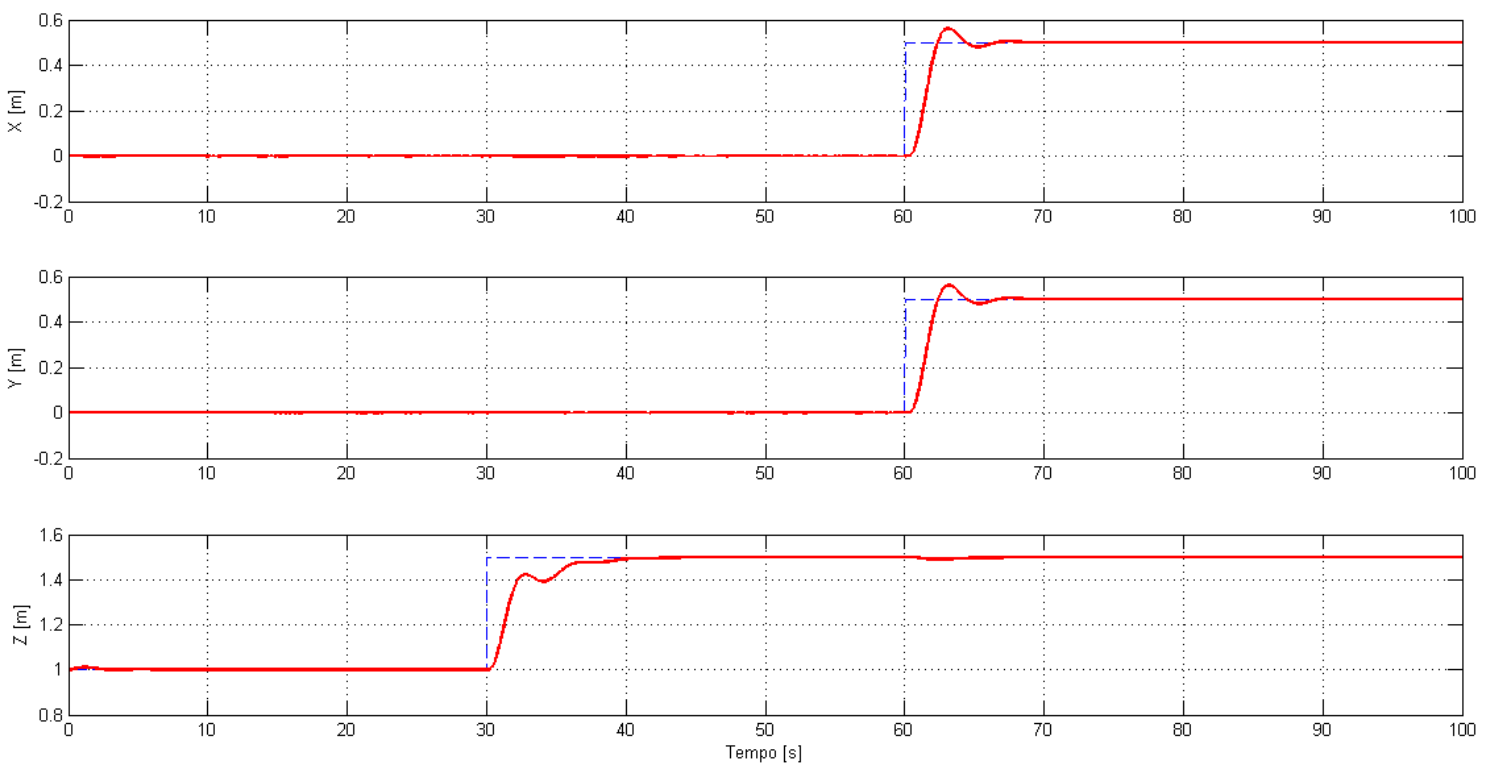

Figura 56. Referências e respostas para as posições lineares do UAV, utilizando controle LQR.

Observa-se na Figura 56 a estabilização do sistema utilizando o LQR. Adicionalmente, comparando-se com a Figura 52, o controlador LQR não permite a movimentação do corpo nas direções $X$ e $Y$ como o que ocorre com 0 controlador por alocação de polos a partir do tempo 30s quando o corpo se movimenta na direção Z. Por outro lado, os sobressinais nas direções $X$ e $Y$ utilizando LQR, são elevados quando comparados aos resultados do controlador por imposição direta de polos. A trajetória do corpo nas direções $X$, Y e Z também são distintas, especialmente na direção $Z$, onde ocorre uma oscilação de baixa frequência ao se aproximar da referência, causando o corpo a possuir um período de acomodação maior quando comparado com o controle por alocação direta de polos.

llustra-se na Figura 57 a resposta das atitudes do corpo na implementação do controle LQR. 

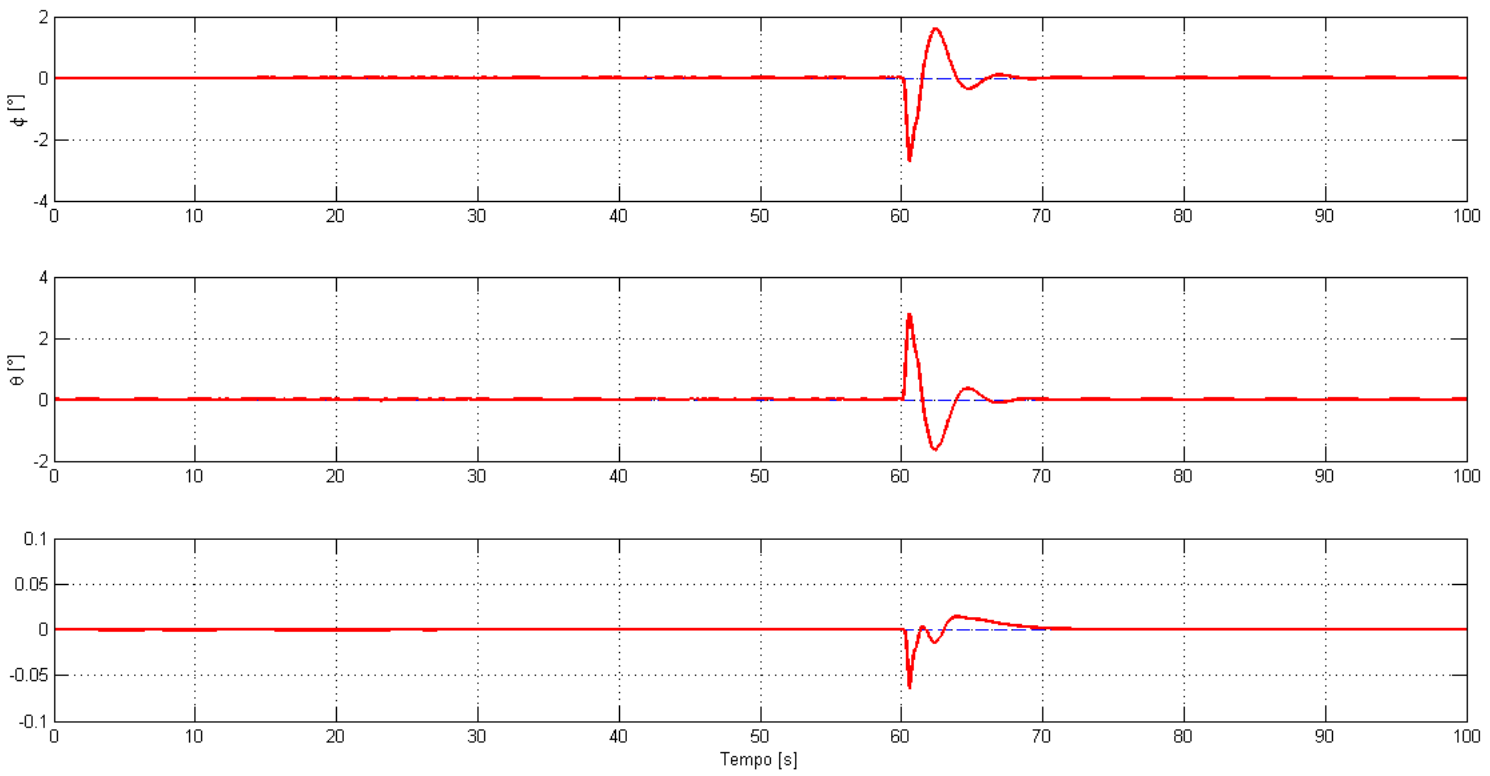

Figura 57. Referências e respostas para as posições angulares do UAV, utilizando controle LQR.

Como já mencionado anteriormente, pode-se observar que as atitudes também não se alteram no tempo 30s enquanto o corpo se movimenta na direção $Z$, consequentemente o UAV não se movimenta nas direções $X$ e $Y$.

Finalmente, na Figura 58 pode-se observar os esforços de controle gerados para movimentar o UAV.
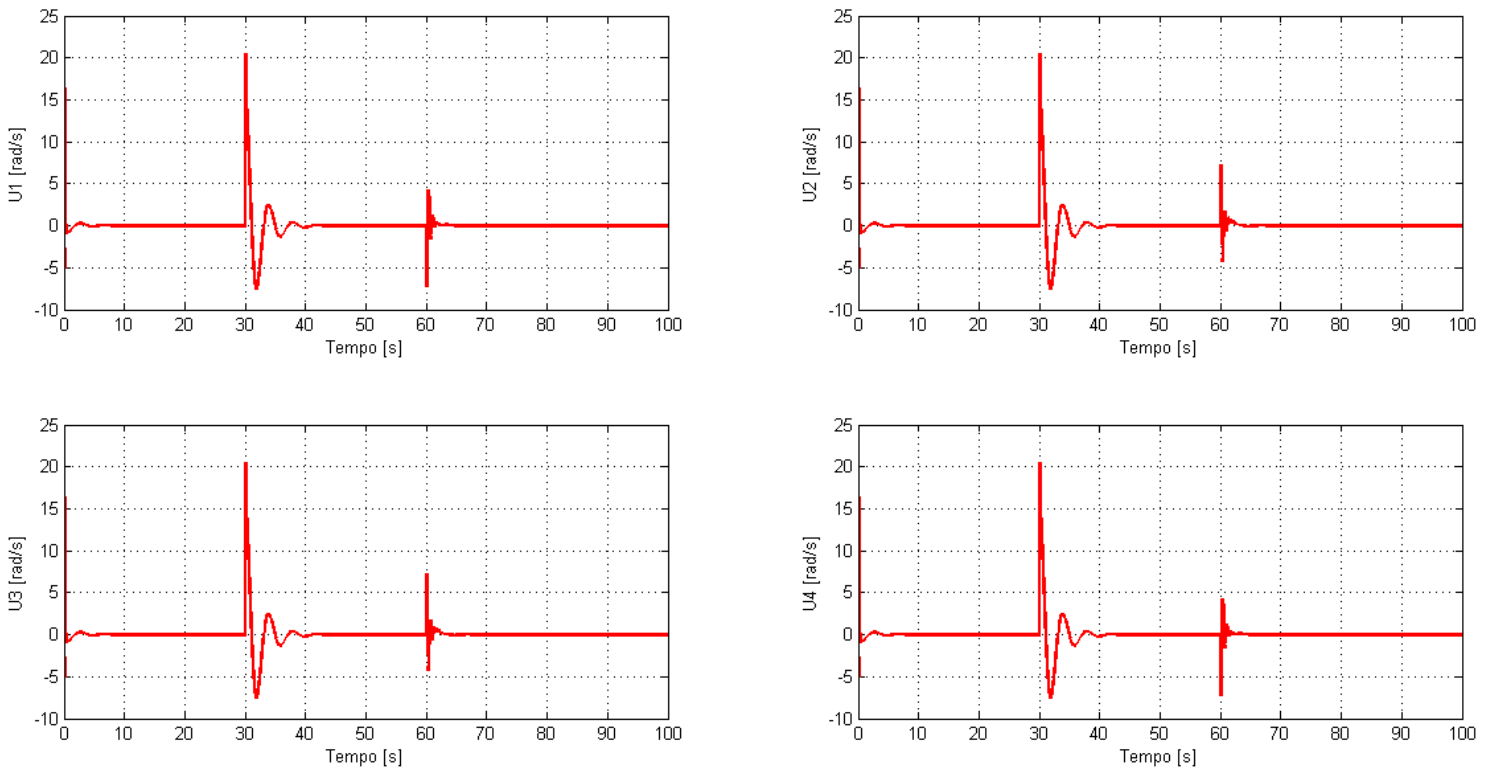

Figura 58. Esforços de controle nos rotores, utilizando LQR. 
Comparando os gráficos da Figura $58 \mathrm{com}$ a Figura 54, observa-se uma diferença significativa no esforço de controle aplicado, sendo o controlador LQR mais eficiente para movimentar o UAV.

Nas simulações o filtro de Kalman foi implementado utilizando $Q_{\text {kalman }[i, i]}=10^{-2}$ e $R_{\text {kalman }[i, i]}=10^{-5}$ para todos os elementos da diagonal principal das respectivas matrizes.

Após a comparação dos resultados dos dois métodos de controle, observou-se que o controlador LQR utilizando o filtro de Kalman, consumirá menos bateria do UAV, tendo em vista sua atuação nos motores. O perfil de consumo utilizando LQR pode ser observado na Figura 59.

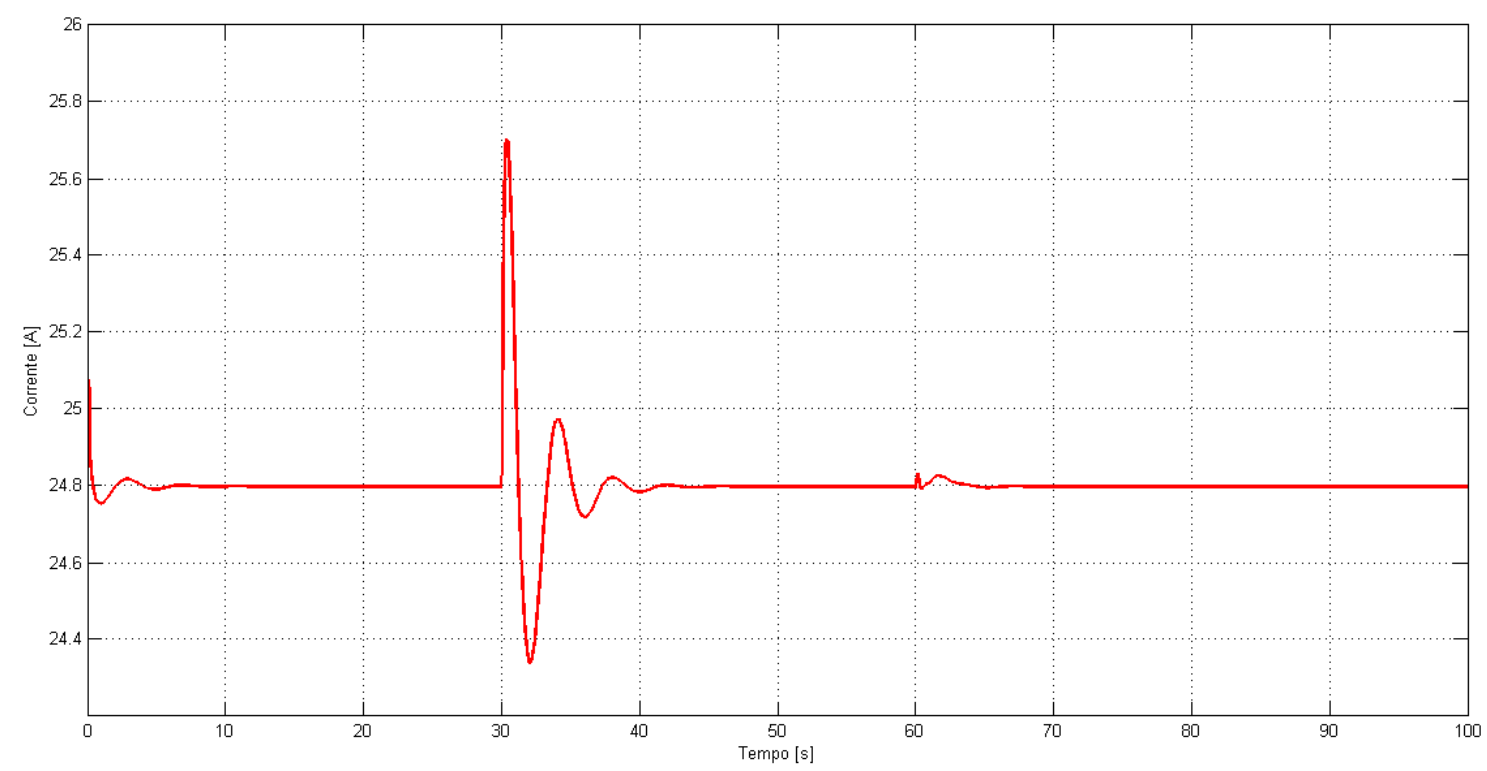

Figura 59. Consumo de corrente utilizando controle LQR.

Observou-se ainda que o controle utilizando LQR, produz variações mais suaves dos estados, quando comparado à implementação da imposição direta de polos realizada neste trabalho.

Portanto, a partir das comparações realizadas, o controlador selecionado para aplicação na planta real foi o LQR em conjunto com o filtro de Kalman. 


\subsection{Simulação do Controle $L Q R$ com Introdução de Ruídos} de Medição e Processo

Com o controlador LQR selecionado, iniciam-se simulações introduzindo ruídos de medição e processo.

Para definir as características de tais perturbações, ensaios foram realizados utilizando o quadrirotor com os motores ligados liminarmente abaixo das velocidades nominais para decolagem e aferindo os valores dos sensores para verificar seu comportamento com as vibrações geradas pelos motores, bem como interferências elétricas e/ou eletromagnéticas do circuito eletrônico. $\mathrm{Na}$ Figura 60 pode-se observar uma imagem da configuração do ensaio

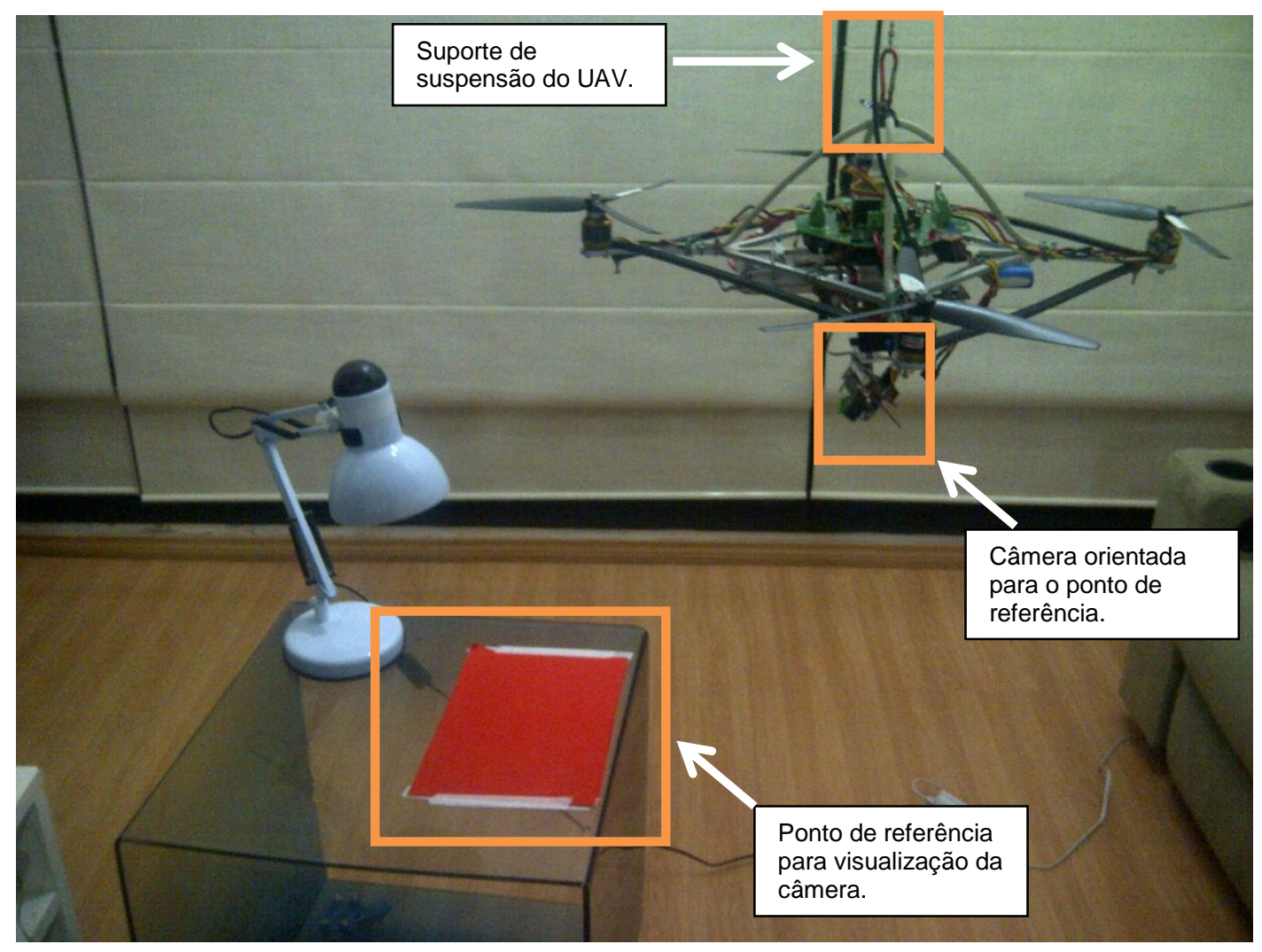

Figura 60. Configuração do quadrirotor para os ensaios de checagem de ruídos de medição.

Observou-se em todos os sensores a presença de ruídos brancos com média zero, sendo os acelerômetros os mais afetados pela rotação dos 
motores. Para a câmera que faz o sensoriamento das posições lineares, o período de amostragem é maior, portanto o ruído possui frequência menor, este sensor também possui menores amplitudes de ruído.

A partir dos ensaios, foram extraídas as medidas de variância dos sinais dos sensores utilizando um filtro passa-alta visando eliminar as movimentações involuntárias do corpo durante o teste.

Observa-se na Figura 61 a variância dos sinais dos acelerômetros.

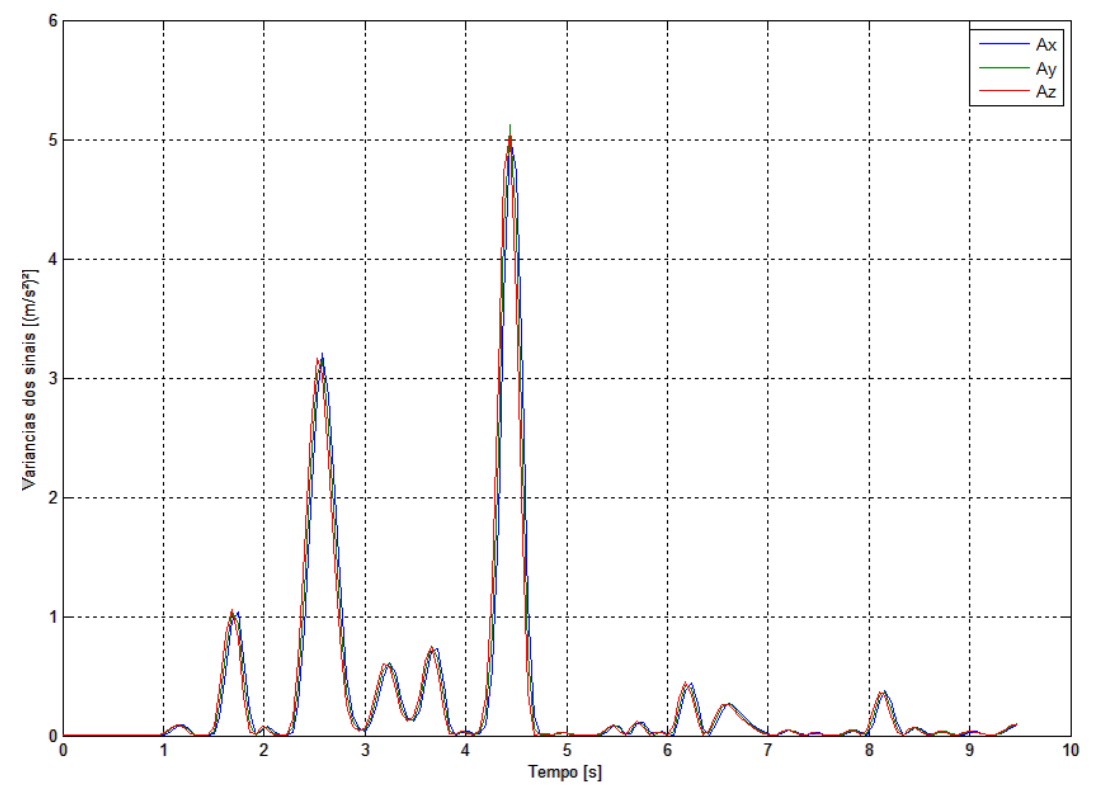

Figura 61. Variâncias instantânea dos sinais mensurados pelo acelerômetro.

Na Figura 62 observa-se também a variância dos sinais medidos pelo giroscópio. 


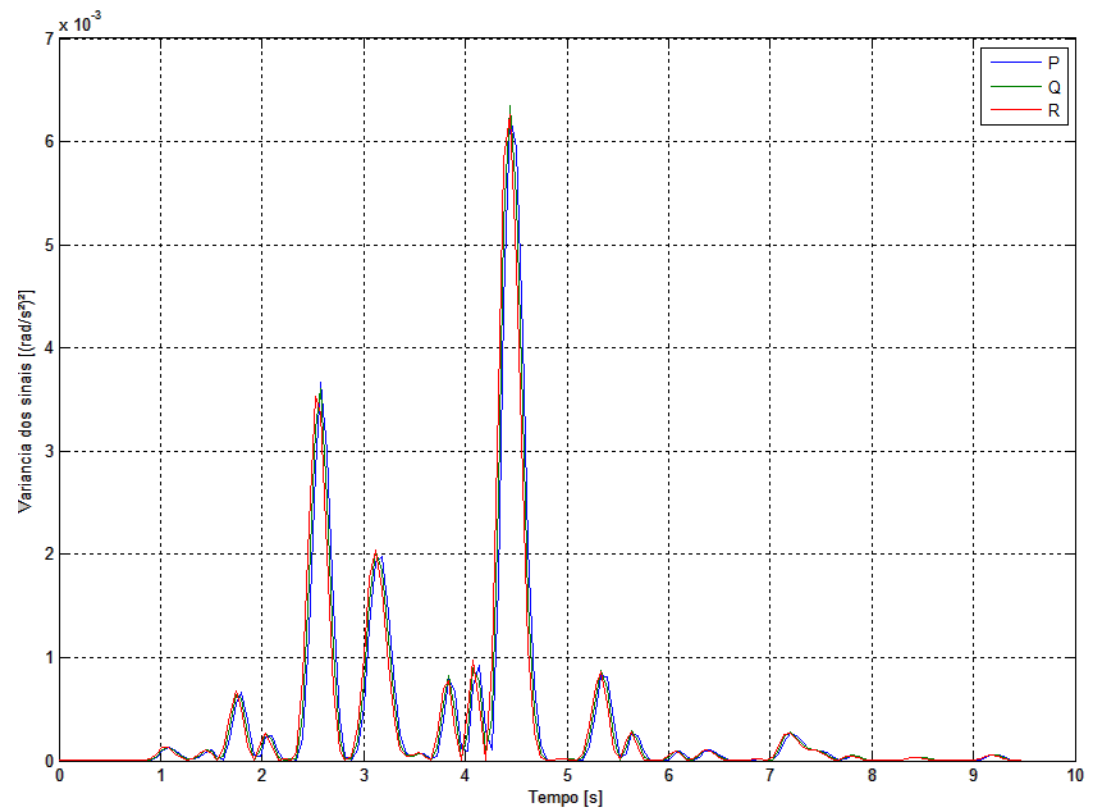

Figura 62. Variâncias instantânea dos sinais mensurados pelo giroscópio.

llustra-se na Figura 63 as variâncias extraídas das medidas de posição linear.

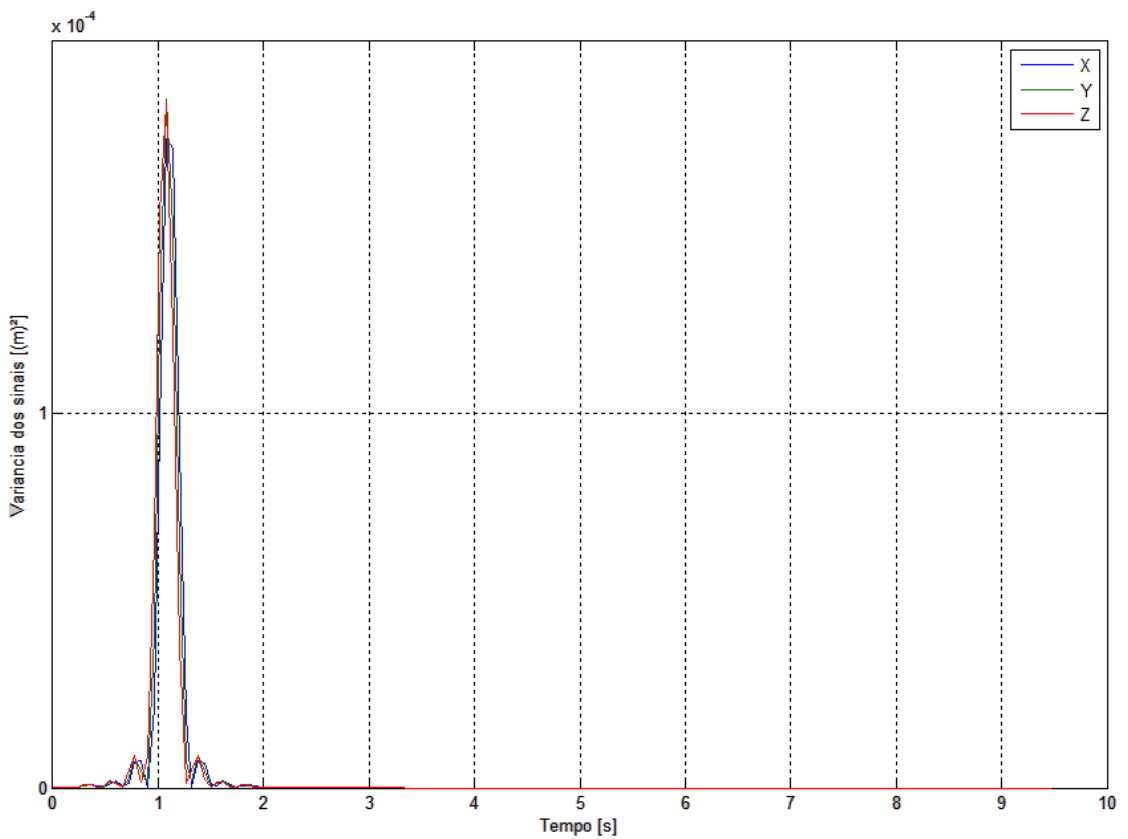

Figura 63. Variâncias instantânea dos sinais de posição linear.

Finalmente, na Figura 64 pode-se observar a variância do sensor magnetômetro. 


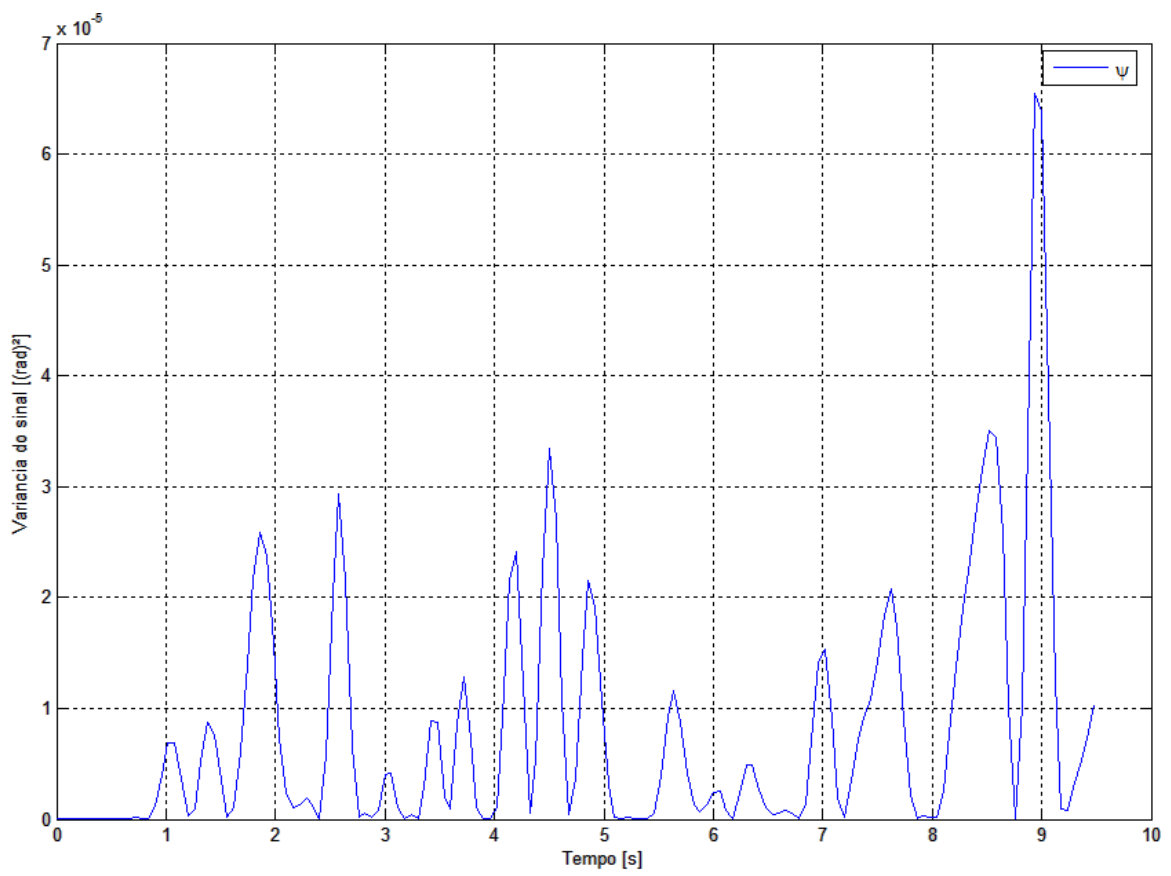

Figura 64. Variância instantânea do sinal do sensor magnetômetro.

Sumarizando os valores das variâncias instantâneas dos ruídos de cada sensor e levando em consideração os piores casos no tempo amostrado, tem-se:

- Acelerômetros: $5,2\left[\mathrm{~m} / \mathrm{s}^{2}\right]^{2}$;

- Giroscópios: $6,5 \cdot 10^{-3}[\mathrm{rad} / \mathrm{s}]^{2}$;

- Câmera (sensor de posição linear): $2.10^{-4}[\mathrm{~m}]^{2}$;

- Magnetômetro: $7.10^{-5}[\mathrm{rad}]^{2}$.

Nota-se que para as medidas dos acelerômetros, as variâncias dos sinais são discrepantes com relação ao restante dos sinais, durante os ensaios observou-se que os acelerômetros são fundamentalmente afetados pelas vibrações dos motores.

Compondo o bloco de introdução de ruídos de medição presente no diagrama na Figura 48, observa-se o diagrama do bloco de ruídos de medição na Figura 65. 


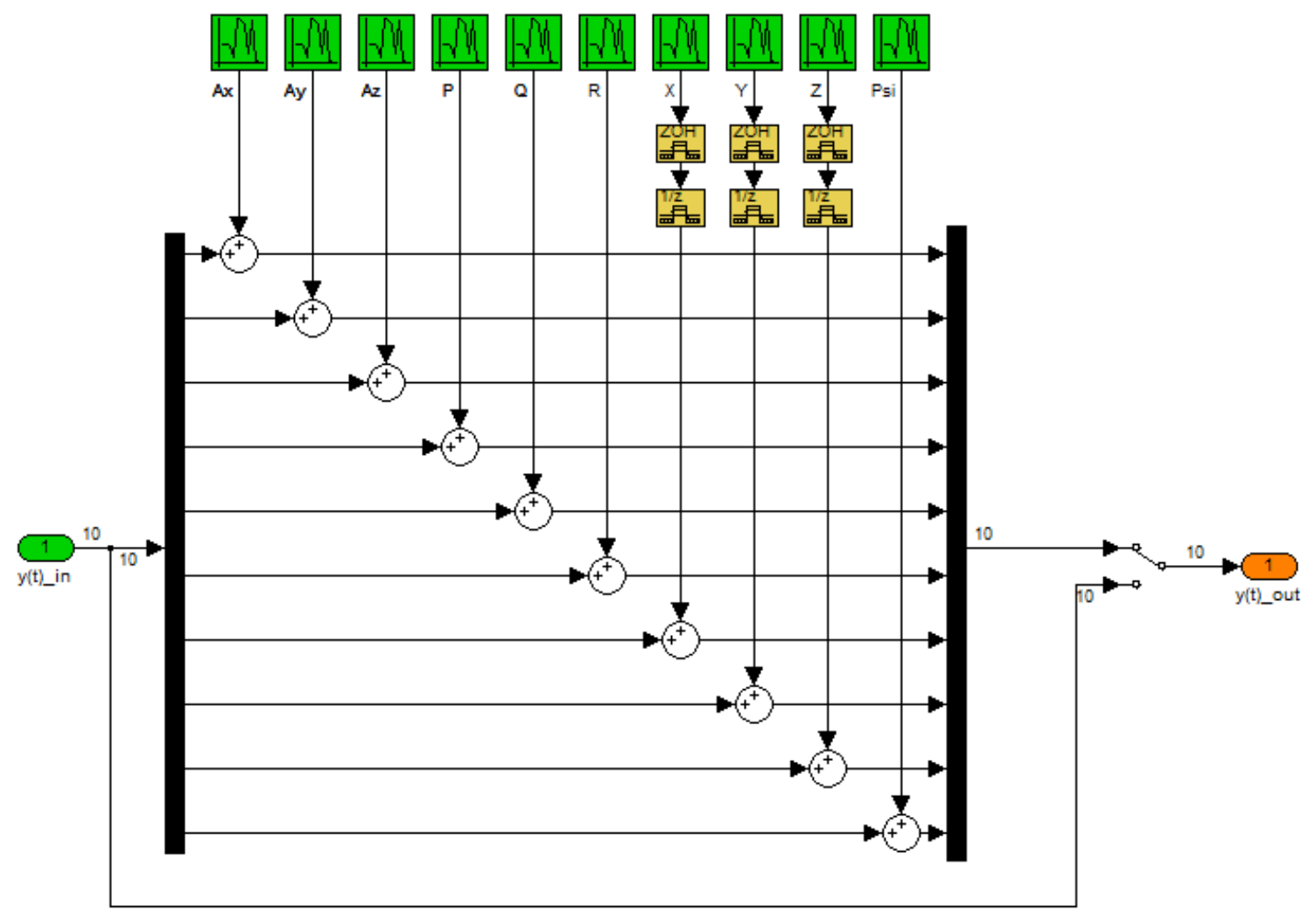

Figura 65. Diagrama do bloco de introdução de ruídos de medição no sistema.

Para o ruído de processo, foi selecionado o valor de $10^{-2}[\mathrm{rad} / \mathrm{s}]^{2}$, tendo em vista que esta interferência não pode ser experimentalmente medida.

Foram realizadas simulações com a introdução dos ruídos definidos e a estabilização do sistema não foi possível, mesmo com a manipulação dos valores definidos para os ruídos no filtro, onde o filtro de Kalman não foi capaz de filtrar suficientemente os sinais graças aos elevados ruídos presentes nos sensores acelerômetros.

Visando contornar esta situação, decidiu-se acrescentar uma alteração na composição mecânica da aeronave, com a inclusão de um amortecedor na placa eletrônica do UAV. O damper modelo Shore 38 utilizado pode ser visualizado na Figura 66. 


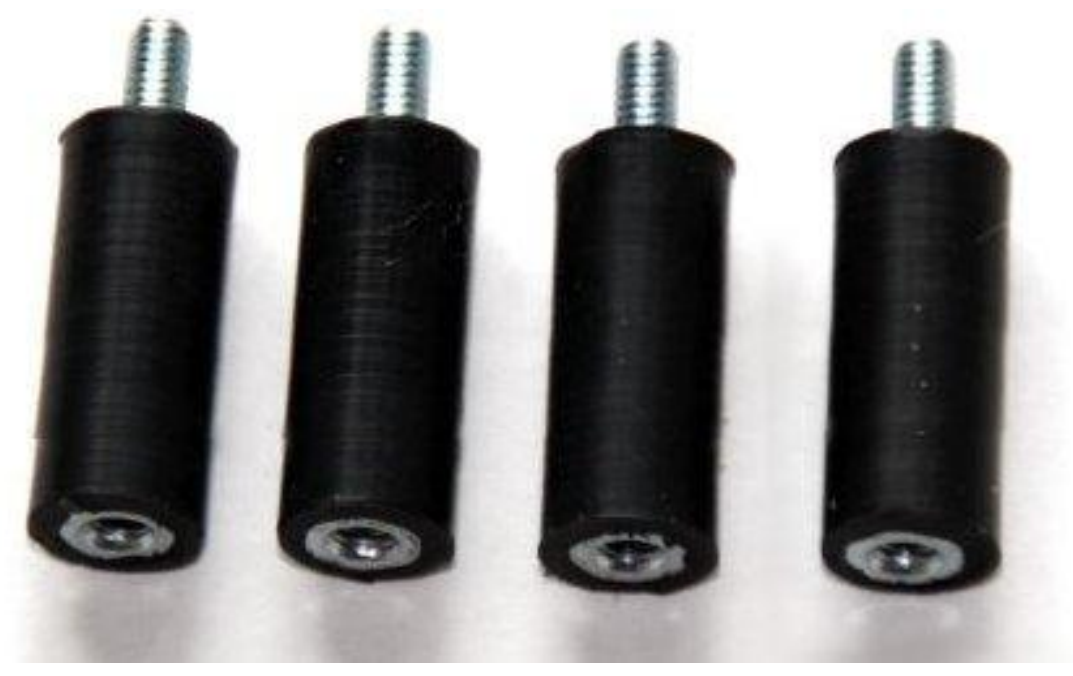

Figura 66. Amortecedor de vibração Shore 38.

Com a inclusão deste amortecedor, obteve-se uma considerável melhora nos ruídos de medição dos sensores, sendo os novos valores experimentados:

- Acelerômetros: $0,8\left[\mathrm{~m} / \mathrm{s}^{2}\right]^{2}$;

- Giroscópios: $8.10^{-4}[\mathrm{rad} / \mathrm{s}]^{2}$;

- Câmera (sensor de posição linear): $2.10^{-4}[\mathrm{~m}]^{2}$;

- Magnetômetro: $1,3 \cdot 10^{-5}[\mathrm{rad}]^{2}$.

As simulações com a presença dos ruídos introduzidos e com a inclusão do amortecedor são realizadas aplicando as mesmas referências das simulações anteriores. Inicialmente verificam-se as posições lineares. A resposta para as posições lineares pode ser observada na Figura 67. 

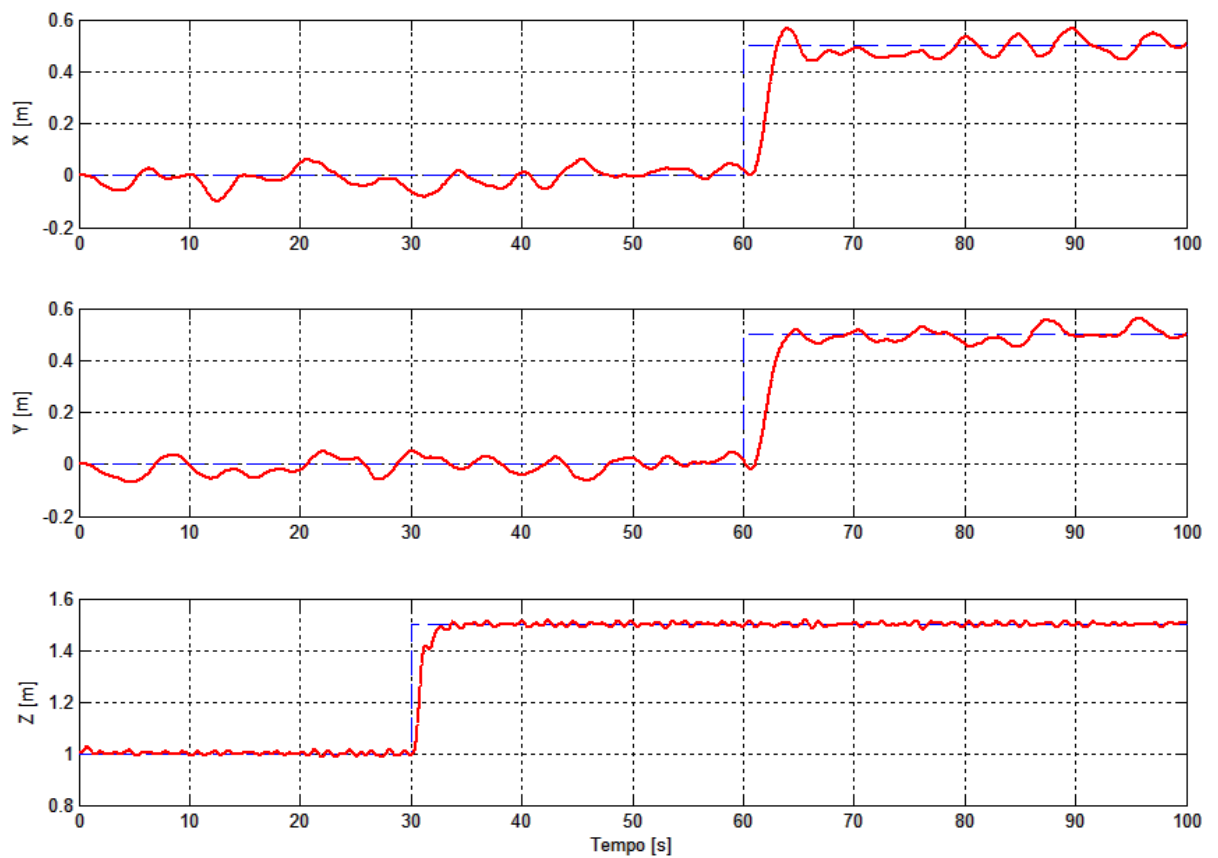

Figura 67. Referências e respostas para as posições lineares do UAV, com presença de ruídos de medição e processo.

Observa-se no gráfico da Figura 67, que o sistema permanece estável e capaz de rastrear as referências de posições lineares, onde nas direções $\mathrm{X}$ e $\mathrm{Y}$ o corpo não se desloca além de $8 \mathrm{~cm}$ da referência, em regime. $\mathrm{Na}$ direção $Z$, o corpo não se desloca além de $3 \mathrm{~cm}$ da referência, em regime.

$\mathrm{Na}$ Figura 68 se encontram os gráficos referentes aos deslocamentos angulares do corpo, onde se observa também os efeitos do ruído, onde o controlador juntamente com o filtro de Kalman, são capazes manter a estabilidade do corpo. 

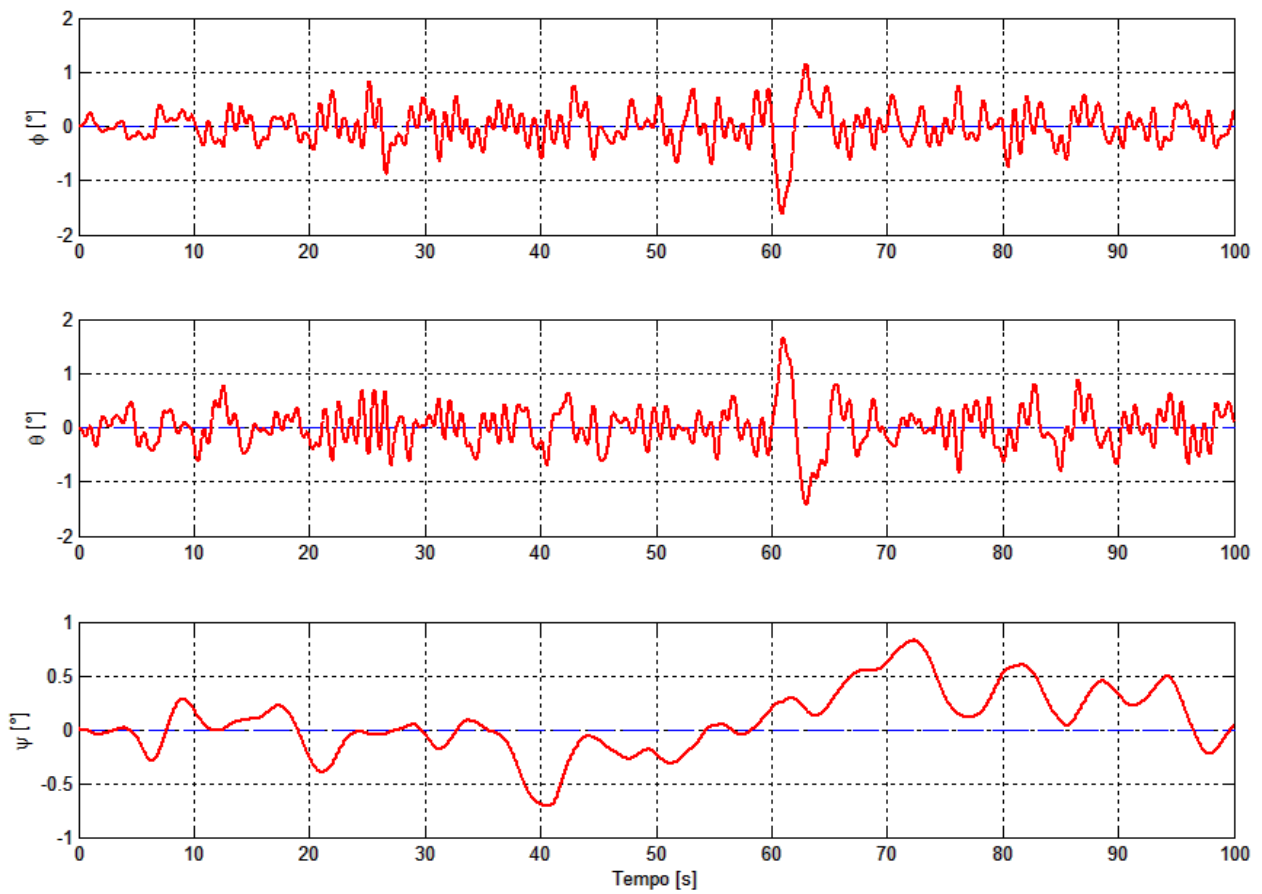

Figura 68. Referências e respostas para as posições angulares do UAV, com presença de ruídos de medição e processo.

As variações das velocidades angulares dos motores podem ser observadas na Figura 69.
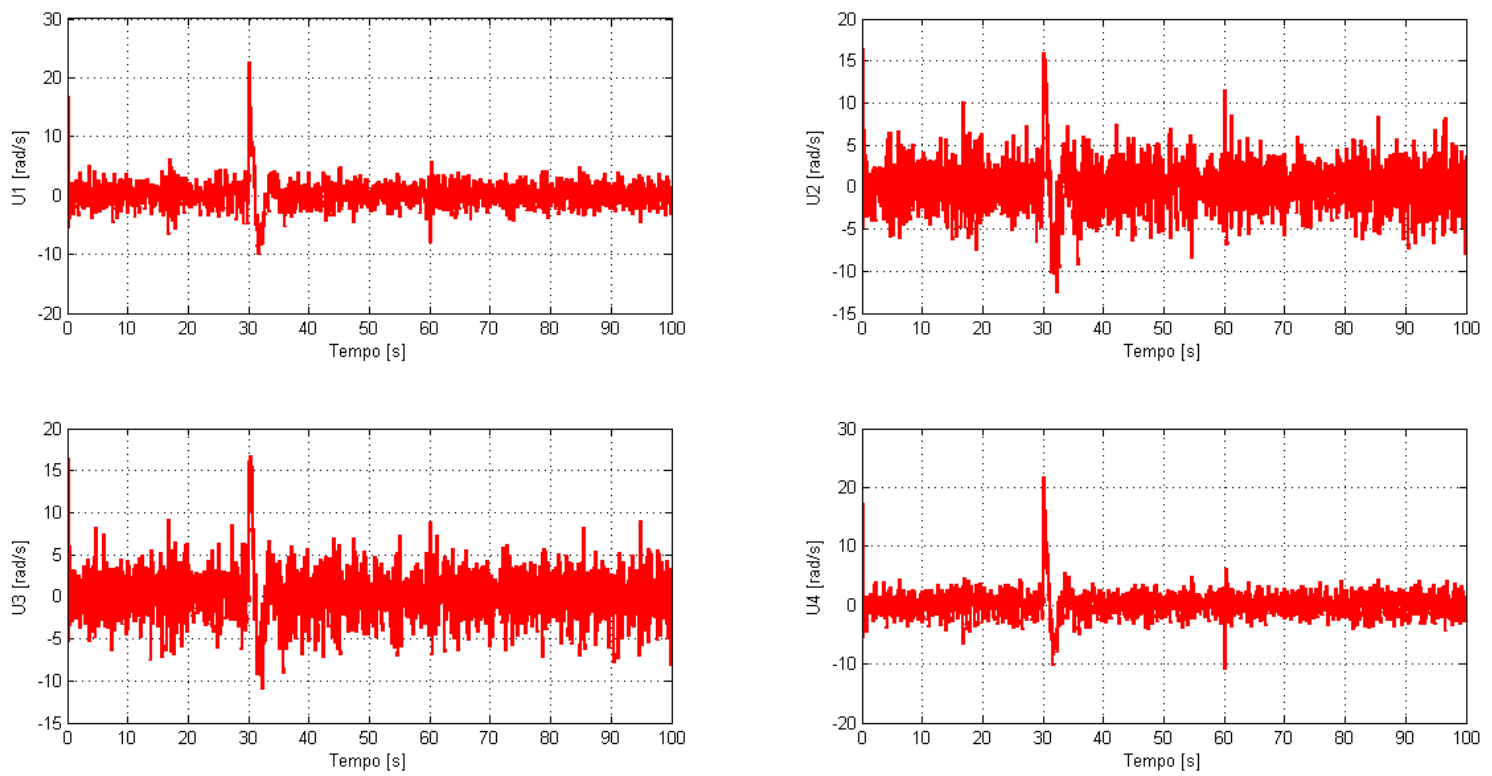

Figura 69. Esforços de controle nos rotores, com a presença de ruídos de medição e processo. 
Observa-se ainda, na Figura 70, a corrente drenada pelo sistema com a presença dos ruídos.

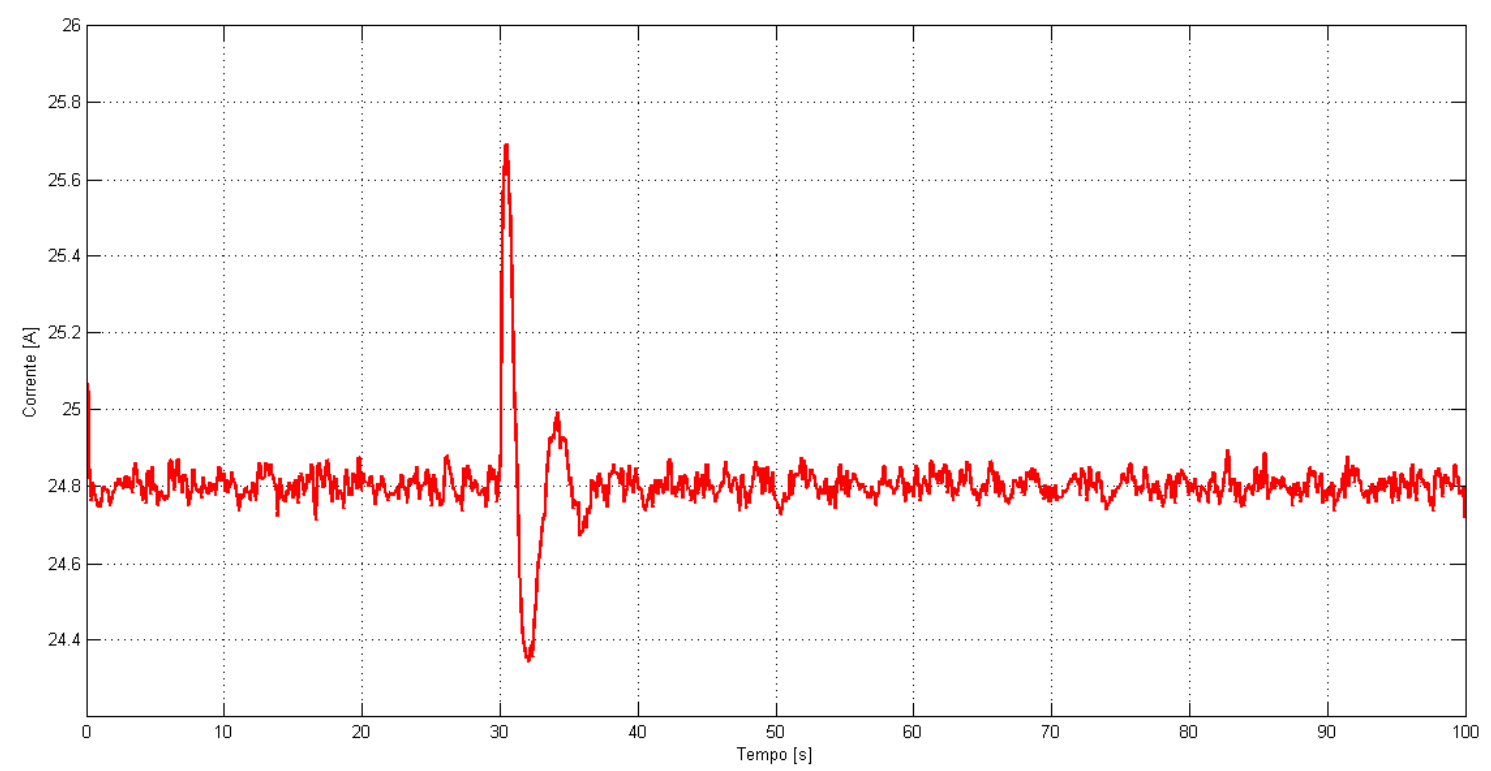

Figura 70. Consumo de corrente do UAV, com a presença de ruídos de medição e processo.

A partir dos gráficos apresentados nesta subseção, é possível afirmar que o controlador LQR selecionado, em conjunto com o filtro de Kalman implementado, é capaz de absorver os ruídos de medição e processo, filtrandoos de maneira a manter a estabilidade do sistema dentro de níveis aceitáveis de desempenho.

Com o sistema inteiramente simulado, e com presença de interferências do sistema, pode-se partir para a implementação e testes práticos do controlador e filtro de Kalman no sistema real. 


\section{Capítulo 6. Implementação e Resultados na Planta}

\section{Real}

Serão abordados nesta seção os ensaios práticos no UAV, para validação do controle e filtro de Kalman selecionados na planta real do sistema. A planta será ensaiada utilizando a técnica HIL (Hardware in the Loop Hardware no Loop), onde o controlador será implementado no software MATLAB/Simulink®, recebendo os dados dos sensores via comunicação RF e enviando os comandos para as velocidades angulares dos motores do UAV. $\mathrm{Na}$ Figura 71 ilustra-se a organização do sistema de controle, planta e comunicação de dados.

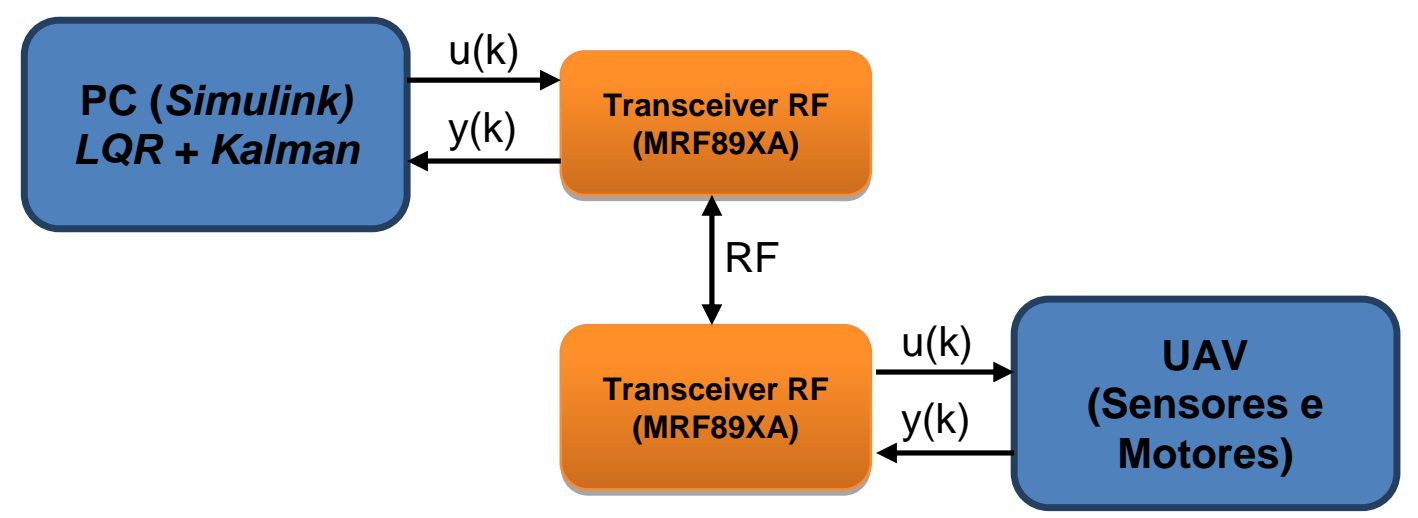

Figura 71. Diagrama de blocos para o ensaio prático utilizando HIL.

Para a aplicação da técnica HIL, um diagrama no MATLAB/Simulink® foi gerado, na Figura 72 pode-se observar o diagrama principal da aplicação, com o bloco de recepção de dados via Real Time Target, bloco da implementação do controle, e saída de dados para o UAV. Um joystick também é introduzido à aplicação para fornecer as referências de posições lineares. O PC por sua vez, se comunica com o transceiver RF por meio de comunicação USB. 


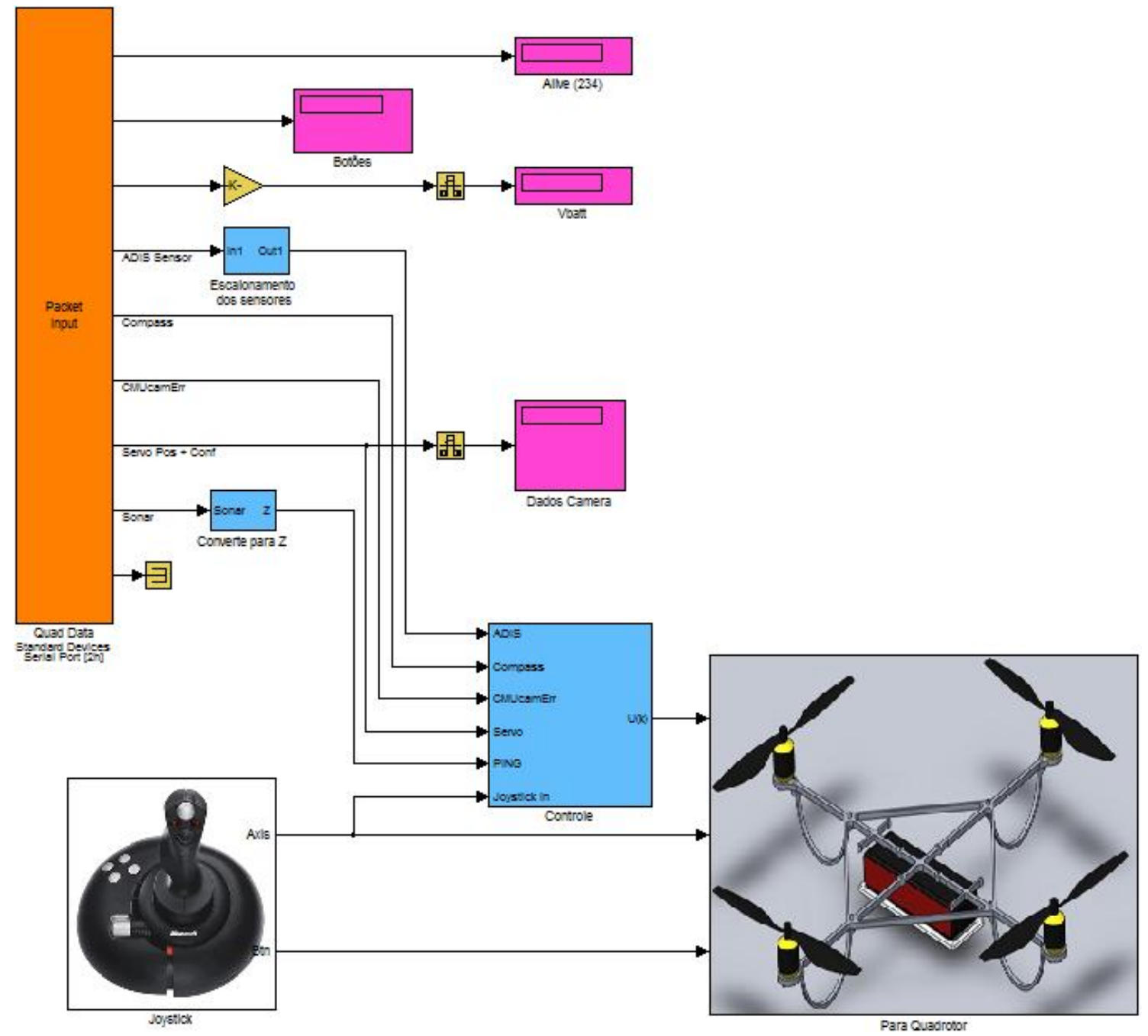

Figura 72. Diagrama principal para interface e controle com o UAV, no software MATLAB/Simulink.

No diagrama apresentado na Figura 72, o bloco de controle possui a mesma configuração do bloco de controle apresentado na Figura 50, com a adição da formatação dos dados recebidos pelos sensores e joystick.

Com a aplicação no MATLAB/Simulink® definida, podem-se iniciar os ensaios práticos no sistema. Para validar o controle e modelo, os ensaios serão divididos em dois estágios: inicialmente será aplicado um simples degrau de $+0,2 m$ na direção $Z$. Em sequencia serão aplicadas as mesmas referências usadas nas simulações anteriormente realizadas. $O$ ambiente de ensaio com a planta real será o mesmo apresentado na Figura 60. 
Para o ensaio inicial de rastreamento de altitude, o quadrirotor permaneceu amparado por uma corda de sustentação, desta forma pode-se minimizar o efeito solo que os propulsores podem gerar e manipular de forma segura o UAV reduzindo a possibilidade de acidentes, tendo em vista que a movimentação do corpo é limitada pela corda.

Nos ensaios realizados, não foi possível elevar o UAV com as configurações definidas nas simulações. Inicialmente foram ajustados os parâmetros do controlador e filtro de Kalman, mas nenhum resultado positivo foi obtido.

Observou-se nos testes que os motores começaram a falhar aleatoriamente durante os procedimentos. A partir deste fato, iniciou-se uma investigação na composição eletrônica e comunicação do sistema, onde se constatou que a comunicação utilizando o módulo RF selecionado perde pacotes aleatoriamente e não realiza uma requisição de nova mensagem, portanto um sistema de retransmissão de mensagens foi criado para atuação em caso de perda de pacotes de mensagens. A implementação deste algoritmo causou um efeito negativo no período de amostragem que teve de ser aumentado para acomodar a possibilidade da transmissão de pacotes adicionais de mensagens no caso de falha no envio. Sendo assim, o período de amostragem $T_{\mathrm{s}}$ foi alterado de 20 para $60 \mathrm{~ms}$. Deste modo o problema da transmissão de mensagens foi solucionado e não houve mais falhas dos motores.

A partir do novo período de amostragem, foram obtidos novos valores para o controlador e filtro de Kalman, porém o sistema permaneceu instável.

Analisando o comportamento do sensor magnetômetro, notou-se que devido à variação da velocidade dos motores e a proximidade do sensor aos mesmos, interferências eletromagnéticas ocorrem graças à natureza dos motores, corrompendo os dados dos sensores variavelmente com a velocidade de cada motor. Para aprimorar a leitura do sensor, optou-se por movê-lo para 
uma posição mais distante dos motores, solucionando assim este efeito de corrupção.

Analisou-se adicionalmente o comportamento do sensor de imagem, que ao se movimentar no campo de trabalho, oscila sua orientação de maneira a gerar erros no calculo de posição linear, comprometendo os dados para a fusão sensorial e estimação das atitudes. O controlador aplicado para orientar a câmera ao ponto de referência foi aprimorado, minimizando este efeito para uma pequena área de operação, tendo em vista que para diferentes posições do campo de trabalho, diferentes ganhos para o controlador da câmera são necessários.

Após a aplicação das contramedidas de aprimoramento das leituras dos sensores, o sistema permaneceu instável. Voltando o foco para o filtro de Kalman realizou-se um ensaio com os motores desligados para verificar se 0 filtro é capaz de estimar os estados corretamente sem a presença das vibrações causadas pelos motores. Manipulando o UAV manualmente com seus propulsores desativados e movimentando-o pelo campo de trabalho, confirmou-se que o filtro de Kalman é capaz de estimar as atitudes do quadrirotor satisfatoriamente, onde as inclinações reais foram medidas com um transferidor e comparadas com os valores estimados pelo filtro.

Como recurso final, foram realizados ensaios com o UAV, manualmente limitando sua movimentação linear e angular visando verificar se o corpo é capaz de se sustentar e rastrear a referência de altitude. Neste caso confirmou-se a capacidade de rastreamento da referência de altitude, porém de maneira precária e discrepante das simulações realizadas anteriormente. $\mathrm{Na}$ Figura 73, pôde-se observar os resultados obtidos com a planta real, sendo que os sinais apresentados são as saídas estimadas pelo filtro de Kalman. 

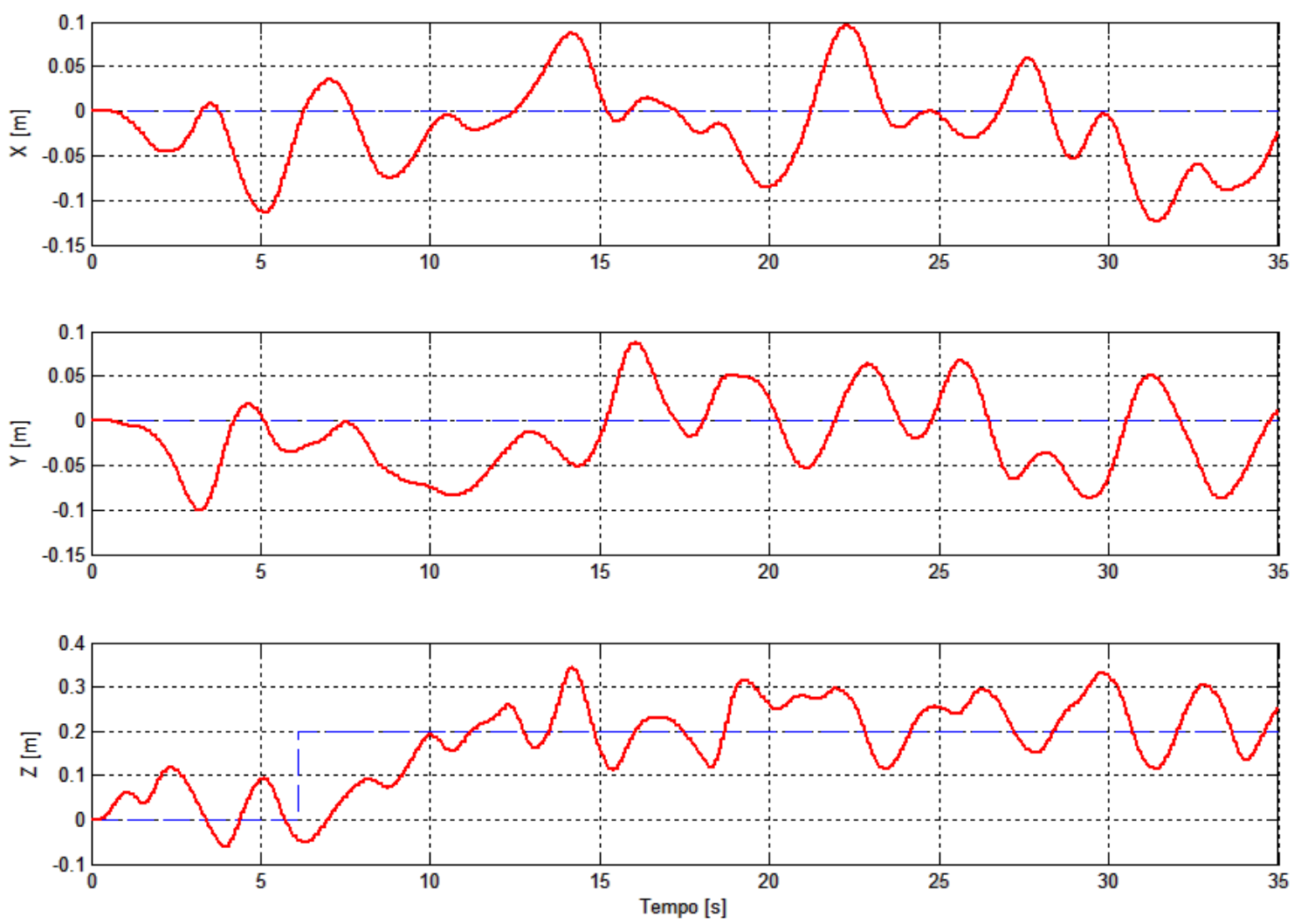

Figura 73. Posições lineares do UAV, limitando a movimentação do corpo para alcançar a referência de altitude.

Complementarmente aos resultados de posições lineares apresentadas, apresentam-se as atitudes estimadas pelo filtro de Kalman na Figura 74. 

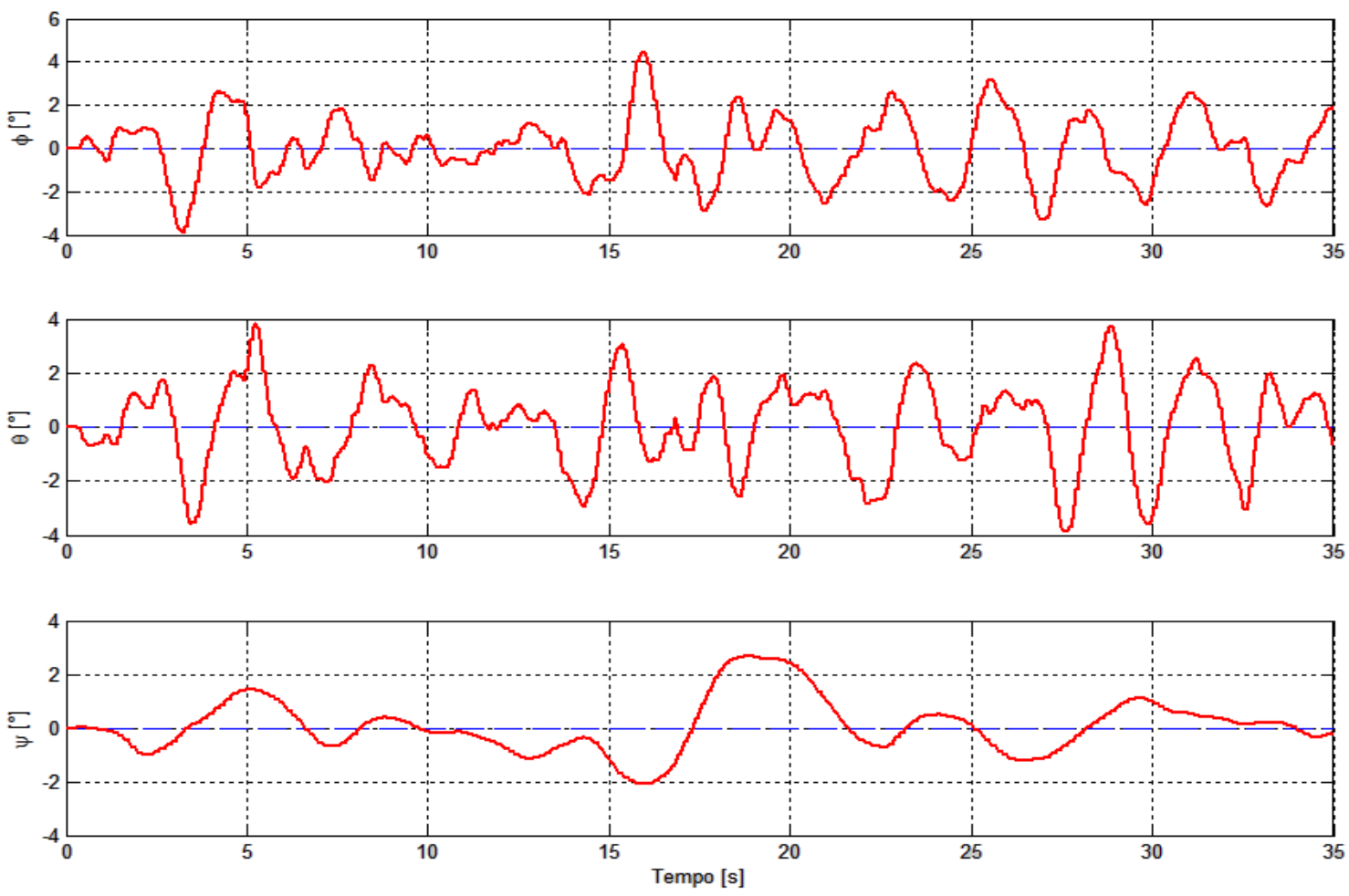

Figura 74. Posições angulares do UAV, limitando a movimentação do corpo para alcançar a referência de altitude.

Após o último ensaio realizado, não foram realizados novos ensaios com estas referências de posição. Testes preliminares foram realizados com as referências de posição aplicadas nas simulações porem o UAV não conseguiu se manter estável sem restrições de movimentação, o que invalida a possibilidade de realizar testes aprofundados neste escopo de referências.

\subsection{Discussões Adicionais quanto à Aplicação da Técnica} $H I L$

Dados os resultados insatisfatórios obtidos utilizando a técnica HIL, investigações adicionais foram realizadas no protocolo de comunicação entre 0 $P C$ e o quadrirotor, onde se depurou a integridade dos dados transferidos entre o UAV e a aplicação no MATLAB/Simulink®.

Verificou-se que o link de comunicação é capaz de transferir os dados corretamente, porém após alguns segundos com a aplicação do PC sendo executada, a comunicação USB entre o PC e a placa com o transceiver 
RF fica intermitente, de modo a perder o determinismo temporal da comunicação. Atestou-se, portanto, que não é possível garantir o período de amostragem determinado na modelagem do sistema de controle com a composição previamente determinada. Observou-se que este efeito se deve à quantidade de atividades exercidas pelo sistema operacional simultaneamente com a aplicação no MATLAB/Simulink®, fazendo com que a aplicação aguarde a execução de outras tarefas do sistema operacional para calcular e enviar os dados pelo canal USB.

Após diversas tentativas de minimizar este efeito, não foi possível garantir que a comunicação USB fosse capaz de manter um período de amostragem satisfatório. A partir deste ponto, optou-se por embarcar todo o sistema de controle no UAV. Sendo a aplicação no PC dedicada apenas à telemetria das variáveis de estados e envio de referências via joystick.

\subsection{Firmware Resultante para Controle Embarcado ao UAV}

A partir da decisão de alterar a configuração de implementação do controle no UAV, novas considerações são apontadas principalmente quanto ao período de amostragem do sistema, consumo de memória e ao processamento exigido do MCU utilizado no quadrirotor. Onde:

- Foi possível reduzir o período de amostragem para $20 \mathrm{~ms}$ novamente, tendo em vista que os pacotes de dados trocados entre o PC e UAV foram reduzidos, minimizando a necessidade de retransmissões de mensagens;

- Graças às novas variáveis inseridas e 0 algoritmo necessário para realizar os cálculos com o ganho de controle e filtro de Kalman, o consumo de memoria RAM e FLASH resultantes foram $6,6 \mathrm{~KB}$ e $22,4 \mathrm{~KB}$, respectivamente.

Visando uma melhor fluência nos ensaios práticos, criou-se ainda uma função para recepção do ganho de controle e variáveis do filtro de Kalman através da comunicação RF, onde é possível recalcular novos ganhos de 
controle em uma aplicação no MATLAB® e enviá-los para o UAV sem a necessidade de reprogramar o controlador do quadrirotor, facilitando assim testes com diferentes configurações de controle com agilidade.

Com os novos requisitos de processamento e algoritmos, incluiu-se uma maquina de estados no firmware, onde cada estado representa uma etapa para execução do controle do UAV. Estes estados são alterados por meio de comandos do joystick e transições temporizadas inerentes a execução do código do UAV. Sendo o diagrama apresentado na Figura 75.

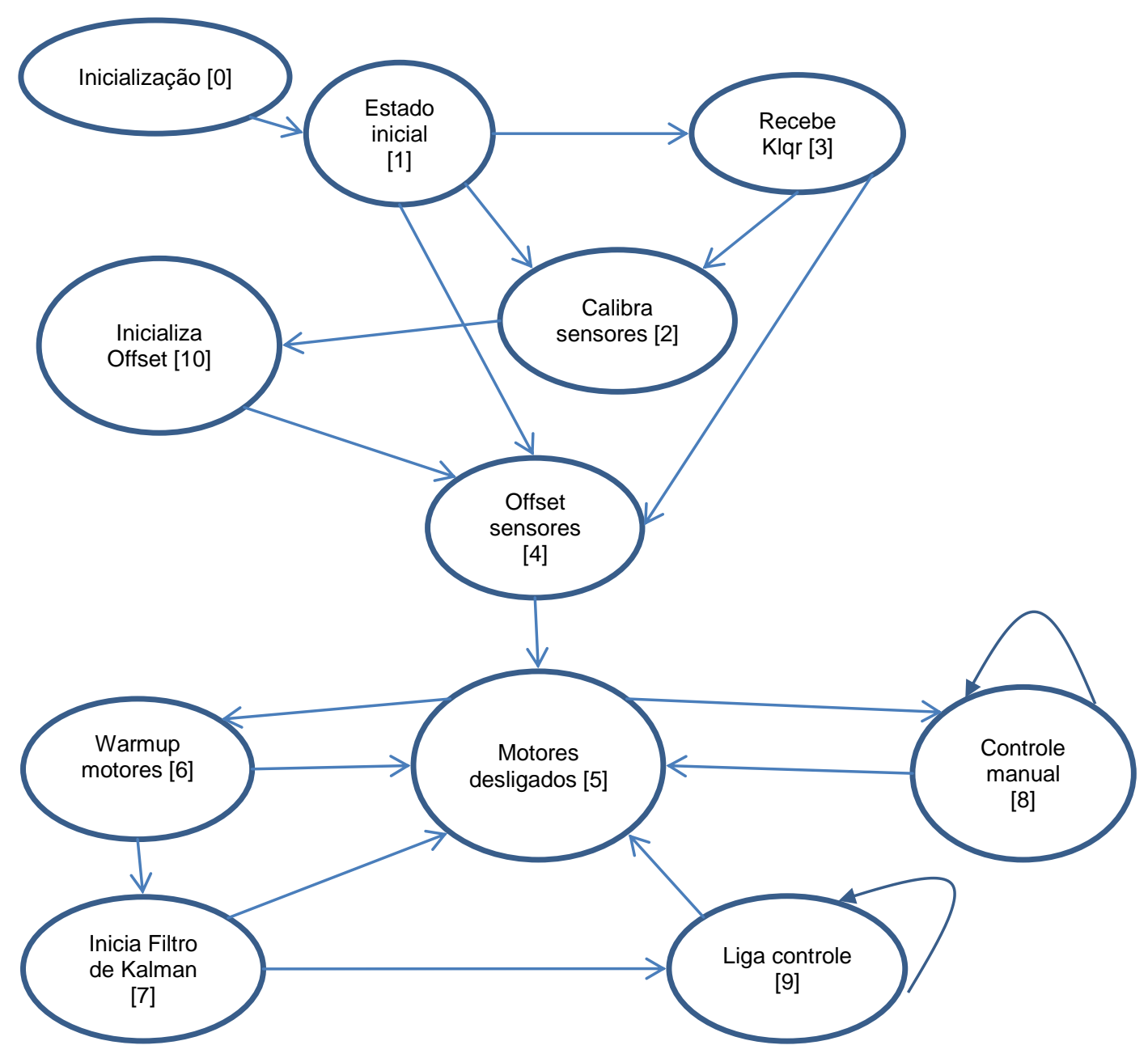

Figura 75. Diagrama de estados para o UAV com controlador embarcado.

$\mathrm{Na}$ máquina de estados criada, existem 11 estados, numerados respectivamente na Figura 75 . Onde: 
- Inicialização [0]: Estado primário da maquina, onde são inicializadas todas as temporizações para os estados futuros. A transição deste estado acontece após 15 segundos;

- Estado Inicial [1]: Utilizado como temporizador simples e limpeza de variáveis que serão utilizadas nos estados futuros. A transição deste estado acontece após o decorrer de 15 segundos, ou comando do joystick por meio dos botões três (JB3) ou quatro (JB4);

- Calibra sensores [2]: Executa calibração dos sensores acelerômetros, giroscópios, bússola e sensor ultrassom. A transição deste estado acontece após um segundo;

- Recebe Klqr [3]: Inicia função para recebimento do ganho de controle e parâmetros do filtro de Kalman via RF. A transição deste estado acontece cinco segundos após a conclusão do recebimento, podendo também ser cancelado pelo comando de botão três do joystick (JB3);

- Offset sensores [4]: Calcula a média dos sinais dos sensores para criar os offsets necessários na bussola, acelerômetros e giroscópios. A transição deste estado ocorre após quinze segundos;

- Motores desligados [5]: Estado de repouso do UAV, com motores desligados. A transição deste estado ocorre somente com o comando do joystick por meio do botão dois (JB2) ou cinco (JB5);

- Warmup motores [6]: Inicia procedimento de aquecimento dos motores até a velocidade nominal do UAV. A transição deste estado ocorre após oito segundos, podendo também ser cancelada por meio do botão um (JB1), do joystick;

- Inicia filtro de Kalman [7]: Habilita a execução da função de estimação de estados e filtragem de sensores utilizando o filtro de Kalman. A transição deste estado ocorre após quatro 
segundos com o filtro ligado, podendo também ser cancelada por meio do botão um (JB1), do joystick;

- Controle manual [8]: Estado auxiliar onde pode-se verificar o funcionamento dos motores, nenhum tipo de controle automático é realizado. Onde se utiliza o joystick para manobrar o UAV. Este estado pode ser cancelado por meio do botão um (JB1), do joystick;

- Liga controle [9]: Estado final da máquina de estados, onde o controle implementado é executado, em conjunto com o filtro de Kalman. Este estado não possui transição natural, podendo somente ser cancelado por meio do botão um (JB1), do joystick;

- Inicializa Offset [10]: Estado auxiliar prévio ao inicio do estado quatro onde sua transição somente acontece por comando do botão oito (JB8), do joystick;

A máquina de estados apresentada na Figura 75 é executada a cada iteração do firmware em conjunto com o envio dos dados via RF, aquisição dos sensores e atuação nos propulsores. Este laço de execução ocorre a cada $20 \mathrm{~ms}$ como previamente definido como período de amostragem.

\subsection{Ensaios do UAV com Algoritmos de Controle Embarcados}

Com o novo firmware criado para comportar os algoritmos de controle, iniciaram-se novos ensaios com o UAV.

Nos ensaios preliminares, observou-se que a realimentação de posição linear continuou insatisfatória, não sendo possível controlar o sistema. Considerando este comportamento, decidiu-se realizar ensaios apenas com o controle das atitudes do UAV visando rastrear apenas estas variáveis de estados. 
Inicialmente foi realizado um teste com o objetivo de manter as atitudes equilibradas com referências nulas, onde foram obtidos resultados satisfatórios quanto ao controle dos estados de interesse. Os resultados para este ensaio prático são apresentados na Figura 76.
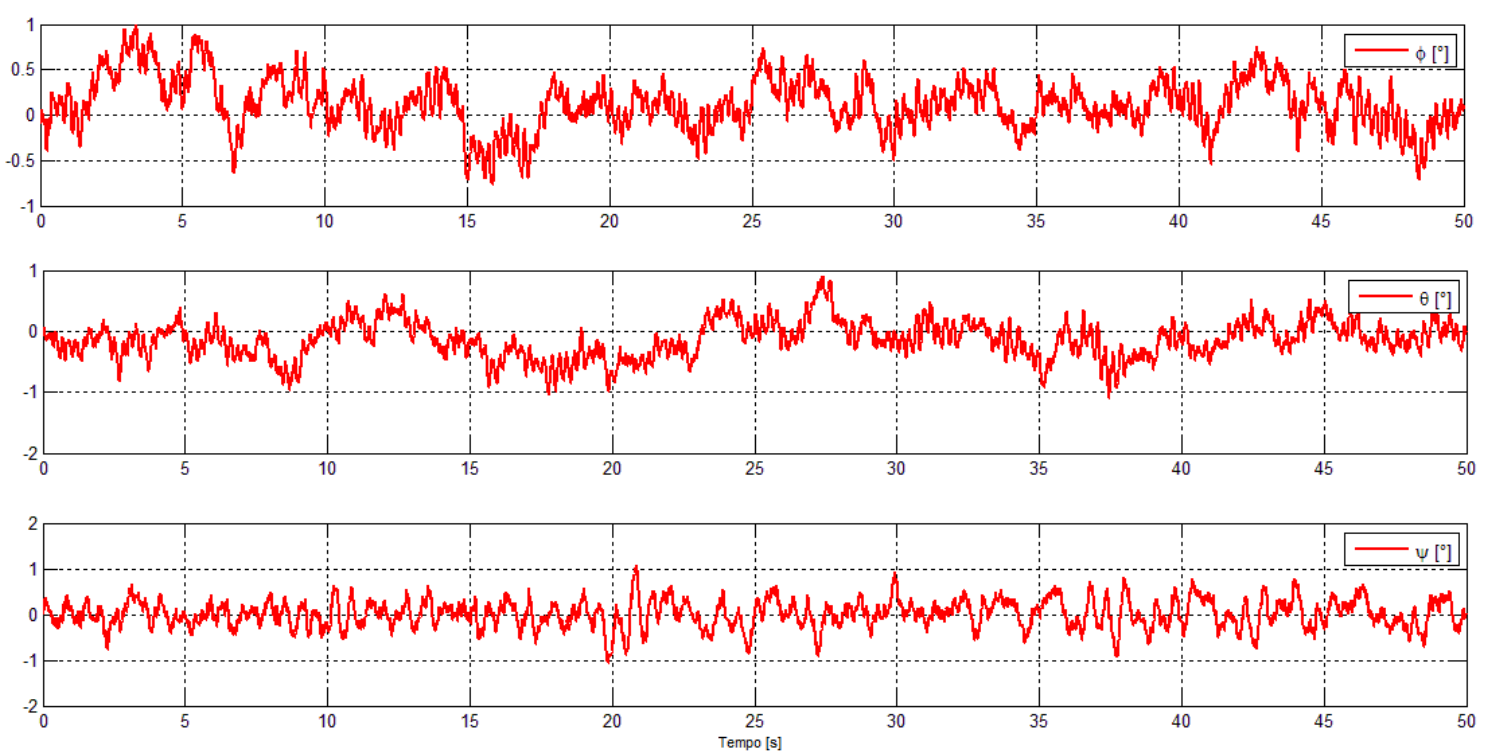

Figura 76. Atitudes estimadas do UAV, com controle embarcado e período de amostragem de $20 \mathrm{~ms}$.

Adicionalmente, ensaios foram realizados para verificar 0 rastreamento de referência para a orientação do UAV. Sendo os resultados apresentados na Figura 77. 

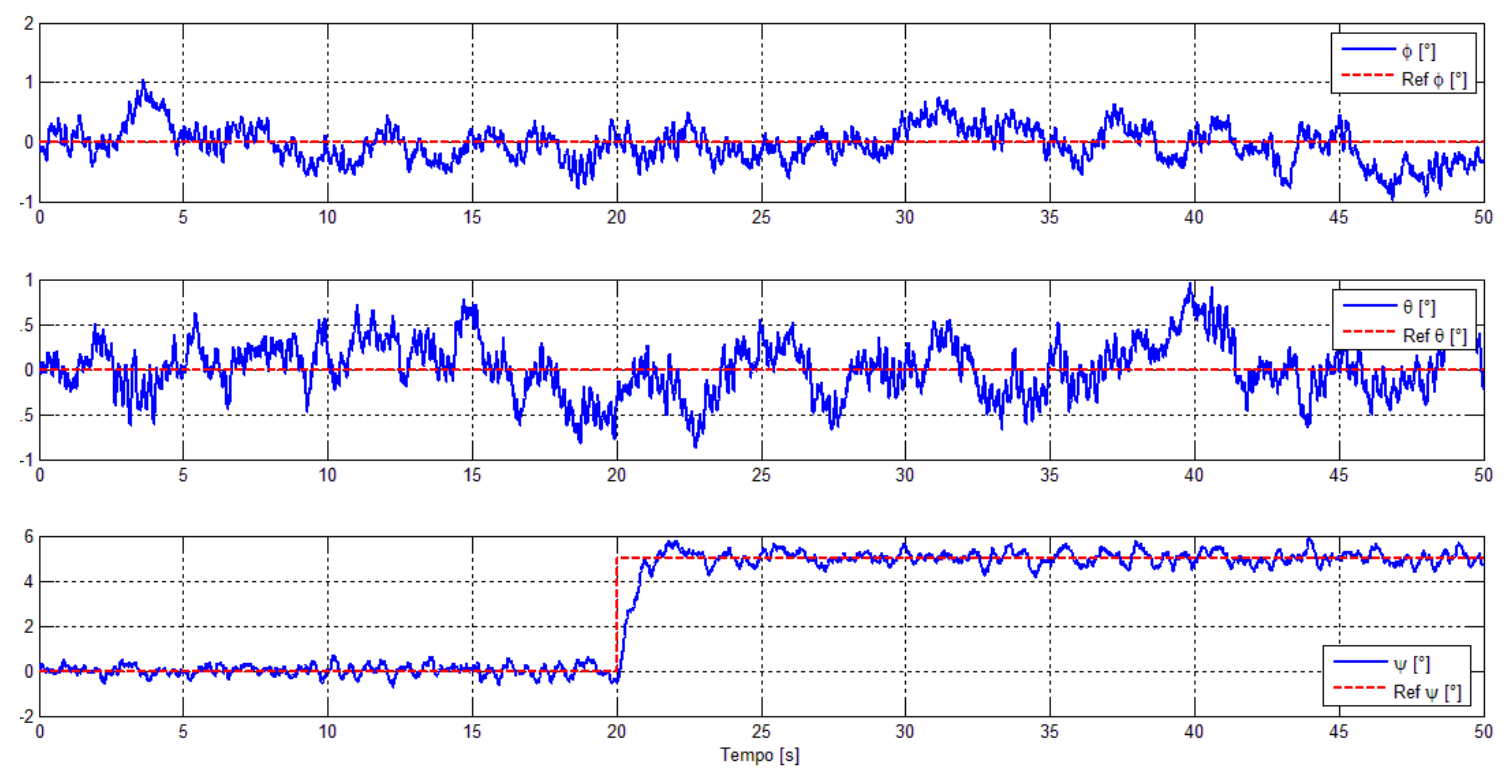

Figura 77. Rastreamento da referência de orientação do UAV.

Não foram ensaiadas referências não-nulas das outras atitudes do UAV pois elas causariam impactos de alta magnitude no que se refere às posições lineares do UAV, impossibilitando um teste controlado do sistema.

Ao se analisar os resultados exibidos na Figura 76 e Figura 77 e comparando-os com os resultados prévios obtidos com o controle utilizando a técnica HIL (Figura 74), observa-se que o ajuste das atitudes do UAV é superior quando o controle é embarcado ao UAV, creditando-se esta melhora principalmente à frequência de amostragem maior $\mathrm{e}$ ao fato de que as amostragens são realizadas de forma determinística, sendo o PC somente necessário para adquirir as referências para os estados controlados. 


\section{Capítulo 7. Conclusões e Trabalhos Futuros}

O principal objetivo desta dissertação foi o de desenvolver e implementar o projeto mecânico, eletrônico e de controle de um quadrirotor, bem como a confecção de um controlador linear visando a operação autônoma da aeronave.

$\mathrm{Na}$ primeira etapa do trabalho, objetivos foram definidos para o desenvolvimento do UAV. A partir deles, estudos foram realizados para fundamentar teoricamente o estado da arte de UAVs quadrirotores, em sequencia modelaram-se as equações analíticas que representam a dinâmica do UAV e a partir delas linearizações foram feitas visando a representação do sistema linearizado no espaço de estados para posterior implementação das técnicas de controle.

Com o conhecimento do modelo analítico para o UAV, realizou-se o projeto mecânico do corpo do UAV, visando a inserção dos sensores e atuadores presentes na planta, os quais também foram selecionados e ensaiados para aplicação física no quadrirotor. Sendo o UAV construído e todos os sensores e atuadores implementados.

Alimentando o modelo dinâmico analítico criado com os parâmetros definidos no projeto mecânico e eletrônico, foram aplicados dois métodos de controle linear, sendo a primeiro por imposição direta de polos em conjunto com um observador de estados de ordem plena, e o segundo por meio de um controlador ótimo LQR em conjunto com um filtro de Kalman discreto. As duas estratégias foram comparadas, em simulação, com relação ao seu desempenho no rastreamento de referências de posição linear e consumo de corrente do UAV, sendo que o controlador LQR juntamente com o filtro de Kalman foi selecionado por apresentar menor consumo de corrente e melhor desempenho para rastrear os estados de interesse. 
Simulações também foram realizadas introduzindo ruídos de medição e processo, extraídos de ensaios na planta real a ser controlada e com os motores acionados. Constatou-se que os acelerômetros utilizados são corrompidos quando os motores estão em funcionamento, graças à vibração gerada por eles. Deste modo, optou-se incluir amortecedores de vibração que solucionou este problema.

Na parte final do trabalho, o controlador e filtro de Kalman projetados foram implementados no software MATLAB/Simulink® e o controle na planta realizado por meio da técnica HIL. Testes práticos foram conduzidos para controlar o UAV. Infelizmente, o único sucesso de rastreamento foi obtido quando o quadrirotor teve suas oscilações restringidas manualmente por um operador. Entretanto, estes resultados demonstraram a atuação do controle no sistema, bem como a ação dos integradores inclusos nas entradas da planta, tendo em vista que a massa do UAV é diferente do projeto graças a inclusão de peças auxiliares no quadrirotor e tolerâncias de produção. Notou-se ainda que a filtragem de Kalman foi capaz de reconstruir os estados do sistema e filtrar os valores dos sensores.

Observou-se ainda que a metodologia de implementação de controle por meio da técnica HIL causou no sistema a perda de determinismo temporal para o período de amostragem e como alternativa, decidiu-se embarcar o algoritmo do controlador LQR juntamente com o filtro de Kalman no MCU da aeronave para estabilizar o período de amostragem e mantê-lo em 20 ms graças à simplificação dos pacotes enviados por RF. Porém, mesmo com este problema solucionado, não foi possível alcançar os resultados esperados e simulados previamente.

Como alternativa final, foram realizados ensaios para verificar somente o controle das atitudes do UAV, que retornaram resultados positivos, provando a capacidade de controle das atitudes da aeronave.

Dentre os principais fatores que implicam na fragilidade da aplicação real do quadrirotor, destacam-se: 
- O projeto mecânico não contemplou análise de vibrações mecânicas do corpo. Observou-se que a estrutura projetada não é suficientemente rígida, transmitindo vibrações mecânicas por todo o corpo do UAV, sendo responsáveis pelos elevados ruídos dos sensores;

- A comunicação RF entre o PC e o quadrirotor também demonstrou que não é suficientemente robusta para transmitir os pacotes com alta taxa de amostragem, o que culminou na necessidade e aumentar o período de amostragem do sistema na metodologia de controle utilizando HIL. Entretanto com a utilização do controle embarcado na aeronave, foi possível minimizar este efeito;

- Para a implementação da técnica HIL nos testes práticos, não se utilizou um computador de tempo real, o que pode causar atrasos no processamento das amostragens;

- O sensor de altitude utilizado na aeronave demonstrou falhas durante a utilização, onde em algumas amostragens retornava valores nulos de altitude, instabilizando o sistema em algumas situações;

- Observou-se em ensaios com duração maior que um minuto que os motores e seus drivers começam a perder eficiência por aquecimento, reduzindo o empuxo total da aeronave. Concluiu-se que este foi 0 principal motivo para a incapacidade do UAV em manter voo;

- Por fim, o sistema de controle implementado para orientar o sensor de imagem se mostrou sensível à variações na posição do corpo, o que reduz a área de atuação do sistema para manter a estabilidade. $O$ sensor selecionado também se mostrou muito sensível a variações de luminosidade.

Foi abordado nesta dissertação um trabalho multidisciplinar, envolvendo todo o projeto e concepção de um veículo aéreo não tripulado, 
englobando áreas como engenharia de sistemas, mecânica, eletrônica, software e controle.

Dentre os diversos enfoques possíveis para abordar este tema, os métodos utilizados se mostraram factíveis em projeto e simulações, entretanto existem pontos a serem aperfeiçoados para a aplicação prática. Em particular, destaca-se o projeto mecânico que pode ser melhorado com a inclusão de um estudo de vibrações mecânicas que a estrutura pode sofrer, bem como peças auxiliares para amortecer as vibrações geradas pelos motores e proteções contra impacto das hélices a objetos desconhecidos. O modelo projetado neste trabalho foi construído empregando alumínio, o estudo da utilização de outros materiais ou até montagens hibridas também podem ser consideradas, o que pode aprimorar o amortecimento de vibrações e redução de massa total do corpo para maior autonomia de voo.

Adicionalmente, outras técnicas de sensoriamento podem ser utilizadas, como por exemplo, o emprego de um sensor barométrico para medição de altitude e diferentes técnicas para sensoriamento de imagem, como uma câmera fixa ou até sensores externos para triangulação de posição.

É necessária também a identificação mais aprofundada dos motores utilizados, tendo em vista que eles não possuem documentação técnica aprofundada por serem normalmente utilizados em aplicações simplificadas. Ainda neste tópico, a criação de um driver mais eficiente para acionamento dos motores pode ser interessante para maximizar a utilização dos motores.

Diferentes técnicas de controle podem ser utilizadas para controlar a movimentação do UAV, inclusive controle não linear. O filtro de Kalman também pode ser substituído pelo filtro de Kalman estendido ou inclusive outros filtros em cascata para aprimorar as estimativas. O modelo também pode ser testado em ambientes extremos onde ele necessitará maior robustez contra distúrbios externos como vento e chuva. Técnicas para navegação como desvio de obstáculos e mapeamento de ambientes podem também ser incluídas. 


\section{REFERÊNCIAS}

BOULET, J. L' Histoire De L'helicoptere. Paris, França: Editions FranceEmpire, 1982.

BRESCIANI, T. Modelling, Identification and Control of a Quadrirotor Helicopter. Dissertação de Mestrado - Lund University, Suécia, 2008. Disponível em: <www.roboticsclub.org/redmine/attachments/467/Quadrirotor_Bible.pdf>.

DOMINGUES, J. M. B. Quadrirotor prototype. Dissertação de Mestrado Universidade Técnica de Lisboa, Portugal, 2009. Disponível em: <https://dspace.ist.utl.pt/bitstream/2295/574042/1/Tese_de_Mestrado.pdf>

GESSOW, A. Aerodynamics of the helicopter. New York, NY: Hungar Publishing CO, 1967.

AZZRAM, A.; WANG, X. Quad Rotor Arial Robot Dynamic Modeling and Configuration Stabilization. 2nd International Asia Conference on Informatics in Control, Automation and Robotics, pp. 438-444, 2010.

ERGINER, B.; ALTUG E. Modeling and PD Control of a Quadrotor VTOL Vehicle. Proceedings IEEE Intelligent Vehicles Symposium, pp. 894-899, 2007.

MOUABDALLAH, S.; NOTH, A. PID vs LQ Control Techniques Applied to an Indoor Micro Qadrotor. Proceedings IEEE/RSJ International Conference on Intelligent Robots and Systems, pp. 2451-2456, 2004.

HOFFMANN, G.; RAJNARAYAN, D.G.; WASLANDER, S.L.; DOSTAL, D.; JANG, J.S.; TOMLIN, C.J. The Stanford testbed of Autonomous Rotorcraft for Multi Agent Control (STARMAC). Proceedings of the 23rd Digital Avionics Systems Conference (DASC'04), USA, 2004. 
SøRENSEN, A. F. Autonomous Control of a Miniature Quadrotor Following Fast Trajectories. Dissertação de Mestrado, Universidade de Aalborg, Dinamarca, 2010.

ABEYWARDENA, D. M. W; MUNASINGHE, S.R. Perfmormance Analysis of a Kalman Filter Based Attitude Estimator for a Quad Rotor UAV. International Congress on Ultra Modern Telecommunications and Control Systems and Workshops (ICUMT'2010), p 466-472, 2010.

PLITZ, U; POPOV, A. P.; WERNER, H. Robust Controller Design for Formation Flight of Quad-Rotor Helicopters. Joint 48th IEEE Conference on Decision and Control and 28th Chinese Conference, p 8322-8328, 2009.

POUNDS, P.; MAHONY, R.; GRESHAM, J.; CORKE, P.; ROBERTS, J. Towards Dynamically-Favourable Quad-Rotor Aerial Robots. 2004.

JOHNSON, E.N. UAV research at Georgia tech.. Georgia Tech School of Aerospace Engineering, EUA, 2002.

CHEN, M.; HUZMEZAN, M. A Combined MBPC/ 2 DOF Hळ Controller for a Quadri Rotor UAV, Department of Electrical and Computer Engineering University of British Columbia Vancouver, Canada, 2003.

COZA, C.; MACNAB, C. J. B. A new robust adaptive-fuzzy control method applied to quadrirotor helicopter stabilization. IEEE Fuzzy Information Processing Society, p. 454-458, 2006.

JANG, J. S. Nonlinear control using discrete-time dynamic inversion under input saturation theory and experiment on the Stanford dragon fly UAVS. Tese de Doutorado, Universidade de Stanford, EUA, 2003

ALTUG, E. Vision based control of unmanned aerial vehicles with applications to an autonomous four rotor helicopter Quadrirotor, Tese de Duotorado, Universidade da Pensilvânia, EUA, 2003. 
SPONG, M. W. Robot Modeling and Control, Estado Unidos da América: John Wiley \& Sons Inc., 2006.

GARCIA, C. Modelagem e Simulação, São Paulo, SP: Editora da Universidade de São Paulo, 2005.

DA CRUZ , J. J. Controle Robusto Multivariável. São Paulo, SP: Editora da Universidade de São Paulo, pp. 145-147, 1996.

YEDAMALE, P. AN885: Brushless DC (BLDC) Fundamentals, Nota de Aplicação, Microchip Inc. EUA, 2003. Disponível em: <http://ww1.microchip.com/downloads/en/AppNotes/00885a.pdf>

ANDREJASIC, M. MEMES Accelerometers, seminário, University of Ljubljana, Eslovênia, 2003. Disponível em: <http://mafija.fmf.unilj.si/seminar/files/2007_2008/MEMS_accelerometers-koncna.pdf>

FLOWERS, D.; Yang, Y. AN1066: Microchip MiWi Wireless Networking Protocol Stack, Nota de Aplicação, Microchip Inc. EUA, 2010. Disponível em: $<$ http://ww1.microchip.com/downloads/en/AppNotes/AN1066\%20\%20MiWi\%20App\%20Note.pdf>

YANG, Y. AN1204: Microchip MiWi P2P Wireless Protocol, Nota de Aplicação, Microchip Inc. EUA, 2010. Disponível em: <http://ww1.microchip.com/downloads/en/AppNotes/01204B.pdf>

FRANKLIN, G. F. Feedback Control of Dynamic systems, Estados Unidos da América: Pearson., 2010.

KALMAN, R. E. A New Approach to Linear Filtering and Prediction Problems. Transactions of the ASME - Journal of Basic Engineering, p. 35-45. 1960.

GREWAL, M.; ANDREWS, A. Kalman Filtering: Theory and Practice. Prentice Hall. 1993. 